UNIVERSIDADE DE SÃO PAULO

ESCOLA DE ENGENHARIA DE SÃO CARLOS

DEPARTAMENTO DE ENGENHARIA ELÉTRICA E COMPUTAÇÃO

PROGRAMA DE PÓS-GRADUAÇÃO EM ENGENHARIA ELÉTRICA

DANIEL FERREIRA LIMA

Mitigação de Variações de Tensão Causadas pela Proteção Anti-Ilhamento de Geradores

Distribuídos via Controle de Taps de

Reguladores de Tensão

São Carlos

2017 

DANIEL FERREIRA LIMA

\title{
Mitigação de Variações de Tensão Causadas pela Proteção Anti-Ilhamento de Geradores Distribuídos via Controle de Taps de Reguladores de Tensão
}

\author{
Dissertação apresentada à Escola de Engenharia de São \\ Carlos da Universidade de São Paulo, como parte dos \\ requisitos para obtenção do título de Mestre em Ciências \\ pelo Programa de Pós-Graduação em Engenharia \\ Elétrica.
}

Área de Concentração: Sistemas Elétricos de Potência

Orientador: Prof. Dr. José Carlos de Melo Vieira Júnior

São Carlos

2017

Trata-se da versão corrigida da dissertação. A versão original se encontra disponível na EESC/USP que aloja o Programa de Pós-Graduação de Engenharia Elétrica. 
AUTORIZO A REPRODUCÃO TOTAL OU PARCIAL DESTE TRABALHO, POR QUALQUER MEIO CONVENCIONAL OU ELETRÔNICO, PARA FINS DE ESTUDO E PESQUISA, DESDE QUE CITADA A FONTE.

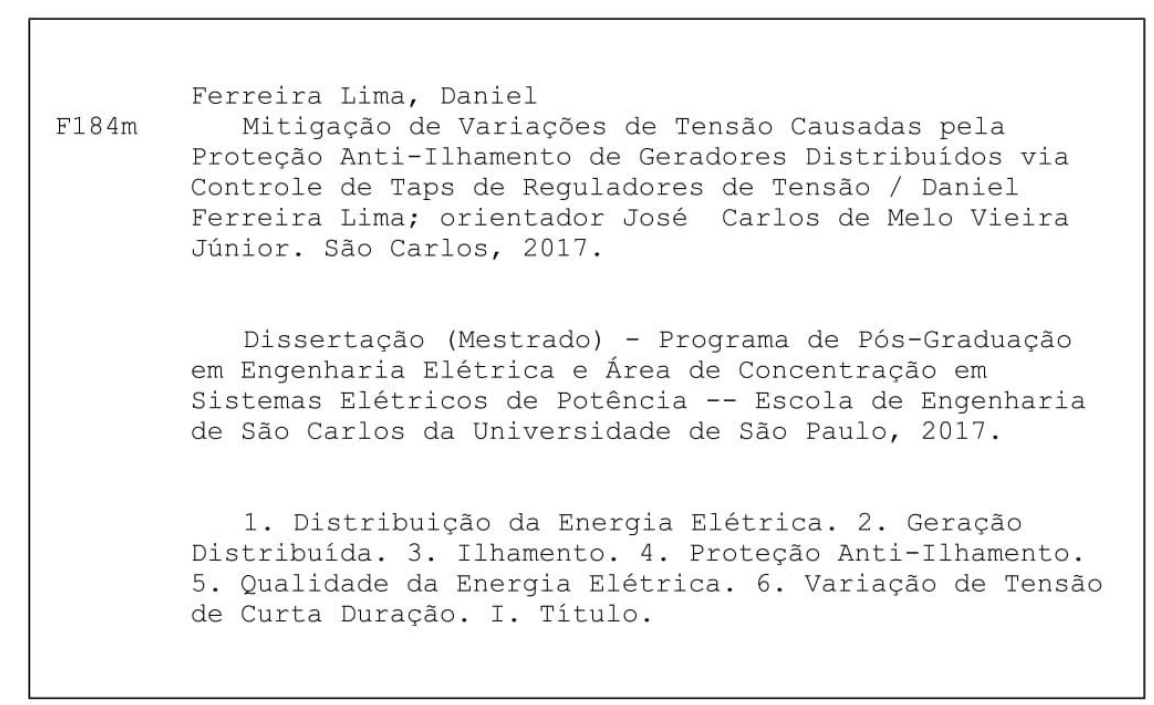




\section{FOLHA DE JULGAMENTO}

Candidato: Engenheiro DANIEL FERREIRA LIMA.

Título da dissertação: "Mitigação de variações de tensão causadas pela proteção anti-ilhamento de geradores distribuídos via controle de Taps de reguladores de tensão".

Data da defesa: 04/08/2017.

Comissão Julgadora:

Prof. Associado José Carlos de Melo Vieira Junior (Orientador) (Escola de Engenharia de São Carlos/EESC)

Prof. Dr. Marcos Jullo Rider Flores

(Universidade Estadual de Campinas/UNICAMP)

Prof. Dr. Marcus Vinicius Borges Mendonça

(Universidade Federal do Triângulo Mineiro/UFTM)
Resultado:

APROVADO APROYAOO APBOVADO

Coordenador do Programa de Pós-Graduação em Engenharia Elétrica: Prof. Associado Luis Fernando Cosía Alberto

Presidente da Comissão de Pós-Graduação:

Prof. Associado Luis Fernando Costa Alberho 


\section{Agradecimentos}

Agradeço a Fundação de Amparo à Pesquisa do estado de São Paulo (FAPESP), processo: $\mathrm{n}^{0}$ 2015/04147-1, pelo suporte financeiro concedido para a realização da pesquisa. As opiniões, hipóteses e conclusões ou recomendações expressas neste material são de responsabilidade do(s) autor(es) e não necessariamente refletem a visão da FAPESP. 


\section{Resumo}

LIMA, D. F.. Mitigação de Variações de Tensão Causadas pela Proteção Anti-Ilhamento de geradores distribuídos via controle de Taps de Reguladores de Tensão. 144p. Dissertação (Mestrado em Engenharia Elétrica) - Escola de Engenharia de São Carlos, Universidade de São Paulo, São Carlos, 2017.

A conexão de geradores distribuídos em sistemas de distribuição deve ser cuidadosamente avaliada para que os mesmos auxiliem efetivamente na melhoria do desempenho das redes elétricas, buscando reduzir ou eliminar eventuais situações que causem a degradação da qualidade da energia elétrica fornecida aos consumidores, entre outros aspectos. Neste contexto, existem vários trabalhos que analisam a influência da conexão de geradores distribuídos no perfil de tensão da rede elétrica, frequência, desequilíbrio de fases e distorção harmônica. No entanto, há poucos trabalhos analisando os efeitos da desconexão de geradores distribuídos na qualidade da energia fornecida aos consumidores. Uma vez operando em paralelo com a rede de distribuição, esses geradores influenciam o perfil de tensão e o comportamento dos dispositivos reguladores de tensão. Como consequência, sua desconexão pode provocar variações de tensão intensas causando danos ou mau funcionamento às cargas. A desconexão pode ser repentina ou devido à atuação da proteção anti-ilhamento, seguida dos procedimentos de religamento automático do alimentador, se houver. Visando estudar este problema, o qual tende a se tornar uma nova preocupação das concessionárias de energia elétrica, e no intuito de minimizar e/ou eliminar os possíveis efeitos negativos dessas variações de tensão, esta pesquisa propõe o desenvolvimento de um método de controle dos taps dos reguladores de tensão. Neste método, o controle dos taps foi modelado como um problema de otimização, minimizando as violações de tensão mencionadas anteriormente e também a quantidade de operações dos reguladores de tensão ao longo de um dia típico. A otimização foi solucionada com um Algoritmo Genético e os resultados obtidos indicaram que é possível minimizar as variações de tensão usando a curva de carga do sistema para planejar a operação dos reguladores de tensão.

Palavras-chave: Distribuição da Energia Elétrica, Geração Distribuída, Ilhamento, Proteção Anti-Ilhamento, Qualidade da Energia Elétrica, Variação de Tensão de Curta Duração. 



\section{Abstract}

LIMA, D. F.. Mitigating Voltage Variations Caused by the Anti-Islanding Protection of Distributed Generator via Voltage Regulator Tap Control. 144p. Dissertation (Master's Degree) - Engineering School of Sao Carlos, University of Sao Paulo, Sao Carlos, 2017.

The connection of distributed generators in an electric power system should be evaluated carefully to ensure that they effectively assist in improving the performance of electrical networks, reducing or eliminating any situations that cause degradation of the power quality of the consumers, and other issues. In this context, there are several studies that analyze the influence of generators connected to distribution systems and how they affect the frequency, cause variations in voltage magnitude, voltage unbalance and harmonic distortion. However, there are a few studies analyzing the effects that the disconnection of distributed generators induces to the power quality of consumers. Once operating in parallel with the distribution network, these generators have an effect on voltage variations and voltage regulator devices. As a result, disconnection can cause severe voltage variations causing damage or malfunction to the loads. The disconnection may be sudden or due to the action of anti-islanding protection, followed by the procedure to reconnect the substation, if it is possible. In order to study this problem, which tends to become a new power quality concern for electric utilities, and in order to minimize and / or eliminate the possible side effects of the voltage variations, this research proposes the development of a control method of voltage regulators' taps. In this method, the control of taps was modeled as an optimization problem which aimed to minimize these voltage variations aforementioned and also the amount of voltage regulator operations over a typical day. The optimization was solved by a Genetic Algorithm and the results obtained demonstrate that it is possible to minimize the voltage variation by using the system load curve to plan the operation of voltage regulators.

Keywords: Electric Power Distribution, Distributed Generation, Islanding, AntiIslanding Protection, Power Quality, Short Duration Voltage Variation. 



\section{Lista de Siglas}

AESO

ANEEL

COD

CSR

COPEL

CPFL

CFP

CT

GD

IEEE

PAC

PRODIST

SD

VTCD
Alberta Electric System Operator

Agência Nacional de Energia Elétrica

Centro de Operação da Distribuição

Compensador Síncrono Rotativo

Companhia Paranaense de Energia

Companhia Paulista de Força e Luz

Controle de Fator de Potência

Controle de Tensão

Geração Distribuída

Institute of Electrical and Electronics Engineers

Ponto de Acoplamento Comum

Procedimentos de Distribuição

Sistema de Distribuição

Variação de Tensão de Curta Duração 



\section{Lista de Símbolos}

$S_{R T} \quad$ Fluxo de potência aparente no regulador de tensão.

$P_{R T} \quad$ Potência ativa que flui pelo regulador de tensão.

$Q_{R T} \quad$ Potência reativa que flui pelo regulador de tensão.

$\boldsymbol{V}_{\boldsymbol{P A C}}$ Tensão no ponto de acoplamento comum em que a geração distribuída se conecta ao sistema.

$\boldsymbol{V}_{\boldsymbol{R} \boldsymbol{T}}$ Tensão no regulador de tensão.

$\boldsymbol{I}_{\boldsymbol{R} T} \quad$ Corrente do regulador de tensão.

$R \quad$ Resistência da linha.

X Reatância da linha.

$\triangle V_{P A C} \quad$ Variação de tensão no ponto de acoplamento comum onde a carga e a geração distribuída estão conectados.

$\Delta \mathrm{V} \quad$ Variação de tensão no barramento monitorado pelo regulador de tensão.

$V_{I} \quad$ Tensão no barramento monitorado antes da desconexão da geração distribuída.

$V_{F} \quad$ Tensão no barramento monitorado após a desconexão da geração distribuída.

$\Delta T_{\text {tap }} \quad$ Atraso que regulador de tensão aguarda para começar a atuar.

$\Delta t_{\text {tap }} \quad$ Tempo necessário para mudança na posição de tap do regulador de tensão.

$\operatorname{Tap}_{I} \quad$ Posição de tap antes desconexão da geração distribuída.

$\operatorname{Tap}_{F} \quad$ Posição de tap após desconexão da geração distribuída.

$\Delta T_{R} \quad$ Tempo total necessário para o regulador de tensão readequar a tensão.

$f_{\text {Objetivo }} \quad$ Função objetivo da otimização.

$f_{\text {Desconexão }}$ Função que representa as violações de tensão após a desconexão da geração distribuída para toda a curva de carga.

$f_{\text {Penalidade }}$ Função de penalidade, ela representa as violações de tensão com os geradores distribuídos conectados, para toda a curva de carga. 
$f_{\text {Tap }} \quad$ Função que representa as variações totais de posição dos taps de todos os reguladores de tensão.

$\omega_{\text {Desconexão }}$ Peso para ponderar a função que representa as violações de tensão após a desconexão da geração distribuída.

$\omega_{\text {Penalidade }}$ Peso para ponderar a função de penalidade.

$\omega_{\text {Tap }}$ Peso para ponderar a função que representa as variações totais de posição dos taps de todos os reguladores de tensão.

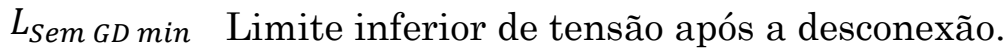

$L_{S e m G D ~ m a ́ x}$ Limite superior de tensão após a desconexão.

Vem GD Tensão em p.u. após a desconexão da geração distribuída em um instante da curva de carga, para uma barra e uma fase do sistema de distribuição.

B $\quad$ Barra do sistema de distribuição.

F $\quad$ Fase da tensão.

$t \quad$ Instante da curva de carga.

$h_{\text {Desconexão }}$ Função que representa as violações de tensão após a desconexão da geração distribuída apenas para um instante da curva de carga, considerando todas as barras e fases do sistema de distribuição.

$g_{\text {Desconexão }}$ Função que representa as violações de tensão após a desconexão da geração distribuída para um instante da curva de carga, em uma fase e em uma barra do sistema de distribuição.

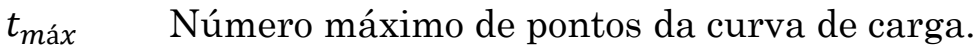

$F_{m a ́ x} \quad$ Quantidade de fases do sistema de distribuição.

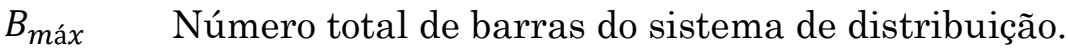

$L_{\text {Com GD min }}$ Limite inferior de tensão com os geradores distribuídos conectados.

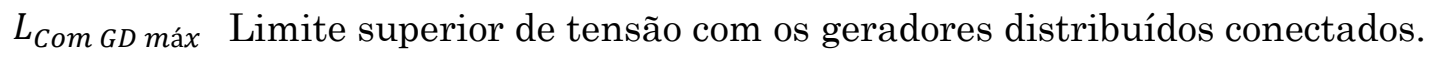

$h_{\text {Penalidade }}$ Função que representa as violações de tensão com a geração distribuída conectada, apenas para um instante da curva de carga, considerando todas as barras e fases do sistema de distribuição.

$V_{\text {Com GD }}$ Tensão em p.u. após a desconexão da geração distribuída em um instante da curva de carga, para uma barra e uma fase do sistema de distribuição.

$g_{\text {Penalidade }}$ Função que representa as violações de tensão com a geração distribuída conectada para um instante da curva de carga, em uma fase e em uma barra do sistema de distribuição. 
$g_{\text {Tap }}$ Posição do tap de um regulador de tensão em um instante da curva de carga.

$R \quad$ Regulador de tensão.

$R_{\text {máx }} \quad$ Quantidade total de reguladores de tensão presentes no sistema de distribuição.

genoma Genoma de cada indivíduo pertencente à população do Algoritmo Genético.

$i \quad$ Indivíduo pertencente à população do Algoritmo Genético. 



\section{Lista de Figuras}

FigURA 1 - MECANISMO de SURGIMENTO de AFUNDAMENTOS DE TENSÃO CAUSADOS PELA PROTEÇÃo ANTI-ILHAMENTO DA GD. ...27

FIGURA 2 - QUANTIDADE ACUMULADA DE CENTRAIS GERADORAS QUE ADERIRAM AO SISTEMA DE COMPENSAÇÃO DE ENERGIA ELÉTRICA

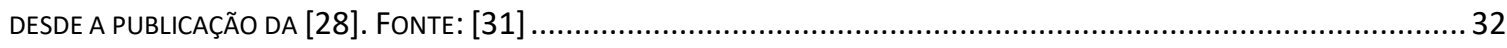

FIGURA 3 - INFLUÊNCIA DA CONEXÃO DE GD NA TENSÃO DE REGIME PERMANENTE. ........................................................ 46

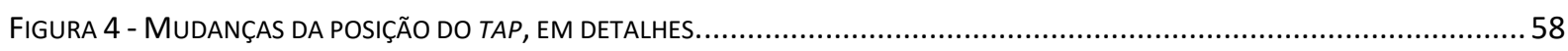

FIGURA 5 - EXEMPLO DA GERAÇÃO DE NOVOS INDIVÍDUOS COM SOLUÇÃO BASEADA NO BRANCH AND BOUND PARA UM CROMOSSOMO

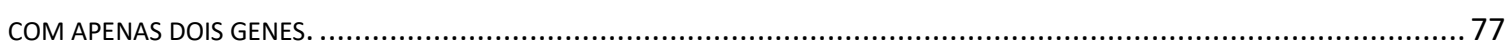

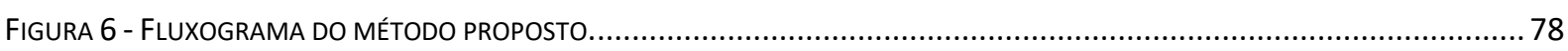

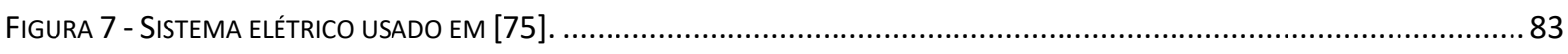

FIGURA 8 - COMPARAÇÃO ENTRE A CURVA DE CARGA ORIGINAL E A APROXIMADA POR PATAMARES...........................................8. 87

FIGURA 9 - POSIÇÕES DE TAP OBTIDAS PELA OTIMIZAÇÃO AO LONGO DE UM DIA TíPICO, REPRESENTANDO POR UMA CURVA DE CARGA

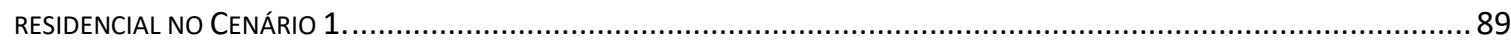

FIGURA 10 - AS TENSÕES COM E SEM A GD CONECTADA NA BARRA 12 AO LONGO DE UM DIA TíPICO, REPRESENTANDO POR UMA

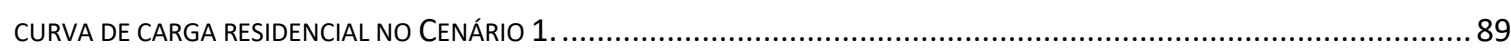

FIGURA 11 - POSIÇÕES DE TAP OBTIDAS PELA OTIMIZAÇÃO AO LONGO DE UM DIA TÍPICO, REPRESENTANDO POR UMA CURVA DE CARGA

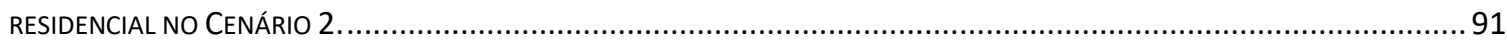

FIGURA 12 - AS TENSÕES COM E SEM A GD CONECTADA NA BARRA 12 AO LONGO DE UM DIA TÍPICO, REPRESENTANDO POR UMA

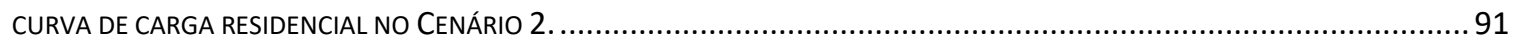

FIGURA 13 - POSIÇÕES DE TAP OBTIDAS PELA OTIMIZAÇÃO AO LONGO DE UM DIA TíPICO, REPRESENTANDO POR UMA CURVA DE CARGA RESIDENCIAL NO CENÁRIO 3.

FIGURA 14 - AS TENSÕES COM E SEM A GD CONECTADA NA BARRA 12 AO LONGO DE UM DIA TíPICO, REPRESENTANDO POR UMA CURVA DE CARGA RESIDENCIAL NO CENÁRIO 3.

FIGURA 15 - POSIÇÕES DE TAP OBTIDAS PELA OTIMIZAÇÃO AO LONGO DE UM DIA TÍPICO, REPRESENTANDO POR UMA CURVA DE CARGA RESIDENCIAL NO CENÁRIO 4.

FIGURA 16 - AS TENSÕES COM E SEM A GD CONECTADA NA BARRA 12 AO LONGO DE UM DIA TíPICO, REPRESENTANDO POR UMA CURVA DE CARGA RESIDENCIAL NO CENÁRIO 4.

FIGURA 17 - POSIÇÕES DE TAP OBTIDAS PELA OTIMIZAÇÃO AO LONGO DE UM DIA TíPICO, REPRESENTANDO POR UMA CURVA DE CARGA RESIDENCIAL NO CENÁRIO 5.

FIGURA 18 - AS TENSÕES COM E SEM A GD CONECTADA NA BARRA 12 AO LONGO DE UM DIA TÍPICO, REPRESENTANDO POR UMA CURVA DE CARGA RESIDENCIAL NO CENÁRIO 5.

FIGURA 19 - POSIÇÕES DE TAP OBTIDAS PELA OTIMIZAÇÃO AO LONGO DE UM DIA TÍPICO, REPRESENTANDO POR UMA CURVA DE CARGA RESIDENCIAL NO CENÁRIO 6.

FIGURA 20 - AS TENSÕES COM E SEM A GD CONECTADA NA BARRA 12 AO LONGO DE UM DIA TíPICO, REPRESENTANDO POR UMA

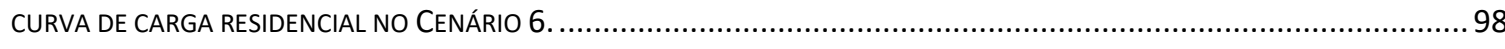

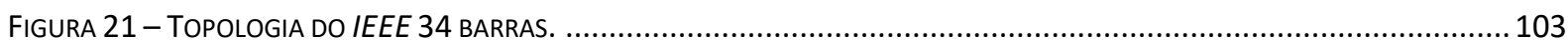

FIGURA 22 - COMPARAÇÃO ENTRE AS CURVAS DE CARGA ORIGINAIS E AS CURVAS DISCRETIZADAS.........................................107

FIGURA 23 - POSIÇÕES DE TAP OBTIDAS PELA OTIMIZAÇÃO AO LONGO DE UM DIA TÍPICO PARA TODOS OS REGULADORES DE TENSÃO, NO CENÁRIO 1.

FIGURA 24 - AS TENSÕES TRIFÁSICAS COM E SEM A GD CONECTADA NA BARRA 840 AO LONGO DE UM DIA TíPICO, NO CENÁRIO 1. 110 
FIGURA 25 - POSIÇÕES DE TAP OBTIDAS PELA OTIMIZAÇÃO AO LONGO DE UM DIA TÍPICO PARA TODOS OS REGULADORES DE TENSÃO, No CENÁRIO 2.

FIGURA 26 - AS TENSÕES TRIFÁSICAS COM E SEM A GD CONECTADA NA BARRA 840 AO LONGO DE UM DIA TíPICO, NO CENÁRIO 2.112

FIGURA 27 - COMPARAÇÃO ENTRE AS CURVAS DE CARGA ORIGINAIS E AS CURVAS DISCRETIZADAS EM 5 PATAMARES. .113

FIGURA 28 - POSIÇÕES DE TAP OBTIDAS PELA OTIMIZAÇÃO AO LONGO DE UM DIA TÍPICO PARA TODOS OS REGULADORES DE TENSÃO, NO CENÁRIO 3.

FIGURA 29 - AS TENSÕES TRIFÁSICAS COM E SEM A GD CONECTADA NA BARRA 840 AO LONGO DE UM DIA TíPICO, NO CENÁRIO 3.115 FIGURA 30 - COMPARAÇÃO ENTRE AS CURVAS DE CARGA ORIGINAIS E AS CURVAS DISCRETIZADAS EM 10 PATAMARES. 116

FIGURA 31 - POSIÇÕES DE TAP OBTIDAS PELA OTIMIZAÇÃO AO LONGO DE UM DIA TÍPICO PARA TODOS OS REGULADORES DE TENSÃO, NO CENÁRIO 4.

FIGURA 32 - AS TENSÕES TRIFÁSICAS COM E SEM A GD CONECTADA NA BARRA 840 AO LONGO DE UM DIA TíPICO, NO CENÁRIO 4. 118 FIGURA 33 - POSIÇÕES DE TAP OBTIDAS PELA OTIMIZAÇÃO AO LONGO DE UM DIA TÍPICO PARA TODOS OS REGULADORES DE TENSÃO, NO CENÁRIO 5.

FIGURA 34 - AS TENSÕES TRIFÁSICAS COM E SEM A GD CONECTADA NA BARRA 840 AO LONGO DE UM DIA TÍPICO, NO CENÁRIO 5. 120 FIGURA 35 - POSIÇÕES DE TAP OBTIDAS PELA OTIMIZAÇÃO AO LONGO DE UM DIA TÍPICO PARA TODOS OS REGULADORES DE TENSÃO, NO CENÁRIO 6. .121

FIGURA 36 - AS TENSÕES TRIFÁSICAS COM E SEM A GD CONECTADA NA BARRA 840 AO LONGO DE UM DIA TíPICO, No CENÁRIO 6. 122 


\section{Lista de Tabelas}

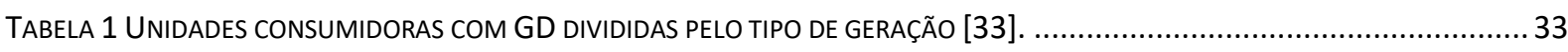

TABELA 2 UNIDADES CONSUMIDORAS COM GD DIVIDIDAS DE ACORDO COM A CLASSE DE CONSUMO [33] ................................. 34

TABELA 3 REQUISITOS MÍNIMOS PARA CONEXÃO DE GERADORES COM DIFERENTES FAIXAS DE POTÊNCIA DE GERAÇÃO INSTALADA AO

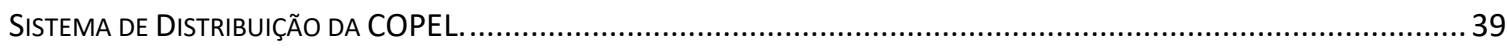

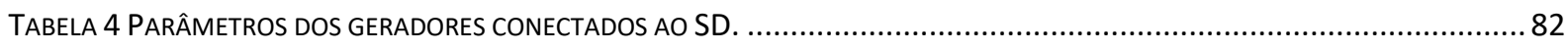

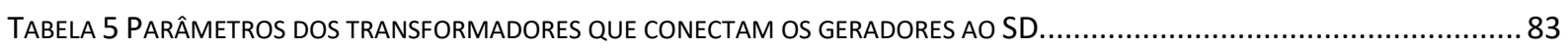

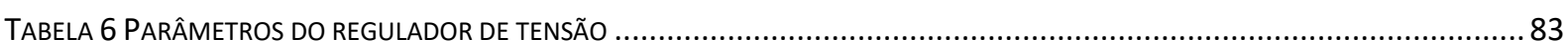

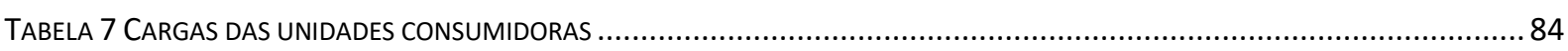

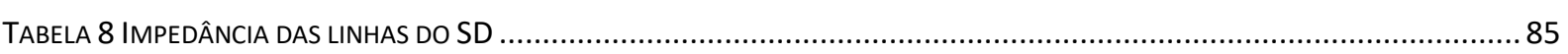

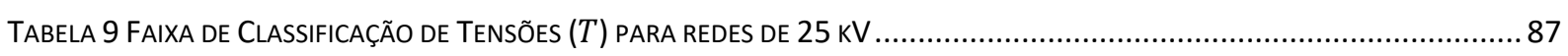

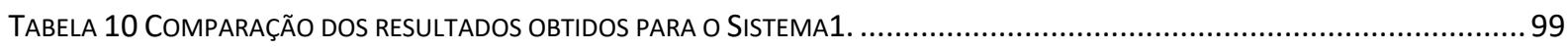

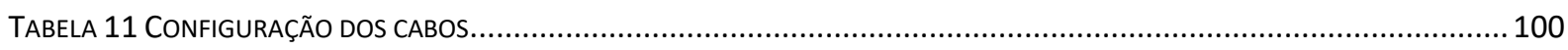

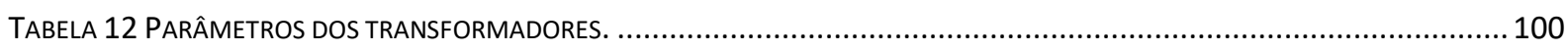

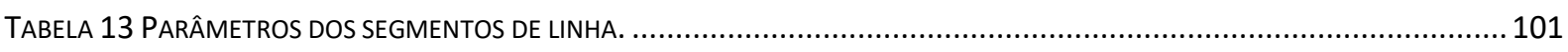

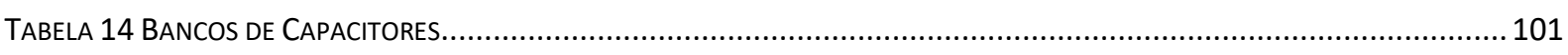

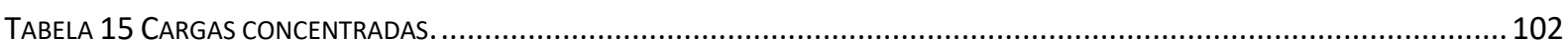

TABELA 16 PARÂMETROS DOS REGULADORES DE TENSÃO.

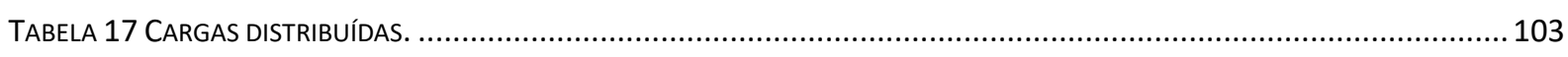

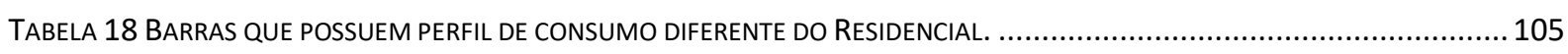

TABELA 19 DENOMINAÇÃO DOS REGULADORES DE TENSÃO NOS GRÁFICOS E SUAS RESPECTIVAS REPRESENTAÇÕES NA MODELAGEM

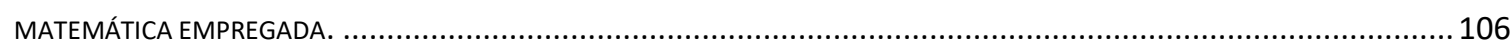

TABELA 20 COMPARAÇÃO ENTRE O MÉTOdO PROPOSTO E A REGULAÇÃO TRADICIONAL, NO CENÁRIO 1................................... 109

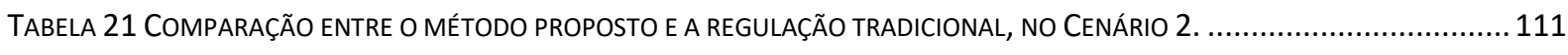

TABELA 22 COMPARAÇÃO ENTRE O MÉTOdo PROPOSTO E A REGULAÇÃo TRADICIONAL, NO CENÁRIO 3.................................... 114

TABELA 23 CoMPARAÇÃO ENTRE O MÉTOdO PROPOSTO E A REGULAÇÃo TRADICIONAL, NO CENÁRIO 4 ...................................117

TABELA 24 CoMPARAÇÃO ENTRE O MÉTOdo PROPOSTO E A REGULAÇÃo TRADICIONAL, NO CENÁRIO 5..................................119

TABELA 25 COMPARAÇÃO ENTRE O MÉTOdO PROPOSTO E A REGULAÇÃO TRADICIONAL, No CENÁRIO 6...................................121

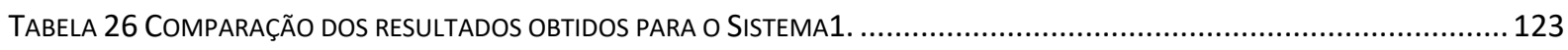

TABELA 27 MÓDULO DAS VARIAÇÕES MÁXIMAS DE TENSÃO QUE OCORRERAM NO SISTEMA E POSIÇÕES DE TAP OBTIDAS FINAIS NO

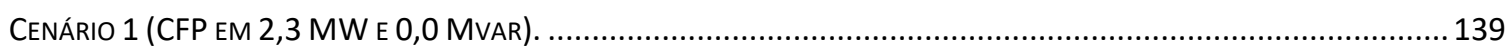

TABELA 28 MÓDULO DAS VARIAÇÕES MÁXIMAS DE TENSÃO QUE OCORRERAM NO SISTEMA E POSIÇÕES DE TAP OBTIDAS FINAIS NO CENÁRIO 2 (CFP EM 4,6 MW E 0,0 MVAR).

TABELA 29 MÓDULO DAS VARIAÇÕES MÁXIMAS DE TENSÃO QUE OCORRERAM NO SISTEMA E POSIÇÕES DE TAP OBTIDAS FINAIS NO Cenário 3 (CFP EM 2,3 MW e 0,9 MVAR).

TABELA 30 MÓDULO DAS VARIAÇÕES MÁXIMAS DE TENSÃO QUE OCORRERAM NO SISTEMA E POSIÇÕES DE TAP OBTIDAS FINAIS NO CENÁRIO 4 (CFP EM 4,6 MW E 1,8 MVAR).

TABELA 31 MÓDULO DAS VARIAÇÕES MÁXIMAS DE TENSÃO QUE OCORRERAM NO SISTEMA E POSIÇÕES DE TAP OBTIDAS FINAIS NO CENÁRIO 5 (CT EM 2,3 MW E 1,0 P.U.). 
TABELA 32 MÓDULO DAS VARIAÇÕES MÁXIMAS DE TENSÃO QUE OCORRERAM NO SISTEMA E POSIÇÕES DE TAP OBTIDAS FINAIS NO CENÁRIO 6 (CT EM 4,6 MW E 1,0 P.U.). 


\section{Sumário}

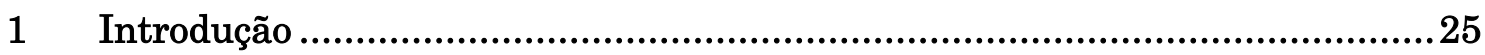

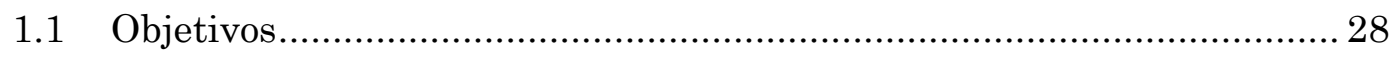

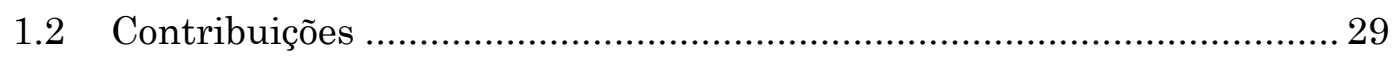

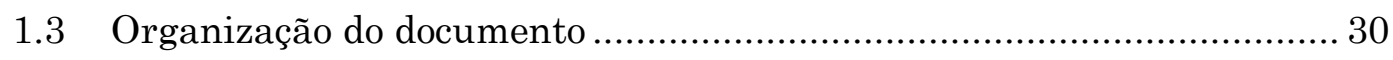

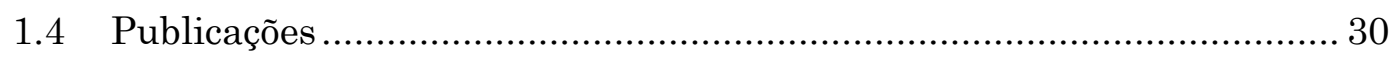

2 Requisitos Técnicos para a Conexão de Geração Distribuída em Sistemas de Distribuição de Energia Elétrica ............................................................. 31

2.1 Módulo 3 - Acesso ao Sistema de Distribuição do PRODIST ................ 34

2.2 1547 IEEE Standard for Interconnecting Distributed Resources with

Electric Power Systems................................................................. 36

2.3 NTC 605100 Acesso de Geração Distribuída ao Sistema da COPEL (com comercialização de energia) e NTC 905200 Acesso de Micro e

Minigeração Distribuída ao Sistema da COPEL................................... 37

2.4 GED-33 Ligação de Autoprodutores em Paralelo com o Sistema de Distribuição da CPFL e GED 15303 Conexão de Micro e Minigeração

Distribuída sob Sistema de Compensação de Energia Elétrica ............. 40

2.5 Alberta Distributed Generation Interconnection Guide ....................... 41

2.6 Requirements for the Interconnection of Distributed Generation to the Hydro-Québec Medium-Voltage Distribution System......................... 42

2.7 Considerações finais sobre o capítulo ............................................... 43

3 Aspectos das Variações de Tensão Causadas pela Geração Distribuída e Possíveis Soluções ......................................................................... 45

3.1 Variações de Tensão Associadas à GD ................................................ 45

3.2 Métodos de Controle de Geradores Distribuídos................................. 48 
3.3 Análises e Soluções Relacionadas à Variação da Tensão após a

Desconexão de Geradores Distribuídos ................................................ 56

3.4 Algoritmos Genéticos Aplicados na Regulação/Controle de Tensão em

Sistemas de Distribuição ............................................................... 62

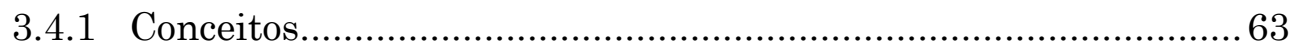

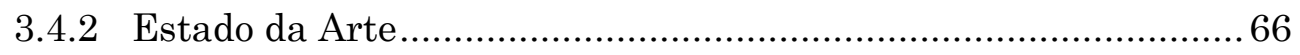

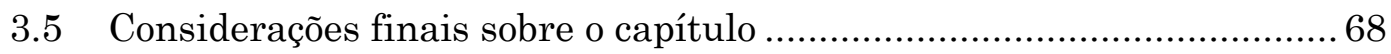

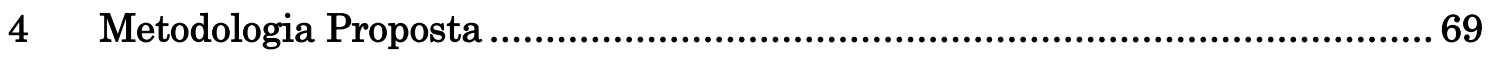

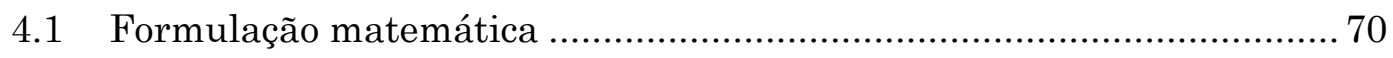

4.1.1 Modelagem para Minimizar as Violações de Tensão após a Desconexão da Geração Distribuída ......................................... 71

4.1.2 Modelagem para Penalizar as Violações de Tensão com a Geração

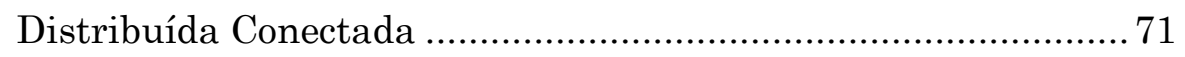

4.1.3 Modelagem para Minimizar as Variações de Posição dos Taps dos

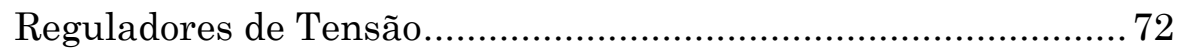

4.2 Apresentação do Método .................................................................... 73

4.3 Considerações finais sobre o capítulo ................................................. 79

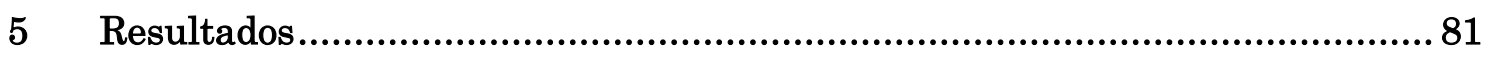

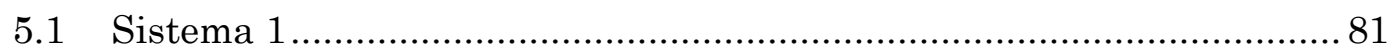

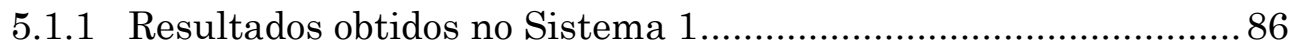

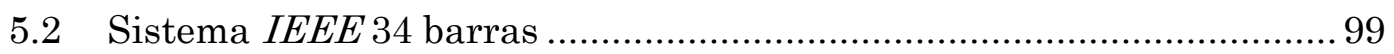

5.2.1 Resultados obtidos no Sistema IEEE 34 barras ....................... 104

5.3 Considerações finais sobre capítulo .................................................... 123

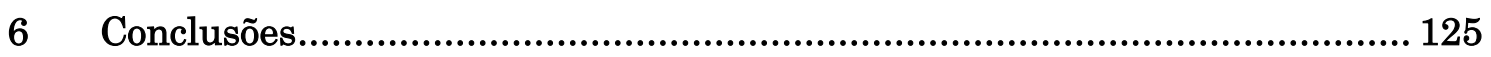

$7 \quad$ Referências Bibliográficas ........................................................... 129

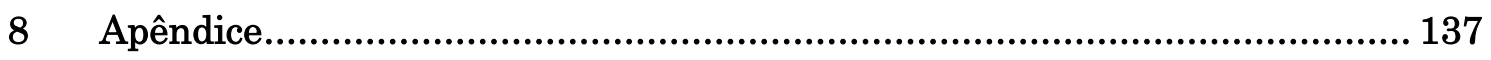

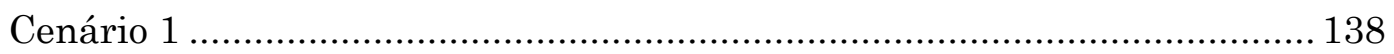

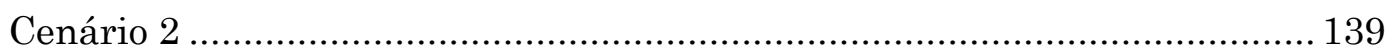

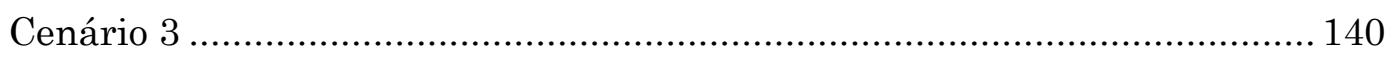

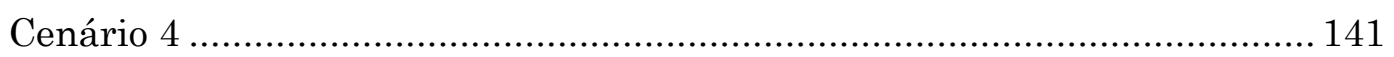

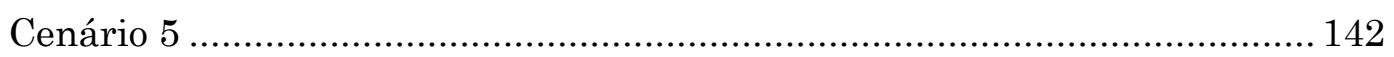

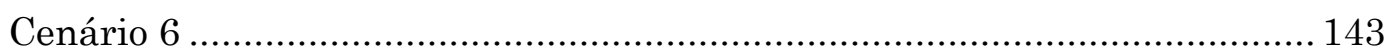




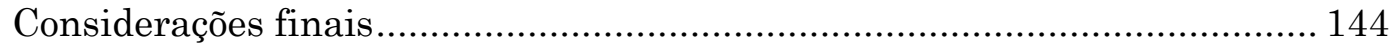





\section{Capítulo 1}

\section{Introdução}

Nos últimos anos, fatores como a reestruturação do setor de energia elétrica em diversos países devido ao rápido crescimento econômico têm levado à necessidade de aproveitamento de diferentes fontes primárias de energia como forma de diversificação da matriz energética. Dificuldades na construção de grandes unidades geradoras e de linhas de transmissão causadas devido ao atendimento à legislação ambiental, bem como avanços tecnológicos na área de geração de energia elétrica têm provocado o aumento considerável do interesse por Geração Distribuída (GD) [1]-[4]. O termo "Geração Distribuída" remete à geração de energia elétrica conectada diretamente no sistema de distribuição de energia e pode agregar formas de geração de energia tanto renováveis quanto não renováveis [5], [6].

Muitos benefícios são esperados com a inserção de geradores distribuídos nas redes de distribuição de energia elétrica, incluindo a redução de emissões de gases poluentes, melhorias na Qualidade da Energia Elétrica (QEE) e na confiabilidade do sistema, podendo ser utilizados como fonte de energia de retaguarda para consumidores quando ocorrer um desligamento da rede principal [6]. Entretanto, modificações nas metodologias de planejamento e adaptações na operação das redes de distribuição de energia elétrica são exigências das concessionárias para os proprietários de geradores distribuídos, visto que os sistemas de distribuição foram inicialmente projetados como redes passivas com fluxo de potência unidirecional, ou seja, da subestação da concessionária para as cargas [6]. Portanto, estudos para avaliar seus impactos em diversos aspectos do sistema de distribuição se fazem necessários. Os principais aspectos que podem ser afetados são: perfil de tensão de regime permanente, estabilidade de tensão, estabilidade de ângulo, filosofia do sistema de proteção, transitórios de tensão, 
correntes de curto-circuito, distorção harmônica, ferro-ressonância e confiabilidade. Quais desses fatores realmente serão mais afetados depende da quantidade de geração a ser instalada, do tipo de gerador a ser empregado e das características da rede elétrica. Nesta pesquisa, foram investigadas ações mitigatórias de impactos negativos dos geradores distribuídos na qualidade da energia elétrica dos sistemas de distribuição de energia elétrica, quando os geradores são desconectados pela sua proteção antiilhamento. As ações mitigatórias desses impactos foram focadas no controle dos taps dos reguladores de tensão do alimentador.

A literatura técnica na área de GD contém um grande número de trabalhos que abordam análises e o desenvolvimento de métodos para a manutenção da qualidade de energia elétrica quando há geradores distribuídos conectados aos sistemas de distribuição [1], [7]-[14]. Apenas para citar alguns desses trabalhos, essas abordagens envolvem a análise de diferentes tecnologias de geração distribuída [8], [9], modos de controle do gerador distribuído [10], [11], a análise dos afundamentos de tensão causados pela atuação de dispositivos de proteção contra curtos-circuitos na presença de geradores distribuídos [12], [13] e o desenvolvimento de estratégias de coordenação entre os geradores distribuídos e dispositivos de regulação de tensão para a manutenção dos valores das tensões dentro da faixa de operação considerada adequada [14]. Contudo, nenhum desses trabalhos analisa possíveis impactos negativos à qualidade da energia elétrica causados pela desconexão de geradores distribuídos.

Os geradores distribuídos operando em paralelo com a rede de distribuição de energia elétrica são requisitados a se desconectarem na ocorrência de contingências do lado da rede, como por exemplo, quando há ilhamento dos geradores [1], [15], [16]. Este procedimento é adotado atualmente nas concessionárias de energia elétrica, sendo estabelecido nos principais guias técnicos em empresas de diversos países [17]-[22]. Uma consequência marcante desta desconexão é o aparecimento de variações de tensão, os quais podem provocar desligamentos e mau funcionamento de equipamentos como microcomputadores, inversores de frequência, motores de indução, entre outros, sendo que os efeitos negativos podem ser mais intensos em equipamentos que contêm circuitos eletrônicos [11], [23].

A desconexão dos geradores distribuídos é obrigatória quando há a atuação de religadores automáticos localizados à montante dos geradores. A operação de religadores automáticos é de extrema importância para a garantia da QEE, pois entre 70\% e 95\% das faltas que ocorrem em linhas de distribuição aéreas são temporárias [24]. Depois da detecção de uma falta, os religadores desconectam o sistema e tentam reconectá-lo após 
um período de tempo, normalmente entre 15 e 20 ciclos seguintes à ocorrência da uma falta. Em alguns casos o religamento pode ser instantâneo ou demorar alguns segundos. Se a primeira tentativa de reconectar o sistema falha, outras (duas ou três) tentativas são refeitas. Após a primeira operação do religador, é muito importante que a GD se desconecte do Sistema de Distribuição (SD), pois caso os geradores se mantenham conectados, a reconexão será realizada fora de fase, podendo causar torques eletromecânicos severos nos geradores, sobretensão excessiva no Ponto de Acoplamento Comum (PAC), grandes correntes de magnetização em transformadores e motores conectados ao SD e dano mecânico em motores devido ao torque excessivo [24]. Por estas razões, é de extrema importância que a GD se desconecte do SD após operação dos religadores e aguarde um tempo previamente determinado para se reconectar.

Para exemplificar a natureza e a importância desse problema, faz-se uso do sistema elétrico da Figura 1(a). Neste sistema, admite-se uma condição normal de operação em que a carga total a jusante do religador seja $5 \mathrm{MW}$ e se admite também que os geradores distribuídos estejam fornecendo $3 \mathrm{MW}$. Neste caso, desprezando-se as perdas nas linhas, o fluxo de potência ativa sobre o religador é 2 MW. Para a condição de operação descrita, o regulador automático de tensão estará configurado com uma posição de tap adequada para manter o perfil de tensão dentro dos valores recomendados pelas agências reguladoras.
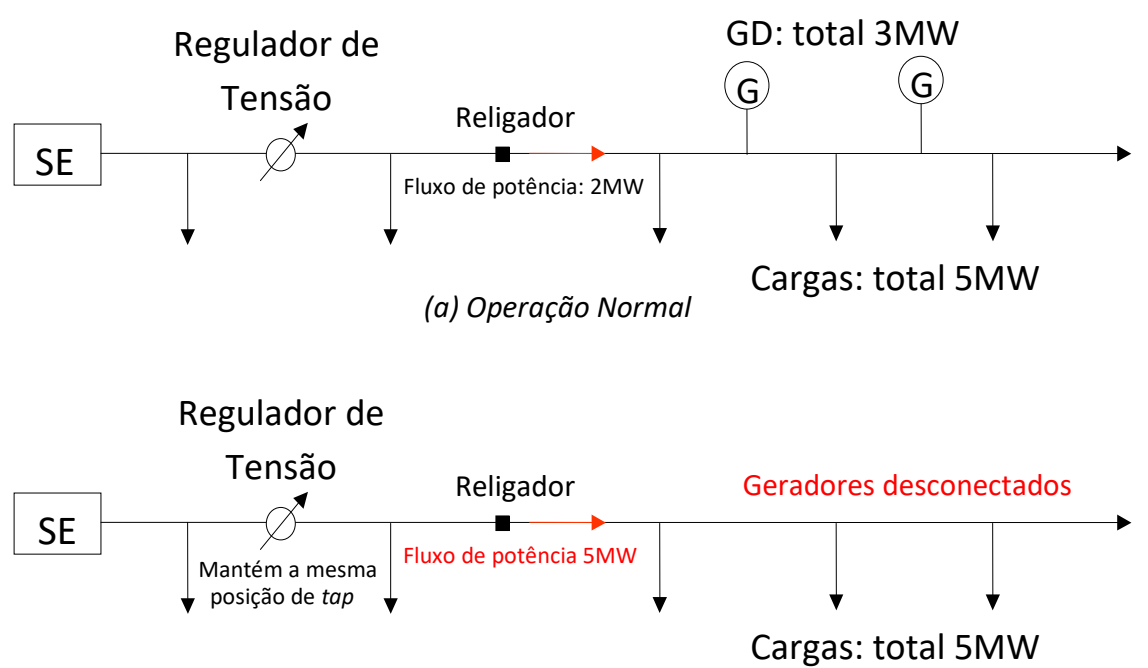

(b) Após a atuação da proteção anti-ilhamento e religamento do religador

Figura 1 - Mecanismo de surgimento de afundamentos de tensão causados pela proteção antiilhamento da GD. 
Ainda referindo à Figura 1(a), considere que o religador atue. No intervalo entre a abertura e o religamento, todos os geradores distribuídos localizados a jusante do religador são desconectados para atender aos requisitos da proteção anti-ilhamento. Assim, após o religamento o fluxo de potência sobre o religador sofrerá um aumento significativo, passando de $2 \mathrm{MW}$ para $5 \mathrm{MW}$, conforme ilustra a Figura 1(b). O resultado disso é o aparecimento de um afundamento de tensão, cuja duração está vinculada ao tempo de operação dos reguladores de tensão e bancos de capacitores existentes no sistema elétrico, o qual pode ser longo em virtude da ação lenta desses dispositivos no processo de correção da tensão. Ressalta-se que este problema pode gerar dificuldades no momento da reconexão dos geradores distribuídos, pois as tensões podem variar significativamente em virtude da ação dos reguladores de tensão e dos bancos de capacitores para restaurar as tensões às partes reconectadas do sistema elétrico. Este problema foi extensivamente estudado em [25] e [26] em que foi mostrado que a intensidade das variações de tensão depende principalmente da posição do tap do regulador de tensão, do nível de carregamento do sistema elétrico e do montante de potência ativa e reativa injetados pelos geradores distribuídos. Em se tratando dos afundamentos de tensão, eles serão mais prejudiciais quanto maiores forem a carga do sistema elétrico e a potência reativa injetada pela GD.

Com base no contexto anteriormente delineado, percebe-se que este é um problema novo no âmbito da qualidade da energia elétrica e, por isso, ainda há poucos relatos sobre a investigação de possíveis soluções para o mesmo. Algumas soluções para este problema são apresentadas em [27], sendo que uma delas foi detalhadamente investigada nesta pesquisa. Neste aspecto, esta pesquisa se propõe a estudar uma potencial solução que visa controlar a posição do tap dos reguladores de tensão em função do carregamento do sistema elétrico e das potências ativa e reativa fornecida pela geração distribuída. Esta potencial solução pode ser considerada como um novo desafio nas áreas de planejamento e operação de sistemas de distribuição de energia, na presença de geradores distribuídos.

\subsection{Objetivos}

O principal objetivo desta pesquisa de mestrado é propor um método para a mitigação das variações de tensão causadas pela desconexão de geradores distribuídos que se baseie no controle centralizado dos taps dos reguladores de tensão existentes nas 
redes de distribuição de energia elétrica utilizando a curva de carga das mesmas. Para atingir este objetivo principal, os seguintes objetivos secundários devem ser alcançados:

- Analisar e compreender a ocorrência dessas variações de tensão em função da posição dos taps dos reguladores, da variação do carregamento do sistema elétrico e do ponto de operação dos geradores distribuídos;

- Formular esse problema como uma otimização. Investigar o uso de um Algoritmo Genético (AG) como um método para resolver esse problema de otimização, minimizando as variações de tensão após a desconexão da GD e também, como objetivo secundário, as operações dos reguladores de tensão em um dia típico.

\subsection{Contribuições}

Como principal contribuição desta pesquisa, foi obtida uma metodologia que permite determinar as posições de tap dos reguladores de tensão que minimizem violações de tensão após a desconexão de toda a GD do sistema, o que pode ocorrer após a ocorrência de uma falta temporária e a subsequente atuação de um religador no SD. A metodologia analisa a ocorrência de violações de tensão considerando, para a mesma posição de tap, a GD conectada e a GD desconectada. Sendo assim, se encontrada uma posição que não cause violação de tensão com e sem a GD conectada, na ocorrência de uma desconexão repentina de toda a GD, a mesma posição de tap do regulador de tensão será mantida, pois ela minimiza as violações de tensão.

A metodologia também minimiza as variações de tap dos reguladores de tensão ao longo de um dia típico representado pela curva de carga do sistema. As alterações de tap necessárias para manter as tensões dentro dos limites de tensão desejados ao longo de um dia típico podem diminuir.

Além disso, a metodologia desenvolvida pode ser utilizada no planejamento da operação em um SD com GD conectada a ele. Adicionalmente, esta pesquisa pode auxiliar na avaliação de outras soluções para este problema, pois a modelagem matemática permite avaliar o quanto o problema da violação de tensão está sendo mitigado. 


\subsection{Organização do documento}

Este documento contém sete capítulos. O primeiro capítulo deste trabalho introduziu o tema de estudo e deu uma visão geral de atual situação da geração distribuída no Brasil e no mundo.

O segundo capítulo aborda as principais normas, resoluções normativas e guias técnicos, brasileiros ou internacionais, relacionados à conexão e desconexão dos geradores distribuídos, focando nos critérios técnicos que podem influenciar o problema estudado neste trabalho.

No Capítulo 3, são apresentados trabalhos que contextualizam o estudo de variação de tensão causada pela introdução de geradores distribuídos a rede de distribuição, métodos de controle de geradores distribuídos, análises que abordam questões semelhantes e métodos que podem auxiliar na resolução do problema.

O Capítulo 4 apresenta a proposta de modelagem matemática para obter uma função objetivo e utilizá-la na otimização, a metodologia adotada para resolução do problema apresentado e por fim, a topologia e os parâmetros dos sistemas, geradores, reguladores de tensão e cargas utilizadas nesta pesquisa.

No Capítulo 5 os resultados obtidos são apresentados e as conclusões da pesquisa são apresentadas no Capítulo 6.

Em seguida, as referências bibliográficas utilizadas neste trabalho são apresentadas. Posteriormente, um anexo com dados obtidos antes da utilização de uma otimização para resolver o problema são apresentados.

\subsection{Publicações}

D. F. Lima and J. C. M. Vieira, "Mitigation of voltage violations caused by the disconnection of distributed generation by using a centralized control of the step-voltage regulator," in 2016 12th IEEE International Conference on Industry Applications (INDUSCON), 2016, pp. 1-5 


\section{Capítulo 2}

\section{Requisitos Técnicos para a Conexão de} Geração Distribuída em Sistemas de Distribuição de Energia Elétrica

Este capítulo tem como objetivo introduzir normas, guias e recomendações relacionadas ao planejamento, operação, teste, considerações de segurança e manutenção da conexão de geradores em sistemas de distribuição, dando foco para as recomendações que podem influenciar o problema de tensão estudado neste trabalho. No Brasil, a Resolução Normativa $n^{\circ}$ 482/2012 [28], revisada pela Resolução Normativa $n^{\circ}$ 678/2015 [29], estabeleceu as condições normativas para a conexão da GD em unidades consumidoras que acessam o SD, exigindo que as distribuidoras disponibilizassem guias relacionados ao acesso de geradores em seus sistemas. Os guias elaborados pelas distribuidoras devem estar de acordo com os Procedimentos de Distribuição em Energia Elétrica no Sistema Nacional (PRODIST) [30] e normas técnicas brasileiras, sendo opcional a consulta às normas internacionais [15].

Em [28] foi criado o Sistema de Compensação de Energia Elétrica, no qual a energia ativa fornecida pela GD é emprestada à distribuidora local, sendo que futuramente o empréstimo é compensado pelo consumo de energia ativa da unidade consumidora no período máximo de 60 meses. A compensação dos créditos obtidos é inicialmente feita na mesma tarifa de energia e período (dentro ou fora da ponta) em que a geração ocorreu. Posteriormente os créditos podem ser compensados em tarifas e períodos de geração diferentes, respeitando a relação de custos entre eles. 
As distribuidoras locais ficaram responsáveis por eventuais melhorias ou reforços no SD que devem ser feitos para acomodar a microgeração distribuída (potência instalada menor ou igual a $75 \mathrm{~kW}$ ), porém qualquer melhoria ou reforço para acomodar a minigeração distribuída (potência instalada superior a $75 \mathrm{~kW}$ e menor ou igual a $3 \mathrm{MW}$ para fontes hídricas ou menor ou igual a 5 MW para demais fontes de energia) deve ter o custo dividido com o solicitante, de acordo as regras de participação financeira do consumidor.

A resolução ainda prevê a instalação de GD em condomínios e em cooperativas, sendo que os créditos obtidos pela energia gerada podem ser divididos entre os consumidores. Um mesmo consumidor também pode gerar energia e utilizar os créditos em diferentes unidades consumidoras, desde que as unidades pertençam ao mesmo titular e elas estejam localizadas na área de atendimento da mesma distribuidora.

O número de conexões de GD tem tido um aumento significativo desde a publicação de [28], como pode ser observado na Figura 2, em que os números de conexões totais entre dezembro de 2012 e janeiro de 2016 são mostrados. Desde 2012, a resolução foi revisada com o objetivo de ampliar as possibilidades para micro e minigeração distribuída [29], aumentando o período para uso dos créditos de energia de 36 para 60 meses e incluindo a possibilidade da geração de energia ser realizada por meio de cooperativas e dentro de condomínios.

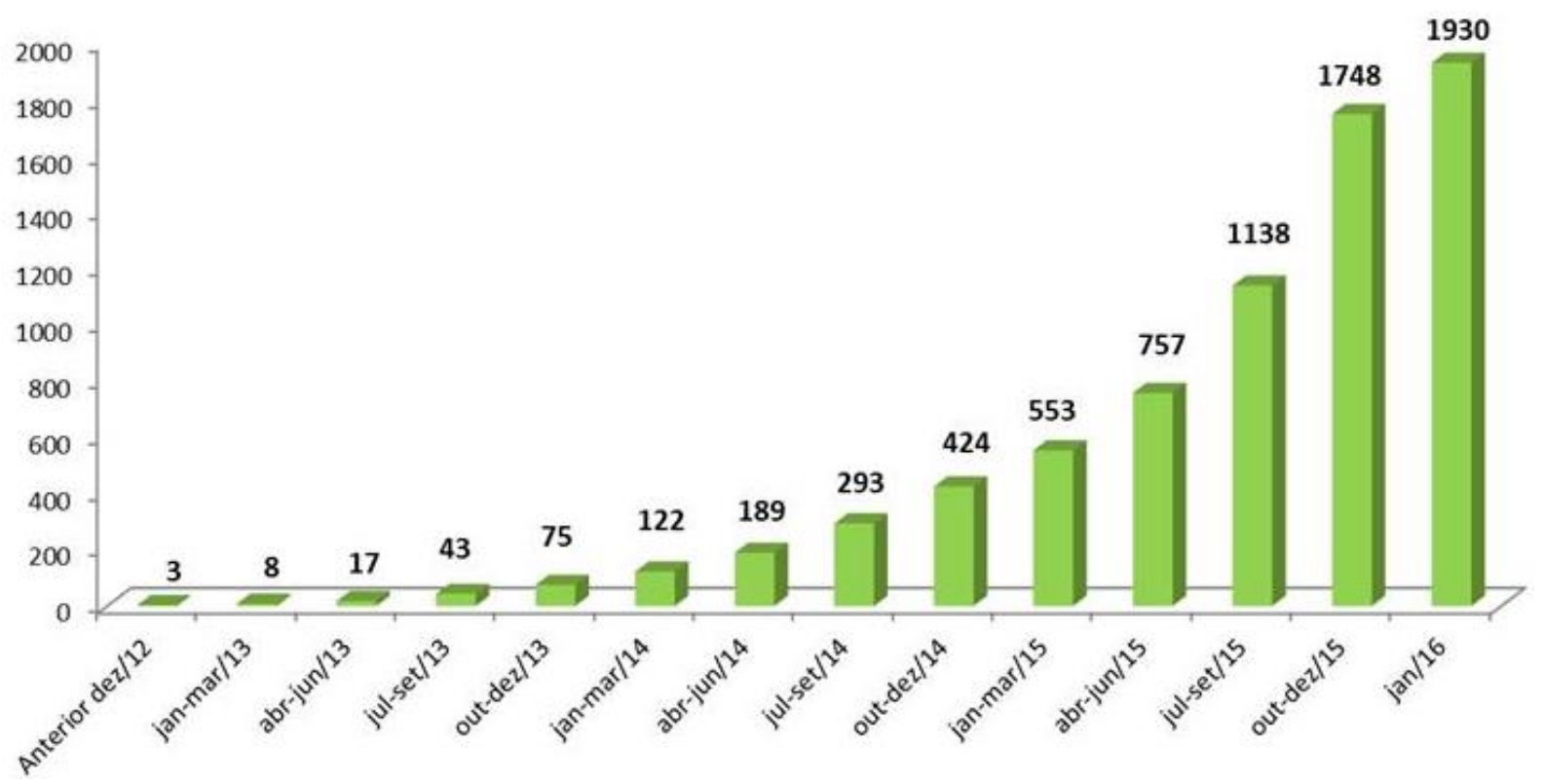

Figura 2 - Quantidade acumulada de centrais geradoras que aderiram ao sistema de compensação de energia elétrica desde a publicação da [28]. Fonte: [31] 
É possível observar uma grande predominância de usinas solares fotovoltaicas em comparação aos outros tipos de GD, 99\% das conexões e 70\% da potência instalada de GD que aderiram ao sistema de compensação de energia elétrica são fontes solares fotovoltaicas, sendo o restante composto por eólicas, biogás, biomassa e hidráulica [32], [33]. Em Maio de 2017, a potência instalada da GD que utiliza esse sistema de compensação pode ser encontrada na Tabela 1, onde as unidades são divididas pelo tipo de geração, e na Tabela 2, onde as unidades são divididas de acordo com a classe de consumo. Nas Tabelas 1 e 2, o total de usinas é de 10.052, sendo que o total de unidades consumidoras que recebem crédito é de 11.230 e a potência instalada total é de 110.942 kW. Na Tabela 2, nota-se que a classe comercial e a classe residencial possuem uma grande participação na potência instalada. É interessante notar que o pico de geração das fontes solares fotovoltaicas no Brasil é entre as 11 e 15 horas [34], período em que a classe residencial, tipicamente, tem um consumo abaixo de seu pico, o que pode causar problemas de QEE [35].

Tabela 1 Unidades consumidoras com GD divididas pelo tipo de geração [33].

Tipo

Central Geradora

Hidrelétrica

Central Geradora

Eólica

Central Geradora Solar

Fotovoltaica

Usinas Termelétricas

Total
11

48

9.951

42
34

49

11.001

146

11.230
Potência

Instalada

$(\mathrm{kW})$

$7.115,00$

$10.168,10$

$77.237,39$

$16.421,50$

110.942

É importante ressaltar que o sistema de compensação de energia elétrica não tem como objetivo estimular a micro e a minigeração distribuída a exceder de maneira excessiva a carga instalada da unidade consumidora, por esta razão os créditos têm prazo de validade para incentivar o consumo da energia gerada [36]. A geração de energia em maior escala já possuía regras bem definidas antes de [28] ser publicada. 
Como a energia será gerada a partir de fontes intermitentes e sua disponibilidade em um período pode ser maior que a média histórica, o prazo de validade (60 meses) torna possível o posterior uso da energia excedente. Para aderir ao sistema de compensação de energia elétrica, a fonte da energia gerada deve ser por meio de cogeração qualificada (utilização combinada de calor e energia elétrica, definido pela Resolução Normativa n²35/2006 [37]) ou fontes renováveis como hídrica, solar, biomassa ou eólica.

Tabela 2 Unidades consumidoras com GD divididas de acordo com a classe de consumo [33].

\begin{tabular}{cccc}
\hline $\begin{array}{c}\text { Classe de } \\
\text { Consumo }\end{array}$ & $\begin{array}{c}\text { Unidades consumidoras } \\
\text { que geram energia }\end{array}$ & $\begin{array}{c}\text { Unidades consumidoras } \\
\text { que recebem os créditos }\end{array}$ & $\begin{array}{c}\text { Potência } \\
\text { Instalada } \\
(\mathrm{kW})\end{array}$ \\
Comercial & 1.523 & 1.890 & $41.909,12$ \\
Iluminação & 6 & 6 & 71,52 \\
pública & 212 & 239 & $22.665,86$ \\
Industrial & 84 & 126 & $3.370,80$ \\
Poder Público & 8.001 & 8.624 & $33.273,40$ \\
Residencial & 200 & 319 & $9.123,67$ \\
Rural & 26 & 26 & 527,62 \\
Serviço Público & 10.052 & 11.230 & 110.942 \\
Total & & & \\
\hline
\end{tabular}

\subsection{Módulo 3 - Acesso ao Sistema de Distribuição do PRODIST}

O Módulo 3 do PRODIST [16] tem como objetivo estabelecer as condições de acesso ao SD, da conexão ao uso, e definir critérios técnicos e operacionais da conexão. Sua abrangência inclui as distribuidoras de energia, as unidades consumidoras que utilizam o sistema de compensação de energia elétrica e os demais produtores de energia conectados ao SD, excluindo instalações conectadas ao sistema de transmissão.

Considerando centrais geradoras com potência instalada superior a $300 \mathrm{~kW}$, as distribuidoras podem, caso haja comum acordo entre as centrais geradoras de energia e o Operador Nacional do Sistema Elétrico (ONS), permitir que ocorra a operação ilhada de 
parte do SD, formando uma microrede, desde que os procedimentos estabelecidos no Módulo 4 do PRODIST [38] sejam respeitados. Uma avaliação técnica deve ser feita para estudar esta possibilidade, sendo que a qualidade da energia entregue a microrede deve ser considerada [16].

Normas de segurança específicas para operações ilhadas devem ser estabelecidas para evitar que ocorram acidentes. Uma das razões da operação ilhada ser evitada é para proteger a equipe de manutenção da distribuidora. Por este motivo, qualquer central geradora conectada ao SD deve possuir uma chave seccionadora visível e acessível para a equipe de manutenção abrir e garantir que a GD está desconectada durante uma eventual manutenção da rede elétrica.

As distribuidoras e as centrais de geração devem estabelecer suas obrigações, deveres e o relacionamento operacional entre as mesmas em um contrato, o Acordo Operativo, definindo também os meios de comunicação, o fluxo de informações e quais dados serão trocados entre os agentes envolvidos. A coordenação e supervisão da operação das centrais geradoras devem ser consideradas. É exigido comunicação de voz e dados entre o Centro de Operação da Distribuição (COD) e o centro de controle da GD, porém, serviços de comunicação que permitam a supervisão e controle em tempo real de grandezas elétricas não são necessários [38].

Centrais geradoras com potência instalada superior a $300 \mathrm{~kW}$ devem possuir sistemas de controle de frequência e tensão. Um disjuntor ou religador no PAC dessas centrais deve ser capaz de detectar e isolar a GD caso ocorra alguma falta no SD. O paralelismo deve ser desfeito quando há interrupção do fornecimento de energia pela distribuidora em um SD, desconectando a geração antes de qualquer tentativa de religamento [16]. A inversão de fluxo de potência nos reguladores de tensão não é permitida.

As distribuidoras são obrigadas a adotar medidas que impeçam variações de tensões que violem os padrões de QEE definidos em [39] na ocorrência da conexão ou desconexão da GD até a atuação dos reguladores de tensão do sistema [16].

As distribuidoras devem fazer estudos que considerem a possibilidade de as centrais geradoras participarem do Controle Automático de Geração e do Esquema de Corte de Geração previstos nos Procedimentos de Rede, documento de caráter normativo elaborado pelo ONS para o planejamento e a operação do Sistema Interligado Nacional 
[40]. Os estudos também deve considerar a possibilidade da GD participar de Centro de Despacho de Geração Distribuída, que pode ser coordenado pelo COD [38].

\subsection{IEEE Standard for Interconnecting Distributed Resources with Electric Power Systems}

A norma 1547 IEEE Standard for Interconnecting Distributed Resources with Electric Power Systems [15], criada em 2003, foi desenvolvida em conjunto com membros pertencentes ao The Institute of Electrical and Electronics Engineers (IEEE) e do American National Standards que reuniu vários profissionais com pontos de vista diferentes para estabelecer uma série de normas, especificações técnicas, condutas sobre a operação, testes, segurança e manutenção relacionados à conexão de GD com potência instalada inferior a 10 MVA no primário ou secundário de SD tipicamente radiais. As recomendações são voluntárias, não havendo a obrigatoriedade de cumpri-las. A norma possui um guia para facilitar seu uso na prática [24] e foi revista em 2014 para atender necessidades mais atuais da GD [41].

Em [15] é definido que a GD pode regular ativamente a tensão do PAC apenas quando essa regulação é executada de maneira coordenada com a distribuidora. A GD não pode causar sobretensão ou subtensão em qualquer barra do SD. A distribuidora e as centrais geradoras devem escolher de maneira conjunta quando os geradores devem ser desconectados na presença de variações de tensão. A GD não pode impedir o funcionamento de qualquer dispositivo de proteção de um SD, como um religador. Sua operação não pode demandar mudanças nas práticas de proteção adotadas pelas distribuidoras. Geradores com mais de $250 \mathrm{kVA}$ devem obrigatoriamente monitorar a tensão do PAC e as potências ativas e reativas injetadas pelos geradores

A GD deve ser desconectada caso ocorra alguma falta no SD. Quando ocorre a formação de uma ilha, a GD deve se desconectar do SD em aproximadamente dois segundos. É recomendável que os religadores possuam proteção para evitar a reconexão de uma porção do sistema ilhada e que a GD aguarde um tempo superior ao da subsequente operação dos religadores para tentarem efetuar a reconexão ao SD. Após a operação de algum religador, a GD só deve se reconectar após a tensão e a frequência do PAC voltarem para valores que não violam a $\mathrm{QEE}$, sendo que um atraso típico de cinco minutos deve ser usado para essa reconexão. O gerador não pode energizar o SD quando 
o sistema está sem energia. Testes em campo devem ser efetuados para assegurar que a proteção anti-ilhamento esteja funcionando da maneira correta. Uma chave seccionadora visível e de fácil acesso é exigida para a equipe de manutenção da distribuidora ser capaz de desconectar a GD quando ocorrerem manutenções do SD.

\subsection{NTC 605100 Acesso de Geração Distribuída ao Sistema da COPEL (com comercialização de energia) e NTC 905200 Acesso de Micro e Minigeração Distribuída ao Sistema da COPEL}

Em dezembro de 2010, a Companhia Paranaense de Energia (COPEL) estabeleceu as condições gerais para a conexão de geradores em seu SD com o objetivo de vender energia [17] e também para as centrais geradoras que optarem por aderirem ao sistema de compensação de energia elétrica [18]. As exigências técnicas e de segurança encontradas no PRODIST e nas resoluções normativas da ANEEL foram consideradas nesta norma. Os documentos abrangem o acesso de geradores aos SD em média tensão de distribuição (13,8 e 34,5 kV), alta tensão de distribuição (69 e 138 kV).

A COPEL realiza estudos sobre a conexão de GD considerando a potência total de geração instalada para determinar o tipo de conexão e o ponto de acesso, buscando o menor custo para adequação do SD. O tipo de conexão pode ser em pingo na rede ou em linha expressa. Em pingo na rede a conexão é feita em um alimentador já existente da distribuidora, ou seja, é compartilhada com outras cargas, subestações e até mesmo outras usinas. A conexão em linha expressa é uma conexão direta e exclusiva até uma subestação. O acessante é encarregado pelas adequações dos sistemas de telecomunicações, proteção, comando e controle que são necessárias em razão exclusivamente de sua conexão. Nas conexões efetuadas em média tensão nenhuma readequação é necessária no sistema de proteção da rede e das subestações quando a potência instalada dos geradores é inferior a $40 \%$ da demanda do sistema em patamar de baixa carga. Nas conexões de alta tensão, readequações nas proteções das subestações são necessárias quando a potência instalada supera $20 \%$ da demanda em patamar de baixa carga. 
Com exceção da microgeração (até $75 \mathrm{~kW}$ ), o acesso dos geradores ao SD deve ser efetuado com um transformador exclusivo, possuindo relés de proteção. Acima de $1 \mathrm{MW}$, a conexão deve possuir um disjuntor ou religador. Acima de $75 \mathrm{~kW}$, todos as fontes geradoras (convencionais, eólicas ou fotovoltaicas) devem ser trifásicas. Entre $75 \mathrm{~kW} \mathrm{e}$ $300 \mathrm{~kW}$ de potência instalada a proteção na baixa tensão é permitida, assim como o uso de geradores assíncronos. A Tabela 3 apresenta características operacionais mínimas exigidas pela COPEL para a conexão de geradores. 
Tabela 3 Requisitos mínimos para conexão de geradores com diferentes faixas de potência de geração instalada ao Sistema de Distribuição da COPEL.

\begin{tabular}{|c|c|c|c|c|c|}
\hline $\begin{array}{l}\text { Potência total de } \\
\text { geração instalada }\end{array}$ & Até 75 kW & $\begin{array}{l}76 \mathrm{~kW} \mathrm{a} \\
300 \mathrm{~kW}\end{array}$ & $\begin{array}{c}301 \mathrm{~kW} \mathrm{a} \\
500 \mathrm{~kW}\end{array}$ & $\begin{array}{c}501 \mathrm{~kW} \text { a } \\
1,0 \mathrm{~kW}\end{array}$ & $\begin{array}{c}\text { Acima de } \\
1,0 \mathrm{MW}\end{array}$ \\
\hline Tipo de conexão & $\begin{array}{l}\text { Pingo na } \\
\text { rede }\end{array}$ & $\begin{array}{l}\text { Pingo na } \\
\text { rede }\end{array}$ & $\begin{array}{l}\text { Pingo na } \\
\text { rede }\end{array}$ & $\begin{array}{l}\text { Pingo na } \\
\text { rede*/ } \\
\text { linha } \\
\text { expressa }\end{array}$ & $\begin{array}{c}\text { Pingo na } \\
\text { rede*/ } \\
\text { linha } \\
\text { expressa }\end{array}$ \\
\hline $\begin{array}{l}\text { Faixa de tensão } \\
\text { eficaz entre as } \\
\text { fases }\end{array}$ & $\begin{array}{l}\text { Baixa } \\
\text { Tensão }\end{array}$ & $\begin{array}{l}\text { Média } \\
\text { Tensão }\end{array}$ & $\begin{array}{l}\text { Média } \\
\text { Tensão }\end{array}$ & $\begin{array}{l}\text { Média } \\
\text { Tensão }\end{array}$ & $\begin{array}{l}\text { Média ou } \\
\text { Alta } \\
\text { Tensão }\end{array}$ \\
\hline $\begin{array}{c}\text { Desconectar o } \\
\text { gerador em caso de } \\
\text { faltas e distúrbios } \\
\text { no SD }\end{array}$ & Obrigatório & Obrigatório & Obrigatório & Obrigatório & Obrigatório \\
\hline $\begin{array}{l}\text { Não permitir a } \\
\text { reconexão do }\end{array}$ & & & & & \\
\hline $\begin{array}{c}\text { gerador durante a } \\
\text { atuação do } \\
\text { religador }\end{array}$ & - & Facultativo & Obrigatório & Obrigatório & Obrigatório \\
\hline $\begin{array}{c}\text { Desconexão } \\
\text { automatizada do }\end{array}$ & & & & & \\
\hline $\begin{array}{l}\text { gerador pelo COD } \\
\text { em casos de faltas e } \\
\text { distúrbios na rede }\end{array}$ & - & Facultativo & Obrigatório & Obrigatório & Obrigatório \\
\hline $\begin{array}{c}\text { Sistema de } \\
\text { comunicação para }\end{array}$ & & & & & \\
\hline $\begin{array}{l}\text { mudanças de } \\
\text { ajustes dos } \\
\text { geradores }\end{array}$ & - & - & - & Obrigatório & Obrigatório \\
\hline
\end{tabular}


potência do PAC. Geradores assíncronos devem utilizar banco de capacitores para adequar seu fator de potência, sendo que os bancos devem ser dimensionados para suprir no máximo $75 \%$ da sua potência reativa máxima. Sistemas de geração distintos devem utilizar tecnologias adequadas para controle do fator de potência. Os valores de fator de potência definidos pela COPEL constarão no Acordo Operativo e no caso de violação comprovada, os geradores poderão ser desconectados.

O acessante deve garantir que os geradores não reduzirão a flexibilidade na recomposição nem interferirão na operação dos religadores presentes no SD, desconectando os geradores antes da subsequente tentativa de religamento. Não é estabelecido um tempo máximo para a desconexão em casos de ilhamento não planejado, porém os geradores devem ser desconectados sem nenhum atraso intencional. A reconexão apenas pode ocorrer, no mínimo, após dois minutos da tensão ter sido normalizada.

Os geradores não podem causar violações dos limites operativos definidos pelo Módulo 8 - Qualidade de Energia Elétrica [39] e do submódulo 2.8 "Gerenciamento de Indicadores de Desempenho e seus Componentes" dos Procedimentos de Rede [40]. A princípio, a operação ilhada não é permitida, com exceção do ilhamento de cargas internas ou de parte do SD (microrrede), desde que estudos de fluxo de potência, proteção e qualidade de energia comprovem a viabilidade do ilhamento.

A operação com despacho centralizada também deve ser estudada, prevendo a possibilidade de participação do Controle Automático de Geração, do Esquema de Corte de Geração e do Centro de Despacho de Geração Distribuída. As centrais geradoras podem também auxiliar na melhoria de níveis de tensão ou fator de potência do PAC, sendo que estas operações devem ser estabelecidas na elaboração do acordo operativo.

\subsection{GED-33 Ligação de Autoprodutores em Paralelo com o Sistema de Distribuição da CPFL e GED 15303 Conexão de Micro e Minigeração Distribuída sob Sistema de Compensação de Energia Elétrica}

Os requisitos técnicos mínimos que devem ser considerados aos consumidores da Companhia Paulista de Força e Luz (CPFL) conectados às redes de média e baixa tensão 
que desejam produzir energia elétrica destinada ao comércio (acima de $1 \mathrm{MW}$ ) [19] ou desejam aderir ao sistema de compensação de energia elétrica [20] são apresentados nesta seção. Para a CPFL, microgeração distribuída são centrais geradoras com potência instalada inferior a $100 \mathrm{~kW}$ e minigeração são centrais geradoras com potência instalada entre $100 \mathrm{~kW}$ e $1 \mathrm{MW}$.

Com exceção da microgeração, todos os geradores devem ser conectados ao PAC por um transformador. Toda central de microgeração deve ser conectada na rede de baixa tensão por intermédio de inversores eletrônicos, para qualquer fonte de energia, mesmo quando o gerador é capaz de ser conectado diretamente.

No PAC deve existir um disjuntor ou religador que seja capaz de desconectar a central geradora quando ocorre alguma anomalia no SD da CPFL, como uma falta ou uma queda acentuada de tensão. Não é permitida a operação ilhada do SD, todas centrais geradoras devem possuir proteção anti-ilhamento que atue no máximo em dois segundos e o tempo de religamento dos geradores é definido no Acordo Operativo. Para potência instalada acima de $1 \mathrm{MW}$, é necessário conectar na saída da subestação que supervisiona o circuito alimentador ao qual a geração está conectada um disjuntor ou religador que seja capaz de bloquear o religamento automático quando há presença de tensão na rede resultante da central geradora. $\mathrm{O}$ fator de potência para a microgeração e a minigeração deve estar entre 0,92 capacitivo e 0,92 indutivo e para a comercialização deve estar entre 0,80 capacitivo e 0,80 indutivo.

\subsection{Alberta Distributed Generation Interconnection Guide}

A distribuidora Alberta Electric System Operator (AESO) é responsável pela distribuição de energia na província de Alberta, no Canada. Seu guia para conexão de GD abrange geradores conectados em redes com tensão até $25 \mathrm{kV}$ [21]. O acessante e a distribuidora devem preparar a operação da GD por via de um Acordo Operativo.

Religadores automáticos são utilizados pela $A E S O$, então o acessante deve levar isso em consideração no planejamento dos esquemas de proteção da central geradora, pois os geradores apenas podem se reconectar ao sistema após a tensão ter sido reestabelecida, com um atraso de pelo menos 60 segundos. Sistemas de comunicação podem ser empregados para coordenar a desconexão e reconexão da central geradora. 
Centrais geradoras com potência de geração instalada acima de 5 MW devem possuir sistemas de comunicação com COD e enviar o estado do disjuntor que conecta os geradores à rede, assim como a quantidade de potência ativa e reativa geradas. A $A E S O$ pode exigir o sistema de comunicação mencionado para potências instaladas menores, caso julgue necessário.

A tensão no PAC deve variar entre 0,95 p.u. e 1,05 p.u.. O fator de potência deve ser entre 0,90 capacitivo e 0,90 indutivo para todos os geradores, com exceção e quando previsto pela $A E S O$ a operação com outro valor. A central geradora deve operar com o fator de potência constante, sendo capaz de trocar o controle para tensão constante caso a tensão se eleve para um valor superior a 1,05 p.u. $O$ ajuste da tensão deve ocorrer entre 0 e 180 segundos, sendo o tempo definido pela AESO. Geradores com potência instalada entre $2 \mathrm{MW}$ e $50 \mathrm{MW}$ devem possuir regulação automática de tensão.

\subsection{Requirements for the Interconnection of Distributed Generation to the Hydro-Québec Medium-Voltage Distribution System}

O guia da distribuidora Hydro-Québec define os padrões mínimos para conexão de geradores em sua rede de distribuição de média tensão de $25 \mathrm{kV}$ [22]. Se o acessante deseja conectar geradores em redes com tensão inferior a $25 \mathrm{kV}$, ainda deve usar o mesmo guia como referência, porém a Hydro-Québec avalia individualmente estes pedidos de conexão e faz recomendações específicas para cada caso.

O acessante deve garantir que a potência ativa máxima injetada não descumprirá os limites operacionais de tensão definidos em [22]. No geral, o fator de potência deve ser mantido constante, operando perto da unidade. Geradores de indução devem possuir bancos de capacitores em seu PAC para regular o fator de potência. Quando ocorre sobretensão, se a central geradora for capaz de regular a tensão, ela deve ajustar seu fator de potência temporariamente para reestabelecer a tensão para uma faixa aceitável de valor. Este ajuste deve ocorrer com o fator de potência variando no máximo entre 0,95 capacitivo e 0,95 indutivo. Se a potência instalada da central geradora for superior a 5 MW a faixa de ajuste do fator de potência deve ser entre 0,90 capacitivo e 0,90 indutivo.

As centrais geradoras devem possuir proteção contra ilhamento. Quando o religador atua, a GD deve ser desconectada, considerando que o primeiro religamento 
ocorre após 10 segundos da primeira operação do religador. Em condições especiais a operação ilhada pode ser permitida.

\subsection{Considerações finais sobre o capítulo}

Este capítulo apresentou normas técnicas nacionais e internacionais que abrangem a conexão de centrais geradoras nas redes de distribuição, dando ênfase para os critérios que podem afetar o problema estudado nesta pesquisa de mestrado. Apesar de existirem pequenas variações, todas as normas exigem a desconexão das centrais geradoras quando os religadores atuam, sendo que o tempo de atuação dos religadores varia entre as distribuidoras. Foi observado que com frequência, dependendo da potência instalada dos geradores, as distribuidoras preveem a opção de estabelecer requisitos específicos em conjunto com o acessante para a conexão e operação da GD. Também é importante destacar que, dependendo da capacidade dos geradores, é exigido um sistema de comunicação entre a central geradora e o COD. O ponto de acesso também pode ser diferente para os geradores, dependendo da potência instalada. A reconexão da GD não pode causar sobretensões na rede e deve ocorrer apenas após a tensão ser reestabelecida, sendo que, no geral, um atraso de dois minutos é utilizado para garantir que a tensão presente na rede de distribuição esteja adequada. 


\section{Capítulo 3}

\section{Aspectos das Variações de Tensão Causadas pela Geração Distribuída e Possíveis Soluções}

Este capítulo apresenta a explicação do problema das variações de tensão causadas pela desconexão de geradores conectados a um SD, pesquisas relacionadas ao fenômeno da variação de tensão causada por GD, assim como métodos de controle dos geradores. Análises sobre o problema e possíveis soluções são também apresentadas.

\subsection{Variações de Tensão Associadas à GD}

Quando geradores são conectados em linhas radiais, como observado no sistema simplificado da Figura 3, a geração de energia provavelmente ocasionará um aumento de tensão na mesma [7]. Para o gerador injetar potência ativa, geralmente a tensão no PAC deve ser maior que a do secundário do regulador de tensão, exceto quando o gerador é capaz de absorver uma quantidade significativa de potência reativa ou quando a carga conectada a jusante do gerador ou no mesmo PAC consome toda a potência ativa injetada 
pelo gerador. Mesmo quando não há inversão de fluxo de potência em direção à subestação, se a potência ativa consumida a jusante ou no PAC da GD for menor que a potência ativa gerada, haverá aumento de tensão no PAC [42]. Elevações de tensão são um dos principais problemas relacionados à conexão de geradores em SDs de média e baixa tensão [23].

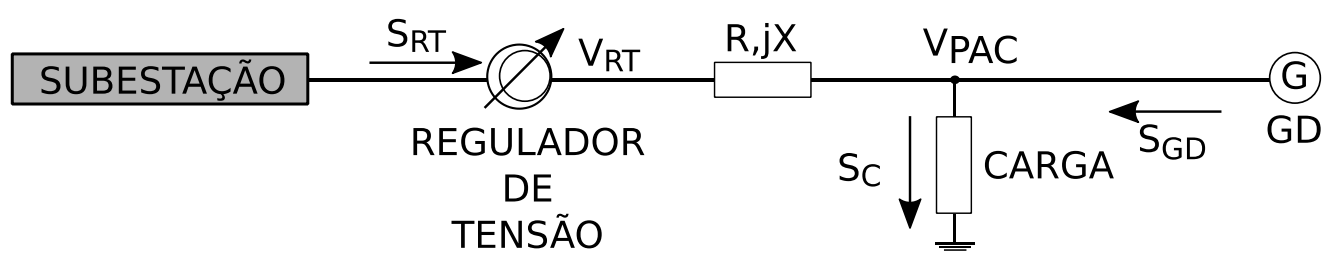

Figura 3 - Influência da conexão de GD na tensão de regime permanente.

Em um exemplo, o SD da Figura 3 foi simplificado para possuir apenas os elementos que influenciam na variação de tensão causada pela GD. Possíveis cargas a jusante em um sistema radial podem ser concentradas no mesmo PAC em que a GD se conecta ao sistema, sem prejuízos nessa formulação. O fluxo de potência aparente no regulador de tensão na Figura 3 é

$$
S_{R T}=P_{R T}+j Q_{R T},
$$

em que $P_{R T}$ e $Q_{R T}$ são, respectivamente, a potência ativa e reativa que fluem pelo regulador de tensão. A tensão no $\operatorname{PAC}\left(\boldsymbol{V}_{\boldsymbol{P A C}}\right)$ é a tensão no regulador de tensão $\left(\boldsymbol{V}_{\boldsymbol{R} T}\right)$ menos a queda de tensão na linha causada pela corrente do regulador de tensão $\left(\boldsymbol{I}_{\boldsymbol{R} T}\right)$, ou seja:

$$
\boldsymbol{V}_{\boldsymbol{P A C}}=\boldsymbol{V}_{\boldsymbol{R T}}-(R+j X) \cdot \boldsymbol{I}_{\boldsymbol{R} T}
$$

em que $R$ e $X$ são respectivamente a resistência e a reatância da linha. A corrente no regulador de tensão pode ser reescrita por:

$$
\boldsymbol{I}_{\boldsymbol{R T}}=\left(\frac{S_{R T}}{V_{P A C}}\right)^{*}
$$

Substituindo (1) e (3) em (2), obtém-se:

$$
\boldsymbol{V}_{\boldsymbol{P A C}}=\boldsymbol{V}_{\boldsymbol{R} \boldsymbol{T}}-\frac{\mathrm{R} \cdot \mathrm{P}_{R T}+\mathrm{X} \cdot \mathrm{Q}_{R T}}{\boldsymbol{V}_{\boldsymbol{P A C}}{ }^{*}}-j \frac{\mathrm{X} \cdot \mathrm{P}_{R T}-\mathrm{R} \cdot \mathrm{Q}_{R T}}{\boldsymbol{V}_{\boldsymbol{P A C}}{ }^{*}} .
$$

Utilizando a tensão no regulador de tensão como referência angular $\left(\boldsymbol{V}_{\boldsymbol{R} T}=\right.$ $V_{R T} \angle 0^{\circ}$ ) e considerando que a diferença angular entre a tensão no regulador e no PAC do 
gerador e da carga é pequena [35], a equação (4) pode ser reescrita sem a parte imaginária:

$$
V_{P A C} \approx V_{R T}-\frac{\mathrm{R} \cdot \mathrm{P}_{R T}+\mathrm{X} \cdot \mathrm{Q}_{R T}}{V_{P A C}}
$$

Considerando que a potência ativa e a potência reativa no regulador de tensão são a diferença de potência entre o consumo da carga e a geração da GD:

$$
\begin{gathered}
P_{R T}=P_{C A R G A}-P_{G D} \\
Q_{R T}=Q_{C A R G A}-Q_{G D}
\end{gathered}
$$

e substituindo (6) e (7) em (5), resulta em:

$$
V_{P A C} \approx V_{R T}-\frac{\mathrm{R} \cdot\left(\mathrm{P}_{C}-\mathrm{P}_{G D}\right)+\mathrm{X} \cdot\left(\mathrm{Q}_{C}-\mathrm{Q}_{G D}\right)}{V_{P A C}}
$$

Portanto, a variação de tensão no PAC onde a carga e a GD estão conectados pode ser obtida por:

$$
\Delta \mathrm{V}_{P A C} \approx V_{P A C}-V_{R T} \approx-\frac{\mathrm{R} \cdot\left(\mathrm{P}_{C}-\mathrm{P}_{G D}\right)+\mathrm{X} \cdot\left(\mathrm{Q}_{C}-\mathrm{Q}_{G D}\right)}{V_{P A C}}
$$

A variação de tensão causada exclusivamente pela GD, sem considerar as cargas $\left(P_{C A R G A}=0\right.$ e $\left.Q_{C A R G A}=0\right)$ pode ser obtida por:

$$
\Delta \mathrm{V}_{P A C} \approx V_{P A C}-V_{R T} \approx \frac{\mathrm{R} \cdot \mathrm{P}_{G D}+\mathrm{X} \cdot \mathrm{Q}_{G D}}{V_{P A C}} .
$$

Em linhas de distribuição a resistência (R) não pode ser desprezada, então ambos os termos $\mathrm{R} \cdot \mathrm{P}_{G D}$ e $\mathrm{X} \cdot \mathrm{Q}_{G D}$ da equação (10) influenciam na variação de tensão. $\mathrm{O}$ termo $\mathrm{X} \cdot \mathrm{Q}_{G D}$ pode ser positivo ou negativo, dependendo se o gerador está importando ou exportando potência reativa, entretanto, este termo da equação geralmente será menor que o termo $\mathrm{R} \cdot \mathrm{P}_{G D}$. Então é de se esperar que o efeito mais comum da adição de geradores nos SDs seja o aumento de tensão no PAC em que o gerador está conectado. Para compensar o aumento de tensão causado pela potência ativa, pode-se atuar na GD fazendo com que opere com fator de potência unitário ou absorvendo potência reativa. Caso a elevação de tensão seja excessiva, uma quantidade significativa de potência reativa deve ser absorvida, o que pode ser inviável devido às limitações dos geradores [7].

O problema da elevação de tensão foi abordado em [7], em que foi feito um estudo de três cenários críticos nos quais a GD pode causar elevações de tensão em sistemas radiais, sendo eles: demanda máxima do sistema sem GD, demanda máxima do sistema 
com geração máxima da GD e demanda mínima do sistema com geração máxima da GD. Foi observado que quando a potência injetada é consumida no mesmo PAC ou a jusante do gerador, não há elevações de tensão no PAC em relação ao secundário do transformador da subestação, porém quando a potência é consumida a montante do gerador haverá elevações de tensão, principalmente quando bastante potência ativa for injetada no sistema. Violações causadas pelas elevações de tensão podem ser mitigadas reduzindo a tensão no secundário do transformador da subestação, permitindo que o gerador importe potência reativa (o que torna o termo $\mathrm{X} \cdot \mathrm{Q}_{G D}$ negativo), utilizando autotransformadores ao longo da linha, trocando os cabos para diminuir a resistência da linha ou ainda reduzindo a geração de energia quando o sistema apresenta baixa demanda [7].

\subsection{Métodos de Controle de Geradores Distribuídos}

Normalmente, a GD opera com o método de Controle de Fator de Potência (CFP), mantendo o fator de potência do gerador constante em um valor previamente estabelecido pelo Centro de Operação da Distribuidora (COD), sem qualquer regulação da tensão [15], [17]-[22]. Poucos geradores operam com o método de Controle de Tensão (CT), em que a tensão é mantida constante. De fato, a contribuição dos geradores na regulação da tensão é limitada [41], pois é comum a unidade geradora ser muito pequena em relação à carga total ou incapaz de controlar a tensão [42]. O controle de tensão pelos geradores pode interferir com a operação do COD, aumentando as chances de ocorrer ilhamento [23]. Entretanto, em [42]-[47] foi observado que é possível uma maior participação de GD sem que ocorram violações de tensão quando os geradores conectados adotam estratégias para limitar o aumento de tensão causado pela injeção de potência ativa no SD. Várias abordagens, centralizadas [48]-[51] e descentralizadas [42], [46], [52], [53], foram propostas para mitigar as elevações de tensão causadas por GD. Os diferentes tipos de abordagens possuem caraterísticas e comportamentos bem distintos nos diversos cenários de operação de uma rede de distribuição [43]-[45], [47]. Estas estratégias colocam o gerador em controle da tensão no PAC, controlando de maneira coordenada com o COD ou de maneira descentralizada as tensões no SD.

O COD pode, de maneira centralizada, controlar a injeção de potência reativa em um SD para controlar as tensões nas barras do sistema, como foi apresentado em [51], em que foi proposto um método de otimização para minimizar o uso da potência reativa 
na regulação de tensão e correção de desequilíbrio de tensão, considerando como restrição as equações de fluxo de potência e os valores máximos e mínimos de injeção de potência reativa pelos geradores. Reguladores de tensão e bancos de capacitores não são utilizados neste trabalho, sendo toda a regulação de tensão e potência reativa da rede feita pelos geradores, porém, o método é capaz de incluí-los caso seja necessário. Foram utilizados sistemas que possuem diversos geradores de baixa capacidade para simular um cenário em que vários clientes residenciais estejam vendendo energia como pequenos produtores, podendo utilizar como fonte turbinas eólicas, painéis solares, unidades de cogeração, entre outros. O método proposto transforma o problema original, podendo assim buscar uma solução, que apesar de não ser ótima, apresenta resultados próximos aos ótimos com um tempo de processamento consideravelmente menor do que no problema original. Nos testes realizados, o perfil de tensão apresentou variação de tensão em torno de $5 \%$ e o desequilíbrio da fase da tensão permaneceu dentro do limite de tolerância de $5^{\circ}$, ambas as variações dentro dos limites de QEE considerados no trabalho. Foi observado que o uso da GD diminui a dependência de reguladores de tensão e bancos de capacitores no controle de tensão do sistema. Na solução obtida pelo método proposto, são injetados $0,006 \%$ de potência reativa a mais que na solução ótima obtida pelo método Branch and Bound. Foi mostrado que não é apenas possível, mas recomendado utilizar GD na regulação de tensão e potência reativa dos SDs.

Um método centralizado de otimização é proposto em [48], tendo como objetivo minimizar a variação de tensão ao longo do SD e maximizar o uso de potência reativa da GD. O método minimiza a variação de tensão para evitar que ocorram violações de tensão devido à injeção de potência ativa pela GD e maximiza a potência reativa dos geradores para aliviar a demanda de potência reativa do SD fornecida pelo sistema de transmissão. O método necessita que exista um sistema de comunicação no SD, pois ele se utiliza do controle centralizado de reguladores de tensão, bancos de capacitores e controla a potência reativa gerada pela GD. A otimização foi feita por algoritmos genéticos e conseguiu melhorar o perfil de tensão do SD.

Em [49] é apresentado um método centralizado de controle que coordena a operação de geradores conectados a um SD por inversores. O método utiliza o Modelo de Controle Preditivo, que divide o problema de controle em dois subproblemas: regime permanente e transitório, otimizando-os separadamente. O uso de diferentes fontes de energia (microturbinas eólicas, painéis fotovoltaicos, bancos de baterias e células de hidrogênio) é 
otimizado para melhorar a QEE entregue aos clientes e garantir que não ocorram variações de tensões no SD. O método otimiza o despacho de energia, escolhendo qual fonte de energia utilizar de acordo com a demanda, favorecendo, por exemplo, o uso da energia fornecida por um banco de baterias em horário de pico e carregando-as quando a demanda é baixa. O método também consegue filtrar os componentes harmônicos gerados por cargas não lineares, alcançar fator de potência unitário no SD e evitar que variações de tensões maiores que 0,06 p.u. ocorram em períodos com diferentes demandas.

Um método centralizado de controle de reguladores de tensão e bancos de baterias em SD com alta participação de energia solar é proposto em [50], tendo como objetivo resolver o problema de elevação de tensão que ocorre em períodos de baixa demanda do sistema e grande geração de energia solar. No método, o banco de baterias é carregado em períodos de baixa demanda e com alta geração de energia solar, sendo que a energia armazenada é utilizada quando a demanda do sistema é máxima e a energia solar gerada é reduzida, diminuindo o pico do sistema. As operações dos reguladores de tensão são reduzidas, pois menos operações para controlar a tensão são necessárias devido à atuação do banco de baterias ao longo do dia.

Três estratégias de controle para mitigar as elevações de tensão e maximizar a potência ativa entregue ao SD foram testadas em [44], [45], sendo elas: limitar a potência ativa injetada quando a demanda é baixa, absorver potência reativa para mitigar o aumento de tensão do PAC e controlar de maneira centralizada os reguladores de tensão. Todas as estratégias de controle apresentadas conseguiram gerar mais energia do que o método tradicional de manter o fator de potência constante (CFP) sem causar elevações de tensões que violem os limites de QEE, sendo que o controle centralizado dos reguladores de tensão, a única estratégia centralizada do trabalho, permitiu maior injeção de potência pela GD em relação às outras duas estratégias descentralizadas.

Ressalta-se que o emprego de qualquer estratégia centralizada necessita de investimentos em sensores, sistemas de comunicação e de controle, podendo tornar o emprego destas técnicas para grandes quantidades de GD muito custoso. Devido ao vasto número de dados e à complexidade dos sistemas de comunicação, o COD pode enfrentar dificuldades em operar o SD de maneira ótima em tempo real [54]. Alguns métodos descentralizados também podem requerer uma rede de comunicação para serem aplicados, porém, necessitam de uma menor troca de dados que métodos tradicionais e não precisam necessariamente trocar informações com o COD. 
Sistemas multiagentes têm sido empregados devido a sua característica descentralizada de atuação. Neles, vários agentes independentes atuam para alcançar um objetivo em comum. Se algum agente falhar ou tornar-se incomunicável, outros agentes continuam atuando para alcançar o objetivo desejado. Propostas descentralizadas de otimização utilizando sistemas multiagentes são apresentadas em [54], [55], ambas não necessitam de modelo detalhado do SD, facilitando o uso das propostas e também necessitam de relativamente pouco esforço computacional.

No âmbito de sistemas multiagentes, o método proposto em [54] busca minimizar as perdas de potência ativa e melhorar o perfil e tensão ao longo do SD. O método controla de maneira ótima a operação de bancos de capacitores, reguladores de tensão e também escolhe a tensão do PAC dos geradores conectados ao SD, todos operando em CT. O método apresentou desempenho semelhante a métodos centralizados quando testado em grandes SD, porém com a vantagem de não necessitar exclusivamente da comunicação entre o COD e a GD.

Em [55], uma proposta de controle otimizado de GD para mitigação de Variação de Tensão de Curta Duração (VTCD) foi apresentada, em que a GD consegue atuar em situações de curta duração nas quais os reguladores de tensão não conseguiriam operar em tempo hábil. A otimização apresentada minimiza a quantidade de potência reativa que todos geradores devem injetar na rede para mitigar uma VTCD, que pode ter sido causada pela desconexão de algum outro gerador ou pela conexão de uma grande carga na rede [23]. O método necessita que exista uma comunicação confiável entre o regulador de tensão e os geradores conectados à rede, porém ele utiliza uma pequena quantidade de dados para operar, enviando a potência reativa injetada/absorvida no instante da comunicação, a capacidade máxima de potência reativa do gerador e um fator de sensibilidade, que é calculado em tempo em tempo real medindo a variação na tensão causada por uma variação na potência reativa injetada/absorvida pelo gerador. O fator de sensibilidade é calculado dividindo essa variação de tensão pela variação de potência reativa. Apesar de necessitar de uma conexão estável, o método utiliza uma pequena quantidade de dados para operar, podendo ser utilizado até em conexão por linha discada (56 $\mathrm{kbaud),} \mathrm{se} \mathrm{for} \mathrm{uma} \mathrm{conexão} \mathrm{estável.}$

Alguns métodos descentralizados de controle de GD operam os geradores em CFP quando a tensão encontra-se dentro de uma faixa segura de valores, porém, quando a 
tensão sai dessa faixa, aumentando ou diminuindo, o gerador adota alguma estratégia para mitigar este efeito, sem necessitar de comunicação entre a GD e o COD [46], [52].

Inicialmente operando em CFP, em [52], após a tensão do PAC sair de uma faixa operacional de tensão previamente determinada, é proposto que cada gerador altere a quantidade de potência reativa injetada ou absorvida no SD gradativamente, até a tensão voltar para a faixa de tensão desejada. O método mostrou que a injeção de potência reativa por parte da GD pode regular de maneira satisfatória a tensão de um SD.

Dois métodos inteligentes e descentralizados de controle de GD que se baseiam no controle do fator de potência foram propostos em [46]. O primeiro é um método determinístico que alterna entre CFP e CT, que consiste em inicialmente manter o fator de potência constante, permitindo que a tensão do PAC varie conforme a carga do SD, porém, caso a tensão atinja algum limite inferior ou superior de tensão previamente definido, o gerador passa a operar em CT, mantendo a tensão constante e variando o fator de potência. O segundo é um método inteligente que utiliza um controlador Fuzzye opera de maneira similar ao primeiro método, mantendo o fator de potência constante, porém, quando a tensão alcança algum limite inferior ou superior de tensão, o controlador Fuzzy ajusta o fator de potência do gerador, permitindo que a tensão seja reestabelecida para a faixa de operação desejada. Ambos os métodos propostos em [46] apresentaram desempenho superior ao método tradicional de CFP, permitindo que mais potência ativa fosse entregue ao SD considerando diferentes demandas das unidades consumidoras. Em uma comparação feita em [43], os métodos propostos em [46] apresentaram desempenho semelhante quando comparados ao método centralizado de controle dos reguladores de tensão proposto em [44], [45]. É importante destacar que quando a GD opera em CT, mesmo brevemente, podem ocorrer conflitos entre a operação dos reguladores de tensão e a GD.

Uma proposta descentralizada de controle da tensão é apresentada em [53]. O método tem como objetivo coordenar os diferentes agentes que irão compor um SD típico da Dinamarca até 2050, pois o país tem como objetivo eliminar combustíveis fósseis de sua matriz energética. Para tal, a GD terá uma grande participação, sendo que será necessário o uso intensivo de energia eólica, que varia a produção de energia ao longo do dia. Cargas flexíveis como aquecedores de água elétricos também terão grande presença. O método utiliza um estimador de tensão adaptado para sistemas com GD, em que as tensões de barras críticas do sistema são estimadas, assumindo um comportamento previsível das cargas e dos geradores. A atuação coordenada de reguladores de tensão, 
dos geradores distribuídos e das cargas flexíveis consegue controlar o perfil da tensão ao longo do sistema. Quando as tensões estimadas ao longo do SD caem, inicialmente os reguladores de tensão atuam. Caso as tensões continuem a cair, posteriormente, a GD passa a injetar potência reativa para tentar elevá-las. De maneira análoga, quando as tensões se elevam, os agentes atuam em momentos diferentes para diminuir as tensões do SD. Inicialmente, as cargas flexíveis são acionadas para tentar reduzir as tensões. Se não conseguirem, os reguladores de tensão atuam, restando por último a GD, que absorve potência reativa. O método conseguiu, de maneira simples e sem o uso de comunicação, coordenar a atuação de diferentes agentes e controlar as tensões de um SD, aumentando a quantidade de potência ativa injetada no sistema pela GD e diminuindo a quantidade de operações dos reguladores de tensão devido à utilização coordenada das cargas flexíveis.

Uma estratégia descentralizada em que o gerador não controla a tensão do PAC é apresentada em [42]. Esta estratégia garante que a injeção de potência ativa não causará interferência nos valores de tensão do SD, não afetando assim a operação do sistema pelo COD. O método é uma variação do CFP e se baseia em descobrir o valor de potência reativa que minimiza o aumento de tensão causado pela potência ativa fornecida pelo gerador. Se o gerador utilizar o método, o perfil de tensão se torna quase independente da potência entregue. Esta é uma grande vantagem, pois o controle é feito de maneira descentralizada e não afeta a operação do COD. O método proposto e o método tradicional de CFP foram comparados em cenários em que a demanda das cargas foi variada e nos dois métodos o perfil de tensão teve comportamento muito parecido, o que comprova que o controle de tensão do SD em função da demanda via reguladores de tensão não é afetado caso o método proposto seja empregado. O propósito do método foi atingido, que era o de injetar potência reativa sem afetar o controle de tensão do SD. Por ser descentralizado e não necessitar de comunicação, o método é relativamente simples de ser utilizado e mostrou-se eficiente diante de diversos cenários de operação.

Uma desvantagem que o método proposto em [42] apresenta é que o tap do regulador de tensão é alterado mais vezes conforme mais potência ativa é injetada no $\mathrm{SD}$, o que pode desencorajar o emprego pelas concessionárias de energia devido ao grande desgaste físico [56] que o regulador apresenta sempre que precisa alterar o valor do tap, diminuindo sua vida útil. Outra desvantagem é que em um SD com baixa potência de curto-circuito, o regulador de tensão pode chegar ao máximo valor de tap e, 
depois disso, o aumento da injeção de potência ativa causará uma elevação de tensão do PAC em que o gerador está conectado. $O$ fato de o método necessitar de posições mais elevadas de tap é preocupante, pois em caso de desconexão repentina do gerador, a variação de tensão no SD pode ser elevada. O regulador de tensão pode demorar cerca de um minuto [25], [27] para comutar os taps, o que pode causar uma VTCD.

Uma comparação entre o método que minimiza o aumento de tensão provocado pela GD proposto em [42], o método determinístico que alterna entre CFP e CT proposto em [46] e o método tradicional de CFP foi realizada em [57]. Dentre as situações consideradas, foi simulado um cenário com elevada geração de potência ativa. O método CFP causou elevações de tensões que violam limites de QEE. O método proposto em [42] fez o gerador absorver uma quantidade excessiva de potência reativa, superior a sua capacidade (FP menor que 0,85) causando uma queda de tensão no PAC. O método proposto em [46] conseguiu injetar a potência desejada sem causar violações de tensões. Também foi considerado um cenário em que a GD é de geração eólica, em que a geração de potência ativa varia bastante e a estratégia proposta em [46] obteve o melhor perfil de tensão devido a sua característica de adaptar o controle dos geradores. Foi observado também que com o método proposto em [42] o regulador de tensão alterou com mais frequência o valor do tap, o que pode causar uma diminuição em sua vida útil [56].

Uma preocupação necessária para emprego dos métodos anteriormente citados é verificar se o gerador pode operar com baixo fator de potência, pois o fator de potência pode cair para níveis bem baixos dependendo da potência reativa gerada. Também deve ser considerada a potência nominal do gerador, que limitará a quantidade de potência reativa absorvida. Diferentes parâmetros de cabos podem afetar o desempenho dos métodos.

Considerando que o aumento de tensão em um SD com grande participação de usinas solares fotovoltaicas é um dos maiores desafios para aumentar a participação desse tipo de GD, em [35] foi proposto um método descentralizado que utiliza comunicação entre as unidades geradoras, sendo que nesse cenário considerado também existem unidades armazenadoras de energia instaladas no mesmo local dos geradores. $\mathrm{O}$ método gerencia a utilização das unidades armazenadoras de energia de acordo com a capacidade individual de cada unidade, controlando assim a tensão de maneira coordenada com todas as unidades. Ainda é utilizado um algoritmo que gerencia o uso de energia considerando o quanto de carga há em cada unidade armazenadora, pois algumas unidades podem apresentar relativamente menos energia que as outras, devido 
a um problema técnico ou a passagem de nuvens no local de geração dessas unidades fotovoltaicas.

Um método online fundamentado em dividir o SD com GD em regiões foi desenvolvido em [58], em que cálculos de fluxo de potência são realizados variando a potência injetada em cada barra e procurando por pontos críticos de tensão, de maneira semelhante aos métodos para sistemas de transmissão. Limites superiores e inferiores de tensão são obtidos e esses limites podem ser aproximados por hiperplanos sem perdas significativas de precisão. O trabalho propõe um método rápido para obter os coeficientes do hiperplano que permita o cálculo em tempo real e o controle de geradores e reguladores de tensão presentes no sistema. O método se mostrou mais rápido que estratégias convencionais e utilizou menos esforço computacional.

O controle combinado de reguladores de tensão e a GD foi proposto em [59], em que o conflito entre os reguladores de tensão e a GD foi minimizado, assim como também foi minimizada a quantidade de operações dos reguladores para normalizar a tensão. Para tal, foram utilizados parâmetros do SD para determinar zonas de controle para cada regulador de tensão e de cada gerador. Essas zonas foram combinadas com uma nova maneira de operar o regulador de tensão, em que a queda de tensão foi estimada admitindo que a carga está espalhada uniformemente pela linha. Os geradores operam de maneira similar, variando a potência ativa e reativa injetada. $\mathrm{O}$ método, além de flexível e de simples utilização, se mostrou capaz de reduzir as operações dos reguladores e os conflitos que ocorrem na operação dos mesmos em conjunto com geradores quando a GD auxilia na regulação da tensão do sistema.

Uma estratégia para a coordenação entre a GD e reguladores de tensão, considerando a disponibilidade dos geradores e possíveis mudanças na topologia do SD, foi proposta em [60]. Além de zonas de controle de tensão, foi considerada a influência de todos os geradores e dos reguladores de tensão em todas as barras do SD. Quando a tensão em alguma barra precisar ser regulada, é dada prioridade para os geradores presentes na mesma zona de controle de tensão e com maior influência nessa barra para tentar regular a tensão. Se não for possível, geradores com menos influência na barra ou de outras zonas de controle de tensão atuam. Se ainda a tensão não for regulada, os reguladores de tensão começam a operar de maneira similar aos geradores, porém os reguladores de zonas de controle de tensão mais distantes da barra que necessita ser regulada são priorizados. A estratégia conseguiu reduzir os conflitos entre diferentes 
geradores e reguladores de tensão no SD em que foi testado e ainda reduziu a quantidade de operações dos reguladores de tensão.

Redes neurais artificiais foram utilizadas para coordenar o uso de um compensador síncrono rotativo (CSR) com um regulador de tensão em [61]. O objetivo é que a rede neural artificial minimize as variações da posição de tap do regulador de tensão e da potência reativa injetada ou absorvida pelo compensador síncrono rotativo, usando como entrada as potências ativas e reativas da barra controlada, a posição atual de tap do regulador de tensão e a potência reativa injetada ou absorvida pelo CSR. A proposta é que o compensador síncrono rotativo, devido ao seu menor tempo de atuação, inicialmente atue antes do regulador de tensão, mas assim que possível o regulador de tensão opere e reduza a necessidade de regulação de tensão pelo CSR. A rede neural artificial tem como saída a posição de tap do regulador de tensão, sendo que a rede utiliza-se de um banco de dados de cálculos de fluxo de potência realizados previamente para tomar as decisões. O método proposto conseguiu coordenar o uso do regulador de tensão e do CSR, mesmo em cenários em que ocorrem faltas no SD.

\subsection{Análises e Soluções Relacionadas à Variação da Tensão após a Desconexão de Geradores Distribuídos}

Quando a viabilidade de instalar geradores em SD é analisada, é necessário avaliar várias restrições técnicas além da elevação de tensão. Grande parte dos estudos atuais, porém, não consideram a variação da tensão causada pela repentina desconexão dos geradores. Esta desconexão pode causar graves problemas de QEE, pois os reguladores de tensão podem precisar de cerca de um minuto [25], [27] para conseguirem reestabelecer a tensão para valores aceitáveis.

Em [62] foi avaliada a capacidade de geradores serem adicionados em um SD levando em consideração as variações de tensão causadas pela desconexão repentina dos geradores. A pesquisa usou como critério um limite de variação de tensão de $3 \%$, que é usado no Reino Unido. Um fluxo de potência ótimo foi utilizado para descobrir qual é a geração máxima que pode ser adicionada em um PAC sem violação nenhuma de QEE. Inicialmente foi estudado o quanto de energia pode ser injetada em três barras sem que a tensão eleve-se demasiadamente, analisando para o caso do fator de potência unitário, 
atrasado e adiantado, ambos fixos em 0,95. A capacidade de geração para o caso em que o fator de potência é adiantado foi o maior, seguido do fator de potência unitário e por último o fator de potência atrasado. Isto ocorreu devido ao comportamento dos geradores que seguem a equação (10). Quando foi considerada a desconexão repentina dos geradores com fator de potência unitário e atrasado, a potência possível de ser instalada foi reduzida drasticamente, porém o caso em que o fator de potência é atrasado não foi afetado, pois a potência reativa absorvida pelo gerador neste caso minimiza variações de tensão no PAC, diminuindo os efeitos da desconexão dos GD. Os resultados mostraram que a variação de tensão causada pela desconexão dos geradores pode ser grande o suficiente para afetar de maneira significativa a capacidade de geração, sendo menos aparente este efeito quando os geradores estão operando com fator de potência adiantado [62].

Um método para avaliar quedas de tensão ocasionadas pela desconexão da GD pela proteção anti-ilhamento foi apresentado em [25]. Este fenômeno ocorre devido à lenta operação dos reguladores de tensão, como observado na Figura 4. Na ocorrência de uma falta temporária, o religador atua e quando o sistema é reconectado, sem a GD, existe uma queda de tensão $(\Delta V)$, que pode ser calculada pela equação (11), em que $V_{I}$ (em p.u.) é a tensão no barramento monitorado antes desconexão da GD e $V_{F}$ (em p.u.) é a tensão monitorada após a desconexão.

$$
\Delta \mathrm{V}=\left(V_{I}-V_{F}\right) \cdot 100(\%) .
$$

O regulador de tensão tem um atraso $\left(\Delta T_{\text {tap }}\right)$ para começar a atuar, pois sem este atraso ele pode operar de maneira excessiva, como em partidas de grandes motores, que causam quedas de tensão temporárias [23]. Após este atraso inicial, cada mudança de tap ocorre em um tempo menor $\left(\Delta t_{\text {tap }}\right)$, desde a posição de tap que o regulador de tensão estava operando antes da desconexão da GD $\left(\operatorname{Tap}_{I}\right)$ até a posição final, em que a tensão já foi reestabelecida $\left(\operatorname{Tap}_{F}\right)$. Todo esse ajuste demora um tempo $\left(\Delta T_{R}\right)$, que pode ser calculado pela seguinte equação:

$$
\Delta T_{R}=\Delta T_{\text {tap }}+\Delta t_{\text {tap }} \cdot\left(\left|\operatorname{Tap}_{F}-\operatorname{Tap}_{I}\right|-1\right) .
$$

Observando a equação (12) e considerando parâmetros típicos de reguladores de tensão $\left(\Delta T_{\text {tap }}=30 \mathrm{~s}\right.$ e $\Delta t_{\text {tap }}=3 \mathrm{~s}$ ), foi concluído em [25] que as variações de tensão após a desconexão da GD permanecem tipicamente por mais de 30 segundos, podendo ser mais 
duradouras, dependendo da participação de GD no sistema. Esta variação de tensão pode ser caracterizada pelos índices $\Delta \mathrm{V}, \Delta T_{\text {tap }}$ e $\Delta T_{R}$. As cargas modeladas como potência constante apresentaram maior queda de tensão $(\Delta V)$ do que as cargas de impedância constante, porém a diferença foi no máximo de 3\%. A diferença foi baixa, pois a variação máxima de tensão $(\Delta \mathrm{V})$ foi em torno de $10 \%$, não sendo grande o suficiente para o modelo de carga influenciar significativamente os resultados. Considerando os tempos envolvidos nas mudanças de tap $\left(\Delta t_{\text {tap }}\right)$, o problema pode ser analisado utilizando cálculo de fluxo de potência, não sendo necessárias simulações dinâmicas.

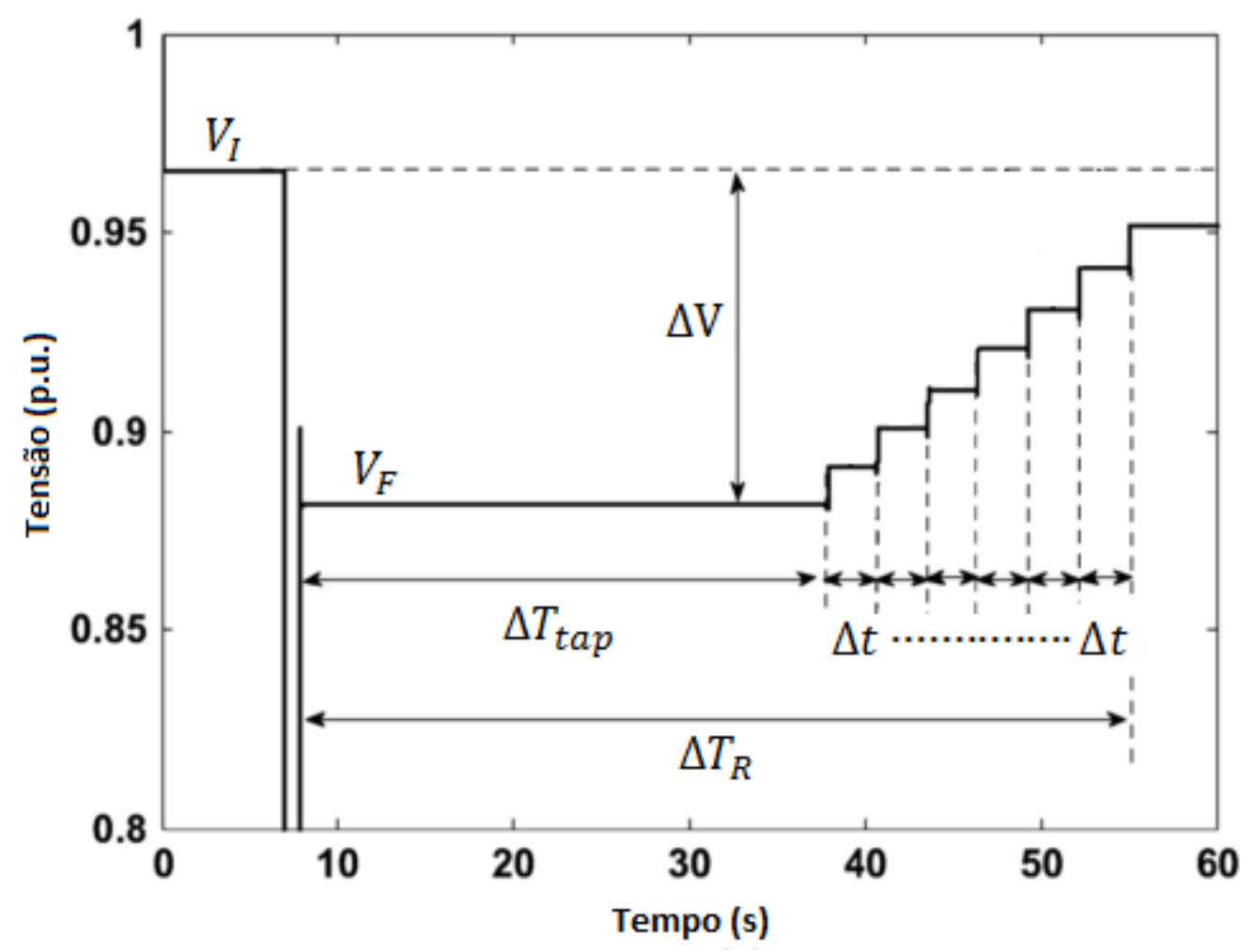

Figura 4 - Mudanças da posição do tap, em detalhes.

As variações de tensão causadas pela desconexão da GD dependem da posição inicial do tap do regulador de tensão, da demanda dos consumidores e da quantidade de potência ativa e reativa injetada pelos GD. Esta desconexão pode ocorrer devido à ocorrência de faltas temporárias no sistema, pois nestas situações a proteção antiilhamento atua e desconecta os geradores. Cinco propostas para tentar solucionar este problema foram apresentadas em [27], sendo elas:

Solução 1. Operação não sequencial dos reguladores de tensão.

Solução 2. Corte de carga. 
Solução 3. Conexão de bancos de capacitores ao SD imediatamente após a desconexão dos geradores.

Solução 4. Operar os geradores em CT, mantendo a tensão no mesmo valor que seria caso os geradores não estivessem conectados ao SD.

Solução 5. Controle centralizado dos dispositivos reguladores de tensão.

A Solução 1 consiste em alterar todas as posições de tap do regulador de tensão necessárias para reestabelecer a tensão de uma só vez, reduzindo o tempo desta operação. O regulador de tensão deve ainda esperar um tempo mínimo para operar $\left(\Delta T_{\text {tap }}\right)$, entretanto este tempo pode ser reduzido pelo COD. Esta solução pode ser utilizada em conjunto com outras estratégias e não necessita de grandes investimentos na rede e nem em sistemas de comunicação. A solução não impede e nem diminui a variação de tensão, apenas diminui a sua duração.

A Solução 2 sugere o corte de cargas, diminuindo a variação de tensão após a desconexão da GD. O COD pode decidir quais cargas podem ser cortadas nestas situações, dando incentivos financeiros aos clientes que optarem pelo corte. Unidades consumidoras que não podem ser desconectadas (hospitais, escolas, bancos, etc) ou unidades que não desejam participar do corte podem ser mantidas conectadas. $\mathrm{O}$ corte da carga é simples de ser efetuado por relés de proteção. A redução da variação de tensão é considerável, porém desconectar a quantidade necessária de cargas pode ser custoso, pois muitos relés teriam que ser instalados ao longo do sistema. É mais fácil desconectar um transformador do que suas cargas individuais, porém esta operação pode desconectar desnecessariamente muitas unidades consumidoras.

A Solução 3 emprega bancos de capacitores que se conectam ao SD logo após a desconexão dos geradores, elevando novamente a tensão. Podem ser reduzidos a variação de tensão, o tempo em que esta variação ocorre e a operação dos reguladores de tensão, porém, grandes bancos de capacitores podem ser necessários e sua operação deve ser cuidadosamente planejada para não causar a ocorrência de sobretensões.

A Solução 4 propõe que os geradores operem em CT, tentando manter a tensão da barra em que o gerador está conectado no mesmo valor em que ela estaria se os geradores não estivessem conectados ao SD. A magnitude e o tempo da variação de tensão são reduzidos e os reguladores de tensão podem até não precisar operar. Nem todos geradores são capazes de operar em CT e esta operação, se não for bem ajustada, 
pode interferir no funcionamento dos reguladores de tensão. Violações do fator de potência também podem ocorrer.

A Solução 5 é um método que determina as posições do tap dos reguladores de tensão que minimizam as variações de tensão causadas pela desconexão dos geradores. $\mathrm{O}$ método é constituído de cálculos de fluxo de carga, que são feitos para determinar quais posições do tap não ocorre nenhuma violação de QEE. A variação de tensão após a desconexão da GD pode ser eliminada. Por ser um método centralizado, a variação de tensão causada pela reconexão dos geradores pode ser reduzida, porém pode apresentar alto custo de implantação. A presença de vários dispositivos reguladores de tensão aumenta o esforço computacional do método.

Comparando as soluções apresentadas em [27], nota-se que a Solução 1 apenas reduz o tempo que o regulador de tensão necessita para alterar as posições de tap, sem alterar a variação de tensão ou elimina-la, porém tem baixo custo; a Solução 2 reduz a QEE entregue a alguns clientes e necessita da instalação de relés de proteção que podem ter alto custo; a Solução 3 pode causar problemas de sobretensão se os bancos de capacitores não forem dimensionados corretamente, e também pode necessitar de grandes bancos de capacitores que possuem alto custo de implantação; a Solução 4 apresenta bons resultados, mas é apenas aplicável a geradores com capacidade de controle de tensão e ainda pode interferir na operação dos reguladores de tensão; a Solução 5 garante que não haverá violações de tensão, porém não diminui significativamente a variação de tensão e devido ao sistema de comunicação que necessita, pode ter um custo de implantação alto.

Esta pesquisa é uma extensão da ideia apresentada em [27] na Solução 5, sendo que a abordagem será mais aprofundada e melhor formulada matematicamente. $\mathrm{O}$ método apresentado em [27] consiste exclusivamente em cálculos repetitivos do fluxo de potência do sistema estudado, variando todas as posições possíveis de tap do regulador de tensão e variando também a demanda do sistema, para poder assim analisar o sistema em diferentes cenários operacionais. O fluxo de potência é calculado primeiramente com GD e posteriormente sem geradores, podendo assim obter as tensões do SD nas duas situações. A Solução 5 consiste nos seguintes passos:

Passo 1. Definir o sistema que será estudado, sua topologia, parâmetros e localização de geradores, bancos capacitores, linhas, cargas (potência, impedância ou corrente constante), reguladores de tensão, religadores, etc.

Passo 2. Obter informações sobre a curva de carga do sistema, para poder assim prever períodos com demanda máxima, intermediária e mínima. Se 
informações mais detalhadas não forem encontradas, é possível aplicar o método definindo patamares da demanda que variem entre a carga mínima e a máxima.

Passo 3. Escolher o método de controle que os geradores devem utilizar, como CFP ou CT e seus parâmetros de operação. Vários cenários podem ser considerados para assim buscar a estratégia de controle dos geradores mais adequada.

Passo 4. Definir os limites operacionais aceitáveis dos valores de tensão para o sistema, sem que ocorram violações de QEE. Podem ser estabelecidos limites para a operação em regime permanente e também outros limites para o momento imediatamente após a desconexão dos geradores.

Passo 5. Calcular o fluxo de potência para todos os cenários de cargas estabelecidos no Passo 2, com os geradores operando conforme estabelecido no Passo 3 e variando todas as posições possíveis do tap dos reguladores de tensão.

Passo 6. Dispondo dos valores de tensão de todas as barras do SD obtidos no Passo 5, devem ser selecionadas as posições de tap que não provocaram a violação dos limites de tensão definidos no Passo 4.

Passo 7. Calcular o fluxo de potência para todos os cenários de cargas estabelecidos no Passo 2, com os geradores desconectados e variando todas as posições possíveis do tap dos reguladores de tensão.

Passo 8. De maneira semelhante ao Passo 6, dispondo dos valores de tensão de todas as barras do SD obtidos no Passo 7, devem ser selecionadas as posições de tap que não provocaram a violação dos limites de tensão definidos no Passo 4, neste caso considerando a desconexão dos geradores distribuídos.

Passo 9. As posições de tap dos reguladores de tensão que estão presentes em ambos os conjuntos obtidos pelo método no Passo 6 e 8 são as posições possíveis de operar a GD e manter a tensão dentro de limites aceitáveis, com os geradores conectados e logo após a desconexão dos mesmos.

A Solução 5 apresentada garante, após diversos cálculos de fluxo de potência, valores de tap que podem ser utilizados pelo COD para coordenar os reguladores de 
tensão e garantir que os valores de tensão do sistema se mantenham dentro de limites operacionais definidos após a desconexão da GD. Em [27], apenas a barra com menor tensão do SD foi monitorada, o que não garante que violações de tensão não tenham ocorrido em outras barras, porém, se todas as barras forem avaliadas, é possível garantir que não ocorrerão violações de tensão no SD. Muito embora os resultados de [27] mostrem que é possível obter posições de tap do regulador de tensão capazes de minimizar os impactos da desconexão de geradores distribuídos, eles não fornecem uma resposta mais exata sobre qual é a melhor posição do tap. Além disso, a Solução 5 analisa todas as possíveis soluções existentes, o que é inviável para sistemas com vários reguladores de tensão. Logo, esta pesquisa visa preencher essas lacunas, utilizando uma técnica de otimização.

\subsection{Algoritmos Genéticos Aplicados na Regulação/Controle de Tensão em Sistemas de Distribuição}

O problema de coordenação dos taps de reguladores de tensão pode ser modelado como uma busca pela solução mais próxima da ótima, poupando o esforço computacional de avaliar todas as possíveis soluções e ajudando a escolher entre as soluções obtidas. Uma técnica que pode auxiliar na resolução desse problema é o Algoritmo Genético (AG) [63], que é uma técnica baseada nos fundamentos da seleção natural e na evolução biológica.

O AG utiliza o conceito da evolução biológica de sobrevivência do mais apto, isto é, o indivíduo mais adaptado ao meio em que vive possui mais chances de reprodução e assim é mais provável que transmita suas características adiante. É necessário que exista variabilidade entre os indivíduos para existir diferentes níveis de adaptação. O AG se utiliza de linguagem matemática para resolver problemas de otimização, porém, não há necessidade de conhecimento prévio sobre a resolução do problema, desde que o problema seja modelado adequadamente.

Para resolver um problema de otimização, cria-se uma população, sendo ela um conjunto de soluções iniciais do problema que está sendo resolvido. Essas possíveis soluções que compõem a população são chamadas de indivíduos, cuja suas características matemáticas são representadas pelo seu genoma, um conjunto de genes. O gene é a unidade fundamental do modelo matemático de cada possível solução, sendo que a 
avaliação dessas características somente é possível observando o fenótipo, que são as características observáveis de cada indivíduo. Todas as possíveis soluções são avaliadas e comparadas com o restante da população e as melhores são selecionadas para o cruzamento, que é quando são gerados novos indivíduos com características semelhantes aos que foram selecionados. Assim, garante-se que características das melhores soluções serão mantidas e que possíveis combinações entre as melhores soluções podem resultar em indivíduos com melhor aptidão do que os indivíduos de origem. No cruzamento, é importante que ocorra a mutação, que é o processo de alterar o genoma, garantindo uma variedade maior para a população. Após esses processos, os novos indivíduos são adicionados à população inicial ou uma nova população é formada inteiramente por esses indivíduos, sendo esta avaliada novamente. Os fundamentos da evolução biológica auxiliam o AG a melhorar o grau de adaptação dos indivíduos da população, que é o quão bem cada solução resolve o problema proposto. Após algumas iterações, se a otimização foi adequadamente modelada, o AG consegue encontrar soluções próximas das ótimas ou ainda melhores que as soluções iniciais. Existem diversas formas de se aplicar os conceitos anteriormente mencionados. A seguir, serão apresentados os principais conceitos relacionados à utilização de AG.

\subsubsection{Conceitos}

A seguir, serão apresentados sucintamente os conceitos mais básicos e comuns necessários para aplicação de AGs. Existem diversas maneiras de aplicar o algoritmo que podem apresentar melhores resultados para certos tipos de otimizações, porém as mais frequentes serão apresentadas, de acordo com [63], [64].

\subsubsection{Inicialização}

A maneira que a população inicial é gerada tem grande influência no comportamento de AGs, sendo que usualmente os indivíduos são gerados aleatoriamente para assim garantir uma grande variabilidade entre os mesmos. Isto permite que o algoritmo consiga mais efetivamente procurar soluções com uma boa cobertura do espaço de busca.

A inicialização pode ser randômica não uniforme [64], com predominância de certos valores que possam ser úteis para o algoritmo encontrar a melhor solução do problema 
que está sendo resolvido. É possível ainda que a população inicial contenha todas as combinações possíveis de uma determinada região do espaço de busca do problema. Indivíduos já otimizados podem ser inseridos na população inicial, porém isso pode restringir o espaço de busca em apenas soluções similares a esses indivíduos.

\subsubsection{Avaliação}

Após a população ser gerada, os indivíduos precisam ter suas soluções avaliadas, o que consiste em determinar o quanto cada solução está perto do objetivo da otimização. Uma função objetivo avaliando isso pode ser empregada. Se há mais de um objetivo, eles podem compor uma função objetivo utilizando-se de pesos diferentes para cada um deles. Quando existem restrições, uma penalidade pode ser utilizada para compor a função objetivo. Em um problema de minimização, por exemplo, a penalidade pode adicionar um valor elevado à função objetivo, penalizando essas soluções e diminuindo as chances que essas características sejam repassadas aos novos indivíduos gerados.

\subsubsection{Seleção}

Em AGs, a seleção é utilizada para buscar manter as características desejáveis da população e eliminar as características indesejáveis. Os indivíduos são escolhidos utilizando a avaliação feita anteriormente e existem diversas maneiras de selecioná-los. Podem ser escolhidos os indivíduos de acordo com o grau de adequação de cada um, ou seja, indivíduos com grau de adequação maior que os outros têm maiores chances de serem selecionados. Outra forma bastante empregada é a realização de torneios, em que conjuntos de indivíduos são escolhidos e os que apresentarem a melhor adequação de sua solução são selecionados.

\subsubsection{Reprodução}

Novos indivíduos, os filhos, são gerados na reprodução, utilizando os selecionados anteriormente, os pais. Usualmente utilizam-se dois pais para gerar um filho, mas apenas um ou mais de dois pais podem ser usados. No geral, são escolhidos pais aleatoriamente entre os selecionados para a reprodução, sendo que outros critérios podem ser empregados, como o nível de aptidão das soluções ou a semelhança entre os indivíduos.

$\mathrm{Na}$ reprodução ocorre o cruzamento, que é quando os genes dos pais são recombinados para darem origem aos genes dos filhos. Existem diversas maneiras que essa recombinação pode ocorrer, mas geralmente os genes de cada pai são recombinados 
de maneira aleatória para gerarem os filhos. Um ou mais segmentos do genoma podem ser trocados entre os pais para gerar o filho, ou ainda genes individualmente são escolhidos de forma aleatória entre os pais para gerar o genoma do filho.

\subsubsection{Mutação}

A mutação tem o papel de aumentar a diversidade do espaço de busca, evitando assim que o AG apenas encontre ótimos locais. A mutação pode ocorrer determinando um valor aleatório para algum gene ou ainda somando ou subtraindo um valor para o mesmo. Outras formas de mutação, dependendo da natureza do problema podem ser empregadas. A mutação pode variar de acordo com a adequação da melhor solução obtida em cada iteração [65], gerar uma solução que o AG ainda não considerou [66] ou então garantir que a mutação irá gerar uma solução factível [67].

\subsubsection{Atualização}

Após os novos indivíduos serem gerados, uma nova população é criada. No geral, os indivíduos que estavam na população são descartados e uma nova população é criada com os filhos obtidos no cruzamento, mantendo um tamanho fixo da população. Outras formas de atualização podem ser feitas, como apenas inserir novos indivíduos se esses apresentarem melhor adaptação que os pais ou ainda preservar uma quantidade dos melhores indivíduos da população anterior para assim manter as melhores soluções já obtidas, o que é chamado de elitismo.

\subsubsection{Finalização}

O AG pode encerrar a busca por diversas razões. Como critérios de parada, pode-se considerar quando o melhor individuo obtém sua função objetivo com um valor desejado. Pode ser considerado também se após algumas iterações a melhor solução tem pouca ou nenhuma melhora em relação às ultimas iterações. O AG pode ser interrompido no caso de toda a população ter um determinado nível de semelhança ou ainda após um número máximo de iterações for atingido. Se nenhum desses critérios foi atingido, o algoritmo retorna para a etapa da Avaliação. 


\subsubsection{Estado da Arte}

Diversos trabalhos atuais utilizam AG para resolver problemas em sistemas de distribuição. A seguir, serão apresentados trabalhos relevantes que possuem modelagem semelhante ao problema abordado nesta pesquisa de mestrado.

Um método em que o AG é utilizado para minimizar as perdas e restringir violações na magnitude das tensões em sistemas de distribuição com presença de geração eólica foi proposto em [68]. O método controla a tensão dos geradores eólicos, a posição de tap dos reguladores de tensão e o uso de bancos de capacitores. A natureza estocástica do consumo das cargas e da geração de energia eólica é considerada. Na codificação do problema, quando os genes são formulados, foi utilizado o código de Gray, que é uma codificação binária em que todos os números decimais consecutivos representados são distantes apenas um bit entre si. Essa propriedade auxilia na busca do AG e na eficiência das mutações, pois assim fenótipos adjacentes também possuem genomas adjacentes. Uma função de penalidade foi utilizada para o AG trabalhar com as restrições, sendo que ela possui um fator que implica em pouco peso nas iterações inicias, aumentando sua influência conforme as iterações aumentam. $\mathrm{O}$ método foi testado em dois sistemas, sendo um sistema de teste e outro mais realista, e conseguiu satisfatoriamente reduzir as perdas, satisfazendo as restrições de violações de tensão.

Depois de realizada uma alocação ótima de bancos de capacitores e da GD considerando fontes despacháveis ou não, foi utilizado um AG em [69] para minimizar o custo dos investimentos necessários para a instalação desses elementos mencionados e também para minimizar o custo da operação, considerando a energia gerada e a injeção de reativos da GD. Como restrições, foram consideradas as equações de fluxo de potência e os limites de tensão e corrente para o SD. Utilizando-se de patamares de carga para representar uma curva diária, foram determinadas as operações dos bancos de capacitores e os fatores de potência da GD, despachável ou não. Foi observada grande influência na tensão se a GD não for despachável, sendo ela mitigada pelo uso de bancos de capacitores. Uma abordagem semelhante foi proposta em [70], em que um AG em conjunto com um método analítico foi utilizado para alocar a GD, determinar sua potência máxima, o seu fator de potência e ainda diminuir as perdas do SD. Essa abordagem apresentou melhores resultados na diminuição das perdas em comparação com outros métodos tradicionais utilizados com o mesmo objetivo.

As perdas de sistemas de distribuição reconfiguráveis foram reduzidas em [66], em que um AG modificado foi utilizado. O algoritmo empregado garante que uma mesma 
solução em potencial não seja considerada mais de uma vez durante a otimização, porém essa peculiaridade do AG proposto tem uma exceção: as melhores soluções são mantidas nas próximas iterações, o chamado elitismo, que nesse AG possui uma taxa maior que o convencional. Também foi proposto um método para obter mais eficientemente topologias factíveis como uma solução em potencial avaliada pelo AG. Uma nova mutação foi proposta para garantir que os novos indivíduos não sejam soluções já. O algoritmo encontrou soluções que foram validadas por métodos numéricos em sistemas de teste e sistemas reais. O mesmo problema das perdas em sistemas reconfiguráveis foi abordado em [67], porém o AG, além de minimizar as perdas, diminuiu o desvio de tensão, o balanceamento das cargas e ainda minimizou a quantidade de reconfigurações necessárias para atingir esses objetivos. Também foi proposta uma modificação nas mutações do $\mathrm{AG}$, em que elas não são aleatórias, sendo determinadas a partir de informações sobre o problema de reconfiguração de redes para garantir que apenas soluções factíveis sejam consideradas no algoritmo. Ainda foi proposto um novo método para determinar se as topologias obtidas são radiais ou não, pois essa é uma das restrições, junto com as equações de fluxo de potência, limites de tensão e corrente das linhas. O método, comparado a métodos tradicionais, apresentou resultados satisfatórios com menos custo computacional.

$\mathrm{O}$ uso de fontes despacháveis de energia em conjunto com fontes intermitentes e baterias foi otimizado com o auxílio de um AG em [71]. Baterias foram utilizadas para reduzir a incerteza de fontes intermitentes de energia e maximizar o uso de fontes de energia renováveis como eólicas e fotovoltaicas. Depois de reduzidas as incertezas relacionadas à GD, um AG determina o uso de fontes despacháveis de energia da maneira mais econômica, respeitando os limites de tensão e corrente do SD. O planejamento é feito com um dia de antecedência, sendo que algumas horas antes, o método corrige possíveis desvios do planejamento ocorridos devido à operação das fontes intermitentes. Com uma abordagem similar, em [72] foi proposta uma otimização utilizando AG para minimizar o custo da energia considerando o uso de baterias. Todas as características operacionais das baterias, como influência da regulação de tensão do conversor e a eficiência não linear do conversor para diferentes tensões e diferentes fluxos de potência foram considerados, além das restrições de tensão e corrente do SD. O AG utilizado apresentou bom desempenho computacional considerando que o problema possui um número elevado de combinações possíveis. Para tal, a população inicial do AG 
utilizado, além de ter possíveis soluções geradas aleatoriamente, possui soluções criadas considerando os preços de energia. Essas soluções melhoraram o desempenho do AG e das soluções obtidas de maneira significativa.

\subsection{Considerações finais sobre o capítulo}

Este capítulo analisou os diferentes trabalhos publicados que têm como objetivo minimizar a elevação de tensão causada pela GD ou utilizar os geradores para melhorar a QEE do sistema de alguma maneira. Muitos trabalhos relacionados à GD buscam fazer estudos de despacho de energia, sem tratar da variação de tensão causada pelos geradores. Quando a variação de tensão é considerada, normalmente é estudada a potência instalada máxima que pode ser obtida por algum método em diferentes demandas ou o comportamento diante de cenários anormais de tensão devido a faltas ou entrada/saída de grandes cargas, sem diretamente tratar o problema causado pela desconexão repentina dos geradores. Foi observado que existem vários métodos centralizados que podem controlar a tensão do SD com geradores conectados, porém necessitam de investimentos em comunicação para serem utilizados. Alguns métodos descentralizados ou com mínima comunicação também apresentaram resultados satisfatórios.

A Solução 5, apresentada em [27], será explorada nesta dissertação. A solução possui natureza combinatória, pois em um SD com um grande número de dispositivos reguladores de tensão, como reguladores de tensão e bancos de capacitores, a quantidade de cenários que devem ser considerados aumenta excessivamente, pois cada posição de tap dos reguladores de tensão e as possíveis regulações dos bancos de capacitores devem ser consideradas. O problema estudado neste trabalho foi formulado como um problema de otimização, em que se pretende definir uma função objetivo para auxiliar na escolha da posição do tap. Utilizando um método de otimização, foi possível escolher diferentes critérios para analisar quais ajustes devem ser selecionados, não apenas evitando violações de tensões, mas também sendo possível ainda minimizar o desvio de tensão, as perdas do sistema, a quantidade de operações dos reguladores de tensão ou maximizar a quantidade de potência ativa entregue pela GD. 


\section{Capítulo 4}

\section{Metodologia Proposta}

O método apresentado anteriormente no Capítulo 3, a Solução 5 [27], calcula todas as possíveis soluções e escolhe as que não causam violações de tensão no SD, com e sem GD conectada. Essa é uma abordagem satisfatória para sistemas reduzidos, que possuem apenas um regulador de tensão. Em sistemas com mais reguladores de tensão, obter as posições de tap para todos os pontos da curva de carga necessita de grande esforço computacional. Em cada combinação possível, é preciso avaliar se as tensões com e sem a GD estão dentro dos limites determinados, ou seja, são necessários dois cálculos de fluxos de carga para avaliar cada possível solução. Em um SD com dois reguladores de tensão com 33 posições possíveis de tap cada um, considerando um planejamento com uma curva de carga com 24 pontos, existem 26.136 combinações possíveis. Em um SD com 3 reguladores de tensão, para os 24 pontos da curva de carga existem 862.488 combinações possíveis.

O método proposto nesta pesquisa tem o objetivo de ser aplicado em sistemas com vários reguladores de tensão, podendo ser modificado para controlar também bancos de capacitores, potência reativa injetada pela GD, entre outras variáveis, então é necessário que ele tenha um bom desempenho computacional. Ainda é necessário que o método não apenas elimine as violações de tensão, mas também auxilie no planejamento das posições de tap. Esse auxílio pode trazer algum outro benefício para o SD, como reduzir as perdas, reduzir o desvio de tensão entre barras adjacentes ou diminuir as variações das posições de tap dos reguladores de tensão. Este capítulo apresenta a modelagem matemática 
necessária para a otimização do problema relatado anteriormente e um método baseado em AG para resolvê-lo.

\subsection{Formulação matemática}

É necessária uma função objetivo $\left(f_{\text {objetivo }}(i)\right)$ que consiga medir o quando cada possível solução $(i)$ averiguada pelo AG está apta para resolver o problema pesquisado neste trabalho. Foi optado por modelar um problema de minimização, reduzindo as violações de tensão após a desconexão da GD $\left(f_{\text {Desconexão }}(i)\right.$ ). Além desse objetivo principal, também é necessário garantir que nenhuma violação de tensão ocorra enquanto a GD está conectada, pois esse cenário representa o sistema antes da desconexão e também representa o sistema após a reconexão da GD. Para tal, será empregada uma função de penalidade $\left(f_{\text {Penalidade }}(i)\right)$, que serve para modelar matematicamente alguma restrição. Essa função de penalidade comporá a função objetivo, então sempre que ocorrer alguma violação de tensão, a função de penalidade aumenta o valor da função objetivo, reduzindo as chances dessa possível solução ser utilizada pelo AG para geração de novos indivíduos. Além do objetivo principal, foi considerado outro objetivo secundário de reduzir o número de mudanças de posição de tap de cada regulador de tensão pelo período de um dia $\left(f_{T a p}(i)\right)$. Todas as funções são combinadas em apenas uma, utilizando pesos $\left(\omega_{\text {Desconexão, }} \omega_{\text {Penalidade }}\right.$ e $\left.\omega_{\text {Tap }}\right)$ para ponderar a importância de cada objetivo e direcionar a otimização. Desta forma, a função objetivo pode ser representada por:

$$
\begin{gathered}
f_{\text {Objetivo }}(i)=\omega_{\text {Desconexão }} \cdot f_{\text {Desconexão }}(i)+\omega_{\text {Penalidade }} \cdot f_{\text {Penalidade }}(i) \\
+\omega_{\text {Tap }} \cdot f_{\text {Tap }}(i)
\end{gathered}
$$

Para calcular os valores de $f_{\text {Desconexão }}(i), f_{\text {Penalidade }}(i)$ e $f_{\text {Tap }}(i)$ é preciso possuir os valores de tensão de cada barra $(B)$ do sistema de distribuição, para cada a fase $(F)$ existente. Uma curva de carga é utilizada para permitir o planejamento da operação ao longo de um dia típico do SD, então, para obter esses dados em cada instante $(t)$ da curva de carga, são necessários diversos cálculos de fluxo de carga. Um software ou algoritmo que realize esse cálculo é necessário para aplicação do método proposto e obtenção das tensões com e sem a GD conectada $\left(V_{S e m G D}(i, t, F, B)\right.$ e $V_{S e m G D}(i, t, F, B)$, respectivamente) para cada possível solução $(i)$ considerada no método. 


\subsubsection{Modelagem para Minimizar as Violações de Tensão após a Desconexão da Geração Distribuída}

A função que minimiza as violações de tensão após a desconexão da GD $\left(f_{\text {Desconexão }}(i)\right)$ verifica em todas as barras do SD se a tensão em p.u. $V_{\text {Sem } G D}(i, t, F, B)$, da solução $i$, na barra $B$, com a fase $F$ no instante $t$ da curva de carga está entre os limites inferior e superior de tensão após a desconexão ( $L_{\text {SemGDmin }}$ e $L_{\text {SemGD máx }}$, respectivamente). Caso isso não ocorra, em cada barra, fase e instante da curva de carga, $f_{\text {Desconexão }}(i)$ soma o quanto a tensão está distante desses limites. Devido à sua formulação, conclui-se que para todos os indivíduos $f_{\text {Desconexão }}(i) \geq 0$. Em cada solução (i), esse cálculo é feito para todas as barras e todas as fases considerado apenas um instante da curva de carga em $h_{\text {Desconexão }}(i, t)$ e para toda a curva de carga em $f_{\text {Desconexão }}(i)$. A formulação matemática de $f_{\text {Desconexão }}(i)$ é

$$
\begin{aligned}
& f_{\text {Desconexão }}(i)=\sum_{t=1}^{t_{\text {máx }}} h_{\text {Desconexão }}(i, t) \\
& h_{\text {Desconexão }}(i, t)=\sum_{F=1}^{F_{\text {máx }}} \sum_{B=1}^{B_{\text {máx }}} g_{\text {Desconexão }}(i, t, F, B) \\
& g_{\text {Desconexão }}(i, t, F, B)= \\
& \left\{\begin{array}{rr}
L_{\text {Sem } G D \text { min }}-V_{\text {Sem } G D}(i, t, F, B), & V_{\text {Sem } G D}(i, t, F, B)<L_{\text {Sem } G D \text { min }} \\
0, \quad L_{S e m ~ G D \text { min }} \leq & V_{\text {Sem } G D}(i, t, F, B) \leq L_{\text {Sem } G D \text { máx }}, \\
V_{\text {Sem } G D}(i, t, F, B)-L_{\text {Sem } G D \text { max }}, & V_{\text {Sem } G D}(i, t, F, B)>L_{\text {Sem } G D \text { max }}
\end{array},\right.
\end{aligned}
$$

sendo que $t_{\text {máx }}$ é o número máximo de pontos da curva de carga, $F_{m a ́ x}$ é o quantidade de fases do sistema e $B_{m a ́ x}$ é o número total de barras do SD.

\subsubsection{Modelagem para Penalizar as Violações de Tensão com a Geração Distribuída Conectada}

É essencial que as soluções não causem violações de tensão com a GD conectada, então uma função para penalizar essas violações foi desenvolvida $\left(f_{\text {Penalidade }}(i)\right.$ ). Essa penalidade é semelhante à $f_{\text {Desconexão }}(i)$, porém os limites de tensão inferior e superior de utilizados ( $L_{\text {Com GD min }}$ e $L_{\text {Com GD máx }}$, respectivamente) são escolhidos para quando a GD 
está conectada. A função penalidade apenas pode possuir valores positivos ou ser igual à zero. Em cada solução $i$, esse cálculo é feito para todas as barras e todas as fases considerado apenas um instante da curva de carga em $h_{\text {Penalidade }}(i, t)$ e em toda a curva de carga em $f_{\text {Penalidade }}(i)$, utilizando as tensões com a GD conectada $\left(V_{C o m G D}(i, t, F, B)\right)$. A formulação matemática de $f_{\text {Penalidade }}(i)$ é:

$$
\begin{gathered}
f_{\text {Penalidade }}(i)=\sum_{t=1}^{t_{\text {máx }}} h_{\text {Penalidade }}(i, t) \\
h_{\text {Penalidade }}(i, t)=\sum_{F=1}^{F_{\text {máx }}} \sum_{B=1}^{B_{\text {máx }}} g_{\text {Penalidade }}(i, t, F, B) \\
g_{\text {Penalidade }}(i, t, F, B)= \\
\left\{\begin{array}{c}
L_{\text {Com GD min }}-V_{\text {Com GD }}(i, t, F, B), \quad V_{\text {Com } G D}(i, t, F, B)<L_{\text {Com GD min }} \\
0, \quad L_{\text {Com GD min }} \leq V_{\text {Com GD }}(i, t, F, B) \leq L_{\text {Com GD máx }} \\
V_{\text {Com GD }}(i, t, F, B)-L_{\text {Com GD max }} \quad V_{\text {Com GD }}(i, t, F, B)>L_{\text {Com GD max }}
\end{array}\right.
\end{gathered}
$$

\subsubsection{Modelagem para Minimizar as Variações de Posição dos Taps dos Reguladores de Tensão}

Como objetivo secundário, serão minimizadas as variações totais $\left(f_{\text {Tap }}(i)\right)$ de posição dos taps $\left(g_{\text {Tap }}(t, R)\right)$ de cada regulador de tensão $R$ presente no $\mathrm{SD}$, entre todos os instantes da curva de carga do período considerado. A formulação matemática de $f_{\text {Tap }}(i)$ é:

$$
\begin{gathered}
f_{\text {Tap }}(i)=\sum_{R=1}^{R_{\text {máx }}} h_{\text {Tap }}(i, R) \\
h_{\text {Tap }}(i, R)=\left|g_{\text {Tap }}(1, R)-g_{\text {Tap }}\left(t_{\text {máx }}, R\right)\right|+\sum_{t=1}^{\left(t_{\text {máx }}\right)}\left|g_{\text {Tap }}(t-1, R)-g_{\text {Tap }}(t, R)\right|,
\end{gathered}
$$

sendo que $R_{\text {máx }}$ é a quantidade total de reguladores de tensão presentes no SD e $h_{\text {Tap }}(i, R)$ são as variações totais de posição de tap para cada regulador de tensão $R$ em todos os instantes da curva de carga. Vale destacar que $f_{\text {Tap }}$ considera a mudança de tap dos reguladores de tensão entre o último instante da curva de carga e o primeiro, pois se entende que a mesma curva de carga representa vários dias consecutivos, como por exemplo, os dias de semana. Números inteiros compõem $g_{T a p}(t, R)$, representando cada 
posição de tap e $f_{\text {Tap }}(i)$ apenas obtém valores positivos ou o zero. Neste trabalho serão considerados dois tipos de reguladores, um mais simples com 17 posições possíveis $\left(-8 \leq g_{\text {Tap }}(t, R) \leq 8\right)$ e outro com 33 posições possíveis $\left(-16 \leq g_{\text {Tap }}(t, R) \leq 16\right)$.

\subsection{Apresentação do Método}

O método proposto foi baseado em AGs, porém ele possui uma particularidade na sua finalização. Inicialmente, um AG tradicional é utilizado e uma solução é obtida. Se a solução for ótima, o método é encerrado, se não, essa solução é usada como base para auxiliar na composição de uma nova população inicial para um próximo AG, que buscará por uma solução melhor do que a alcançada anteriormente. Assim, é evitado que uma solução pertencente a um ótimo local seja obtida, sem aumentar excessivamente o custo computacional, como será explicado ainda nesta seção. Sempre que o AG é encerrado, outra população inicial é gerada e outro AG é iniciado, até o momento em que essa nova população gerada não contém uma solução melhor do que a obtida anteriormente, apenas então o método é encerrado.

Para resolver o problema com o AG, o genoma deve ser definido, pois ele é a representação de cada indivíduo. Cada genoma representa uma possível solução completa, sendo que ele é composto por unidades menores, os genes. O genoma (genoma $(i)$ ) de cada indivíduo $(i)$ foi definido como um vetor contendo $g_{T a p}(t, R)$, que é um gene com a posição de tap de cada regulador de tensão $R$ para cada instante da curva de carga $t$, como observado no exemplo a seguir:

$$
\operatorname{genoma}(i)=\left[g_{\text {Tap }}(1,1), g_{\text {Tap }}(2,1), g_{\text {Tap }}(3,1), \ldots, g_{\text {Tap }}(t, R), \ldots, g_{\text {Tap }}\left(t_{\text {máx }}, R_{\text {máx }}\right)\right] \text {. }
$$

Cada conjunto de genes $\left[g_{T a p}(t, 1), g_{\text {Tap }}(t, 2), g_{\text {Tap }}(t, 3), \ldots, g_{\text {Tap }}\left(t, R_{\text {máx }}\right)\right]$ em um mesmo instante $(t)$ representa um cenário completo do SD, como todas as posições de tap definidas para esse instante da curva de carga. Observa-se que o tamanho desse vetor é dependente do número de reguladores de tensão presentes no SD e da discretização da curva de carga.

Definido o genoma, foi preciso definir como começar o AG, ou seja, como criar a sua população inicial. Nas primeiras aplicações do método, foi utilizada uma população inicial aleatória. Nessas aplicações iniciais, foram obtidos resultados satisfatórios em 
testes realizados em menor escala do problema, em que uma curva de carga discretizada com poucos pontos foi inicialmente utilizada. Contudo, conforme a curva de carga foi discretizada com mais pontos, aumentando o tamanho do genoma, o esforço computacional aumentou excessivamente e o método mostrou-se lento.

Analisando esses testes iniciais, foi observado que o AG necessitava de relativamente pouco esforço computacional para encontrar genomas que causassem poucas violações de tensão, com ou sem GD conectada ao SD $\left(f_{\text {Desconexão }}(i)\right.$ e $f_{\text {Penalidade }}(i)$ minimizados), porém a maior parte do esforço computacional era observado na minimização das variações das posições de tap dos reguladores de tensão $\left(f_{\text {Tap }}(i)\right)$, pois os novos indivíduos gerados na reprodução frequentemente atrapalhavam as funções já minimizadas $\left(f_{\text {Desconexão }}(i)\right.$ e $f_{\text {Penalidade }}(i)$ ). Enquanto $f_{\text {Tap }}(i)$ era minimizada, a minimização de $f_{\text {Desconexão }}(i)$ e $f_{\text {Penalidade }}(i)$ deveria ser mantida, o que dificultava a otimização, limitando a escolha dos indivíduos e aumentando o esforço computacional do algoritmo. Esse fato ocorreu devido à escolha dos pesos $\omega_{\text {Desconexão }}$ e $\omega_{\text {Penalidade, }}$, pois eles são relativamente maiores do que $\omega_{\text {Tap }}$, então o AG prioriza a minimização de $f_{\text {Desconexão }}$ e $f_{\text {Penalidade }}(i)$ antes de $f_{\text {Tap }}(i)$. Essa escolha foi feita, pois minimizar $f_{\text {Desconexão }}(i)$ e $f_{\text {Penalidade }}(i)$ era o objetivo principal do método e minimizar $f_{\text {Tap }}(i)$ era um objetivo secundário.

Optou-se então por iniciar a população inicial somente com indivíduos que atendessem a algum critério em vez de indivíduos gerados aleatoriamente, sendo que o critério escolhido foi gerar diversos genes e entre eles escolher os que apresentassem menos violações de tensão, com ou sem a GD conectada, para um determinado instante da curva de carga. Isto implicou em menores valores de $h_{\text {Desconexão }}(i, t)$ e $h_{\text {Penalidade }}(i, t)$, pois obter esses genes antes de iniciar o AG era possível e reduzia significativamente o esforço computacional do método, melhorando o quanto a população, de maneira geral, resolve o problema proposto. Para tal, são gerados conjuntos de genes aleatoriamente, sendo que esses conjuntos de genes contêm as posições de tap para todos os reguladores de tensão em algum instante da curva de carga. Posteriormente, são calculados os fluxos de potência necessários para obter as tensões e então cada conjunto de genes é avaliado por $h_{\text {Desconexão }}(i, t)$ e $h_{\text {Penalidade }}(i, t)$. Como os conjuntos de genes representam apenas um instante da curva de carga, eles são avaliados sem considerar a curva de carga inteira, como em $f_{\text {Desconexão }}(i)$ e $f_{\text {Penalidade }}(i)$, então o esforço computacional para obtê-los e testálos é menor. Os conjuntos de genes com menores valores de $h_{\text {Desconexão }}(i, t)$ e $h_{\text {Penalidade }}(i, t)$ são selecionados, pois têm o potencial de possuir as soluções buscadas pelo AG. Esses conjuntos de genes, combinados de maneira aleatória entre si, geram 
genomas para a população inicial. Esta população inicial é uma população com melhores indivíduos que uma população gerada aleatoriamente e não precisa de grande esforço computacional para ser gerada.

Com a população inicial gerada, os indivíduos são avaliados de acordo com a função objetivo de cada um. Assim como na escolha inicial da população, é necessário realizar cálculos de fluxo de potência para obter os valores de tensão, e $f_{\text {Desconexão }}(i), f_{\text {Penalidade }}(i)$ e $f_{\text {Tap }}(i)$ são calculados nesta etapa. Em cada iteração $x$, como critério de parada do AG foi considerado se o indivíduo com menor função objetivo $i_{\text {Min }}(x)$ é uma solução ótima (quando $f_{\text {Objetivo }}\left(i_{\text {Min }}(x)\right)=0$, pois $f_{\text {Objetivo }}$ apenas possui valores positivos ou é igual à zero) ou se as últimas duas iterações obtiveram indivíduos com a mesma função objetivo como melhor solução $\left(f_{\text {Objetivo }}\left(i_{\text {Min }}(x)\right)=f_{\text {objetivo }}\left(i_{\text {Min }}(x-1)\right)\right)$. Se nenhum critério de parada do AG for atendido, são selecionados indivíduos para a reprodução.

$\mathrm{Na}$ seleção dos pais para a reprodução e geração dos filhos, são realizados torneios com grupos de indivíduos selecionados aleatoriamente, de tal forma que o indivíduo que possuísse a melhor solução (menor função objetivo) é selecionado. A reprodução consiste em uma escolha de dois indivíduos ao acaso entre os selecionados anteriormente. Cada gene de um dos pais possui $50 \%$ de chances de ser selecionado para um filho, sendo que dois filhos são gerados. Se um gene de um pai era selecionado para um filho, o outro gene que não foi selecionado é usado para compor o segundo filho, assim todos os genes dos pais são passados adiante para os filhos, porém recombinados. A população da próxima iteração é composta pelos filhos gerados na reprodução e pelos melhores indivíduos selecionados anteriormente, utilizando assim o conceito de elitismo.

Depois de gerados os filhos, seus genes podem passar pelo processo de mutação. Os genes possuem uma chance de sofrer mutação, sendo que foram utilizados dois tipos de mutação: a primeira consistia em trocar o valor de um gene por outro valor aleatório e a segunda somava ou subtraia um valor inteiro aleatório pequeno, entre -3 e +3 , do valor atual do gene. Essa segunda mutação faz com que o gene seja alterado para outro gene com características semelhantes, pois a mudança em seu valor é pequena. Como o método começa com uma população selecionada, essa mutação gera outro indivíduo semelhante ao sem mutação, permitindo assim aumentar as chances de obter melhores soluções devido à natureza do problema. Isso ocorre, pois se uma posição de tap do regulador de tensão não viola a tensão, quando apenas essa posição no genoma inteiro for alterada para alguma outra posição semelhante, as chances dessa nova posição 
também não causar uma violação são maiores do que a de usar uma posição aleatória, com um valor muito diferente do atual. Assim, as variações de posição de $\operatorname{tap}\left(f_{\text {Tap }}(i)\right)$ são mais facilmente minimizadas por essa mutação. Como essa função $\left(f_{\text {Tap }}(i)\right.$ ) foi a que mais necessitou de esforço computacional para ser minimizada, essa segunda mutação tem maiores chances de auxiliar o AG na busca de soluções melhores, pois possui menos chances de gerar indivíduos que suas posições de tap causem violações de tensão, podendo assim reduzir as variações de tap sem causar violações de tensão.

Com a nova população gerada, na próxima iteração os indivíduos são novamente avaliados. Se nenhum critério de parada for atingido, o AG continua selecionando mais indivíduos para a reprodução e gerando novas populações. Após atingir algum critério de parada, o AG é encerrado, porém, se a função objetivo não foi zerada, o AG pode estar preso em um mínimo local. Para evitar esse problema, uma população maior pode ser utilizada e assim permitir que o AG tenha um espaço de busca do problema mais completo, porém, aumentar a população também aumenta o esforço computacional, o que não é desejado. Aumentar a taxa de mutação de cada gene também não mostrou bons resultados, pois apesar do AG ter chances menores de ficar preso a um mínimo local, aumentar demasiadamente as mutações, que possuem natureza aleatória, pode prejudicar a convergência do AG. Executar diversas iterações quando é obtido o mesmo indivíduo como melhor solução também não mostrou bons resultados em testes realizados. Isto ocorreu, pois assim é necessário esperar que o AG consiga achar uma solução melhor do que a obtida anteriormente, se ela existir. Encontrar essa solução melhor depende de uma mudança aleatória obtida pela mutação ou de alguma recombinação muito específica entre dois genomas.

Para resolver esse problema, o genoma obtido no AG já finalizado é usado para gerar uma nova população inicial e começar o AG mais uma vez, com a diferença de que essa nova população inicial é criada utilizando o genoma obtido anteriormente e variando em cada gene $\left(g_{\text {Tap }}(t, R)\right)$ um valor inteiro entre -3 e +3 escolhido aleatoriamente. Também são gerados indivíduos utilizando-se de um conceito de um método de otimização chamado Branch and Bound [73], que é baseado em dividir o espaço de possíveis soluções em conjuntos menores (Branch) e escolher quais desses conjuntos podem conter a melhor solução (Bound), dividindo-o também em menores conjuntos sucessivamente até encontrar a melhor solução. Como foi encontrada uma solução que pode pertencer a um mínimo local, são gerados novos indivíduos com apenas um gene diferente, alterando em +1 e -1 cada um dos genes nos novos indivíduos. Este procedimento pode ser observado no exemplo da Figura 5, em que um cromossomo com 
dois genes $([-3 ; 5])$, que pode representar as posições de tap de um regulador de tensão para dois períodos de carga, gera os genes $[-4 ; 5],[-2 ; 5],[-3 ; 4]$, e $[-3 ; 6]$. Assim, genomas bem semelhantes ao obtido anteriormente são produzidos, porém com uma unidade de diferença em apenas um gene.

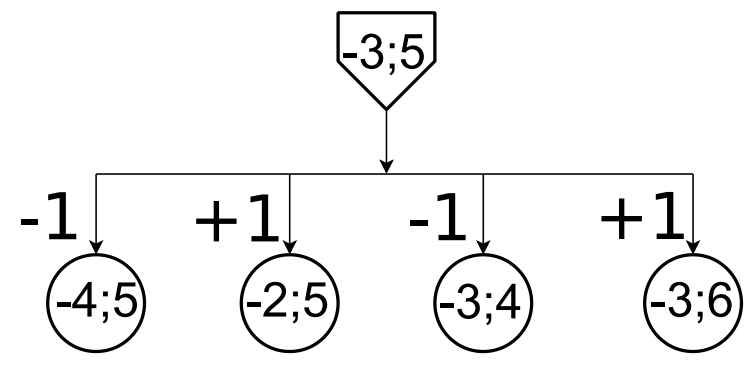

Figura 5 - Exemplo da geração de novos indivíduos com solução baseada no Branch and Bound para um cromossomo com apenas dois genes.

Essa nova população não garante que o AG não encontrará apenas mínimos locais, mas resultados obtidos em testes desta pesquisa indicaram que essa é uma maneira simples de encontrar melhores soluções sem aumentar excessivamente o esforço computacional na aplicação do método. Com essa nova população, o AG busca novamente uma solução melhor semelhante à solução já obtida. Se ela existir, o AG continua a busca de maneira similar à efetuada anteriormente, utilizando os mesmos conceitos de avaliação, reprodução e mutação antes mencionados. Se ainda assim essa nova população não possuir uma solução melhor do que a obtida nas últimas duas iterações $\left(f_{\text {Objetivo }}\left(i_{\text {Min }}(x)\right)=f_{\text {Objetivo }}\left(i_{\text {Min }}(x-1)\right)=f_{\text {Objetivo }}\left(i_{\text {Min }}(x-2)\right)\right)$, o método é encerrado. Um fluxograma com as principais etapas do método proposto pode ser observado na Figura 6. O método foi implementado no Matlab [74]. 


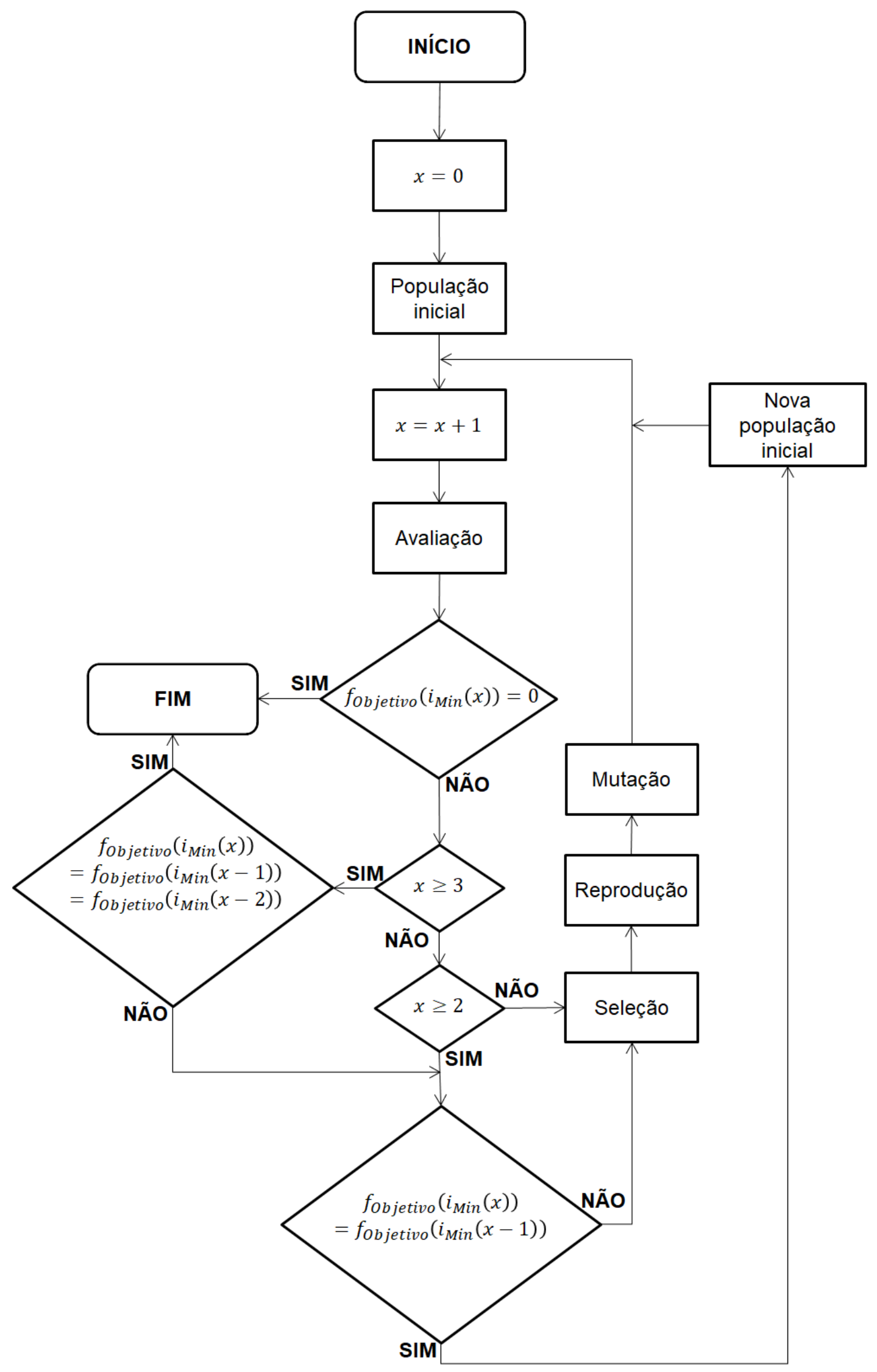

Figura 6 - Fluxograma do método proposto. 


\subsection{Considerações finais sobre o capítulo}

Este capítulo apresentou a formulação matemática proposta nesta pesquisa aplicada na resolução do problema estudado. A formulação pode ser facilmente utilizada, pois apenas necessita de cálculos de fluxo de potência, que podem ser resolvidos por diversos softwares ou algoritmos bem conhecidos.

O método proposto utiliza conceitos bem consolidados de AGs. Utilizar soluções já obtidas em otimizações é uma prática que pode reduzir o custo computacional do método. Devido à grande complexidade do problema que está sendo estudado nessa pesquisa, é importante diminuir o custo computacional para que o método possa ser aplicado em sistemas mais complexos. 



\section{Capítulo 5}

\section{Resultados}

Este capítulo apresenta os resultados obtidos aplicando o método proposto nesta pesquisa. Foram usados dois sistemas de distribuição de energia elétrica. O Sistema 1 foi utilizado no início da pesquisa, pois já havia sido empregado em trabalhos anteriores. Esse sistema possui apenas um regulador de tensão, o que diminui o esforço computacional na aplicação do método. Na etapa final da pesquisa, foi utilizado o IEEE 34 barras para analisar a sensibilidade do método proposto, pois este sistema possui as cargas desbalanceadas, longas linhas, dois bancos de capacitores e dois reguladores de tensão trifásicos que controlam as fases separadamente, tornando um desafio maior à regulação da tensão do mesmo quando há a presença de GD.

\subsection{Sistema 1}

O Sistema 1 é apresentado na Figura 7, que consiste em um SD com dois geradores conectados por transformadores ao sistema, um regulador de tensão, um religador e nenhum banco de capacitores. Dois geradores síncronos estão conectados ao SD, ambos com 5,0 MVA de potência aparente instalada. A conexão dos geradores não é exclusiva por via expressa, então os geradores dividem o alimentador de distribuição com outras unidades consumidoras. O regulador de tensão utilizado possui 17 posições possíveis de 
tap (-8 até +8), sendo que cada tap ajusta o valor de tensão em 0,01250 p.u.. O atraso para a primeira operação do regulador $\left(\Delta T_{\text {tap }}\right)$ é de 30 segundos e as operações subsequentes têm um atraso $(\Delta t)$ de 3 segundos. A tensão nominal do sistema é de 25 $\mathrm{kV}$. A demanda máxima do SD é de 16,39 MW, sendo que 11,35 MW estão conectados a jusante do regulador de tensão. As Tabela 4 a Tabela 8 contêm informações sobre os transformadores que conectam os geradores ao SD, parâmetros dos próprios geradores, do regulador de tensão, das cargas e das impedâncias da linha. O Sistema 1 foi modelado na toolbox SimPowerSystem do Matlab [74], as cargas foram consideradas de impedância constante. Ele é trifásico, mas por ser equilibrado, somente a fase A foi considerada na aplicação do método. A subestação foi representada por um equivalente de Thevenin com potência de curto-circuito de 305 MVA e a relação $X / R$ é de 58,57 .

Tabela 4 Parâmetros dos geradores conectados ao SD.

\begin{tabular}{cc}
\hline Parâmetros & Valores \\
Máquina / Tipo do Rotor & Síncrono / Polos Salientes \\
Potência Nominal (MVA) & 5,0 \\
Tensão Nominal (kV) & 0,48 \\
Frequência Nominal (Hz) & 60 \\
Xd; Xd'; Xd” (p.u.) & 2,$081 ; 0,295 ; 0,193$ \\
Xq; Xq'; Xq" (p.u.) & 1,$144 ; 0,183 ; 0,1$ \\
Td0; Td0'; Td0” (s) & 3,$007 ; 0,0152 ; 0,0081$ \\
Resistência do Estator (p.u.) & 0,003 \\
Número de Pares de Polos & 3 \\
Coeficiente de Inércia (s) & 0,4182 \\
Conexão & Y Aterrado \\
\hline
\end{tabular}


Tabela 5 Parâmetros dos transformadores que conectam os geradores ao SD

$\begin{array}{cc}\text { Parâmetros } & \text { Valores } \\ \text { Conexão } & \Delta: \mathrm{Yg} \\ \text { Tensão Nominal (kV) } & 25: 0,48 \\ \text { Frequência Nominal (Hz) } & 60 \\ \begin{array}{c}\text { Potência Nominal (MVA) } \\ \text { Resistência do primário e } \\ \text { do secundário (p.u.) }\end{array} & 5,25 \\ \text { Indutância do primário e } \\ \text { do secundário (p.u.) } \\ \text { Resistência e Indutância } \\ \text { de Magnetização (p.u.) }\end{array}$

Tabela 6 Parâmetros do regulador de tensão

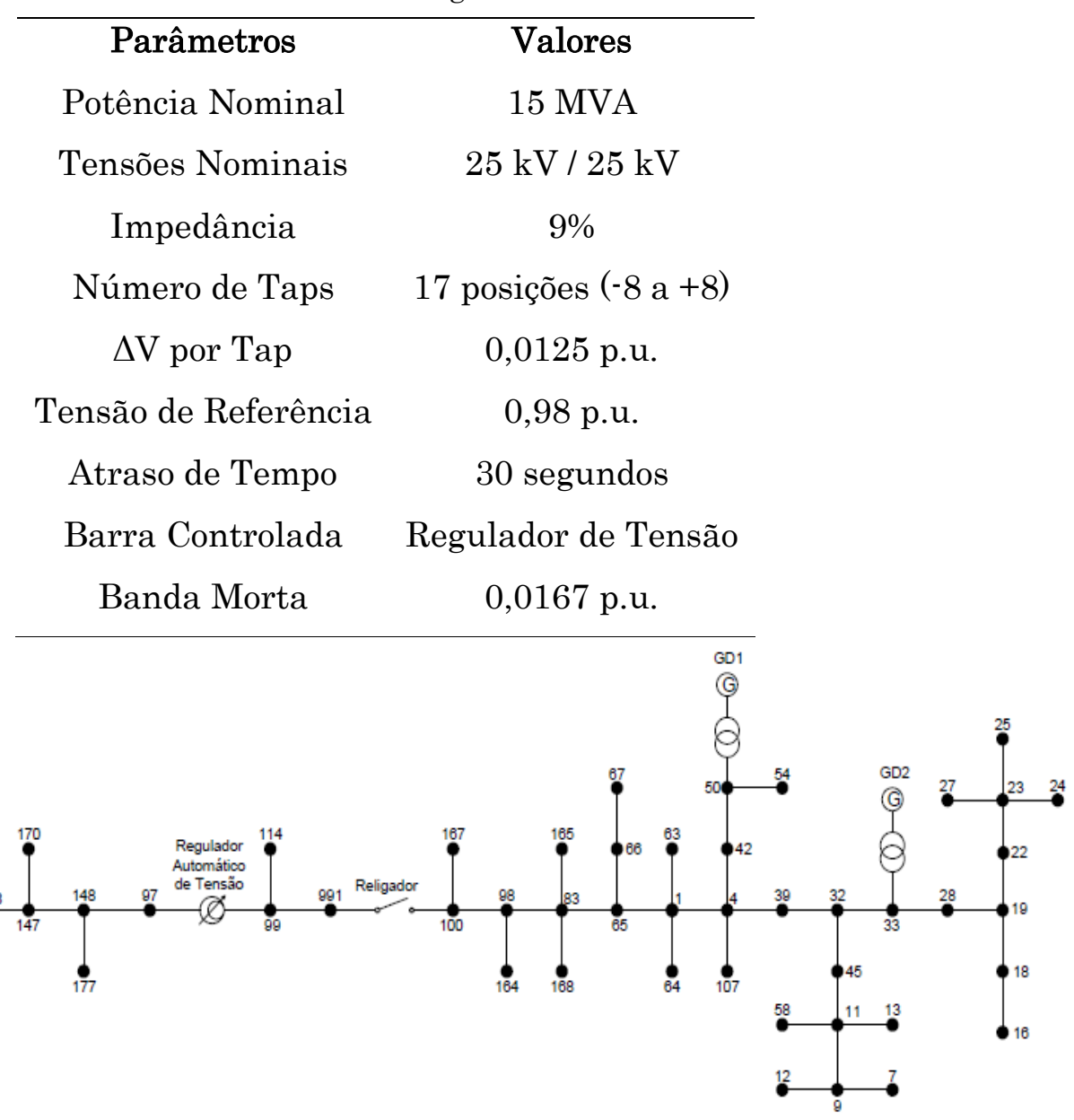

Figura 7 - Sistema elétrico usado em [75]. 
Tabela 7 Cargas das unidades consumidoras

\begin{tabular}{cccccc}
\hline Barra & $\mathbf{P}(\mathrm{kW})$ & $\mathbf{Q}(\mathrm{kW})$ & Barra & $\mathbf{P}(\mathrm{kW})$ & $\mathbf{Q}(\mathrm{kW})$ \\
7 & 101,40 & 48,60 & 66 & 15,20 & 7,30 \\
12 & 253,60 & 121,50 & 67 & 25,40 & 12,20 \\
13 & 169,00 & 81,00 & 107 & 25,40 & 12,20 \\
16 & 50,70 & 24,30 & 114 & 25,40 & 12,20 \\
18 & 25,40 & 12,20 & 127 & 50,70 & 24,30 \\
22 & 25,40 & 12,20 & 128 & 50,70 & 24,30 \\
24 & 50,70 & 24,30 & 129 & 1409,00 & 682,00 \\
25 & 50,70 & 24,30 & 142 & 530,00 & 256,70 \\
27 & 25,40 & 12,20 & 143 & 50,70 & 24,30 \\
28 & 38,00 & 18,20 & 144 & 1103,80 & 534,60 \\
39 & 5,10 & 2,40 & 164 & 551,90 & 267,30 \\
42 & 3160,00 & 1530,00 & 165 & 1690,00 & 810,00 \\
45 & 2110,00 & 1020,00 & 166 & 700,00 & 200,00 \\
54 & 169,00 & 81,00 & 167 & 1000,00 & 300,00 \\
58 & 76,10 & 36,50 & 168 & 1690,00 & 810,00 \\
63 & 25,40 & 12,20 & 170 & 1108,90 & 214,00 \\
64 & 25,40 & 12,20 & - & - & - \\
\hline & & & & &
\end{tabular}


Tabela 8 Impedância das linhas do SD

\begin{tabular}{|c|c|c|c|c|c|c|c|}
\hline Barra & Barra & Resistência & Reatância & Barra & Barra & Resistência & Reatância \\
\hline Origem & Destino & $(\Omega)$ & $(\Omega)$ & Origem & Destino & $(\Omega)$ & $(\Omega)$ \\
\hline Subestação & 126 & 0,2370 & 0,3367 & 1 & 63 & 0,2455 & 0,1139 \\
\hline 126 & 127 & 0,0489 & 0,0122 & 1 & 64 & 0,2709 & 0,0956 \\
\hline 126 & 128 & 0,0167 & 0,0042 & 1 & 4 & 0,1179 & 0,1227 \\
\hline 126 & 129 & 0,0098 & 0,0102 & 4 & 107 & 0,4139 & 0,1965 \\
\hline 129 & 135 & 0,0804 & 0,0841 & 4 & 42 & 0,0094 & 0,0098 \\
\hline 135 & 144 & 0,0025 & 0,0010 & 42 & 50 & 0,0021 & 0,0022 \\
\hline 135 & 138 & 0,1165 & 0,1218 & 50 & 54 & 0,0836 & 0,0757 \\
\hline 138 & 142 & 0,0031 & 0,0012 & 4 & 39 & 0,1414 & 0,1166 \\
\hline 138 & 143 & 0,0597 & 0,0148 & 39 & 32 & 0,1276 & 0,0463 \\
\hline 138 & 147 & 0,1075 & 0,2103 & 32 & 45 & 0,0514 & 0,0652 \\
\hline 147 & 170 & 0,1117 & 0,2375 & 45 & 11 & 0,1791 & 0,1864 \\
\hline 147 & 148 & 0,1406 & 0,2988 & 11 & 58 & 0,2341 & 0,0911 \\
\hline 148 & 166 & 0,0653 & 0,1387 & 11 & 13 & 0,0687 & 0,0267 \\
\hline 148 & 97 & 0,5265 & 1,1081 & 11 & 9 & 0,0446 & 0,0467 \\
\hline 99 & 114 & 0,2633 & 0,5596 & 9 & 12 & 0,0759 & 0,0189 \\
\hline 99 & 991 & 0,0980 & 0,1026 & 9 & 7 & 0,0451 & 0,0434 \\
\hline 104 & 98 & 0,1205 & 0,1260 & 32 & 33 & 0,0386 & 0,0202 \\
\hline 98 & 167 & 0,0413 & 0,0432 & 33 & 28 & 0,8670 & 0,2826 \\
\hline 98 & 95 & 0,1147 & 0,1767 & 28 & 19 & 0,1512 & 0,0493 \\
\hline 95 & 164 & 0,1316 & 0,2797 & 19 & 18 & 0,7807 & 0,2983 \\
\hline 95 & 83 & 52,47 & 1,1103 & 19 & 22 & 0,1034 & 0,0337 \\
\hline 83 & 165 & 0,0964 & 0,0375 & 22 & 23 & 0,1103 & 0,0360 \\
\hline 83 & 168 & 0,0866 & 0,1007 & 23 & 25 & 0,1161 & 0,0378 \\
\hline 65 & 66 & 0,0263 & 0,0086 & 23 & 27 & 0,3507 & 0,1143 \\
\hline 66 & 67 & 0,2333 & 0,0760 & 23 & 24 & 0,0273 & 0,0089 \\
\hline 65 & 1 & 0,0489 & 0,0676 & - & - & - & - \\
\hline
\end{tabular}




\subsubsection{Resultados obtidos no Sistema 1}

Enquanto a formulação matemática ainda estava sendo estudada, nas etapas iniciais dessa pesquisa, o Sistema 1 foi utilizado com o objetivo de compreender o problema, formular sua solução de maneira eficiente como um problema de otimização. Devido à sua menor complexidade em relação ao sistema IEEE 34 barras, é necessário menos esforço computacional para encontrar a solução para o problema nesse sistema. Nesta etapa, foi utilizada a Solução 5 [27], apresentada no Capítulo 3, em que todas as possibilidades da posição de tap do regulador de tensão são testadas. Esses resultados obtidos inicialmente podem ser encontrados no Apêndice. Em seguida, o método proposto foi empregado nos cenários estudados nessa etapa inicial, em que foram considerados diversos cenários de geração, sendo eles:

Cenário 1. Ambos geradores operando em CFP, cada um injetando 2,3 MW e 0,0 Mvar.

Cenário 2. Ambos geradores operando em CFP, cada um injetando 4,6 MW e 0,0 Mvar.

Cenário 3. Ambos geradores operando em CFP, cada um injetando 2,3 MW e 0,9 Mvar.

Cenário 4. Ambos geradores operando em CFP, cada um injetando 4,6 MW e 1,8 Mvar.

Cenário 5. Ambos geradores operando em CT, cada um injetando 2,3 MW e mantendo a tensão do PAC em 1,0 p.u..

Cenário 6. Ambos geradores operando em CT, cada um injetando 4,6 MW e mantendo a tensão do PAC em 1,0 p.u..

Os limites operacionais de tensão foram escolhidos de acordo com o Módulo 8 do PRODIST [39]. Na Tabela 9 são definidas faixas de tensões em que elas são classificadas em Adequada, Precária ou Crítica. A tensão de qualquer unidade consumidora deve ser mantida o maior tempo possível em Adequada, podendo ser Precária por curtos períodos de tempo e Crítica por períodos bem curtos de tempo. Neste trabalho, foi escolhido manter a tensão como Adequada quando a GD está conectada ao SD $\left(L_{\text {Com GD min }}=0,93\right.$ e $\left.L_{\text {Com GD máx }}=1,05\right)$, deixando-a ser Precária no período subsequente da desconexão dos geradores $\left(L_{S e m G D \text { min }}=0,90\right.$ e $\left.L_{S e m G D \text { máx }}=1,05\right)$, pois a sua desconexão repentina deverá ocorrer com pouca frequência, não afetando de maneira significativa os índices de 
QEE da distribuidora. A barra 12 apresentou a menor tensão em todos os cenários considerados, então foi utilizada como exemplo para demonstrar seu perfil de tensão ao longo de um dia típico do SD.

Tabela 9 Faixa de Classificação de Tensões ( $T$ ) para redes de $25 \mathrm{kV}$

$\begin{array}{cc}\text { Tensão de Atendimento } & \text { Faixa de Variação da Tensão (p.u.) } \\ \text { Adequada } & 0,93 \leq T \leq 1,05 \\ \text { Precária } & 0,90 \leq T \leq 0,93 \\ \text { Crítica } & T<0,90 \text { ou } T>1,05\end{array}$

Nas etapas iniciais não era utilizada a curva de carga do SD, eram utilizados patamares de carga $(100 \%, 80 \%, 60 \%, 40 \%$ e $20 \%$ da carga total). Os valores de uma curva de carga residencial [76] foram aproximados para os valores desses patamares, como pode ser observado na Figura 8. A curva de carga original foi discretizada em 96 pontos e a curva de carga aproximada foi discretizada em 24 pontos.

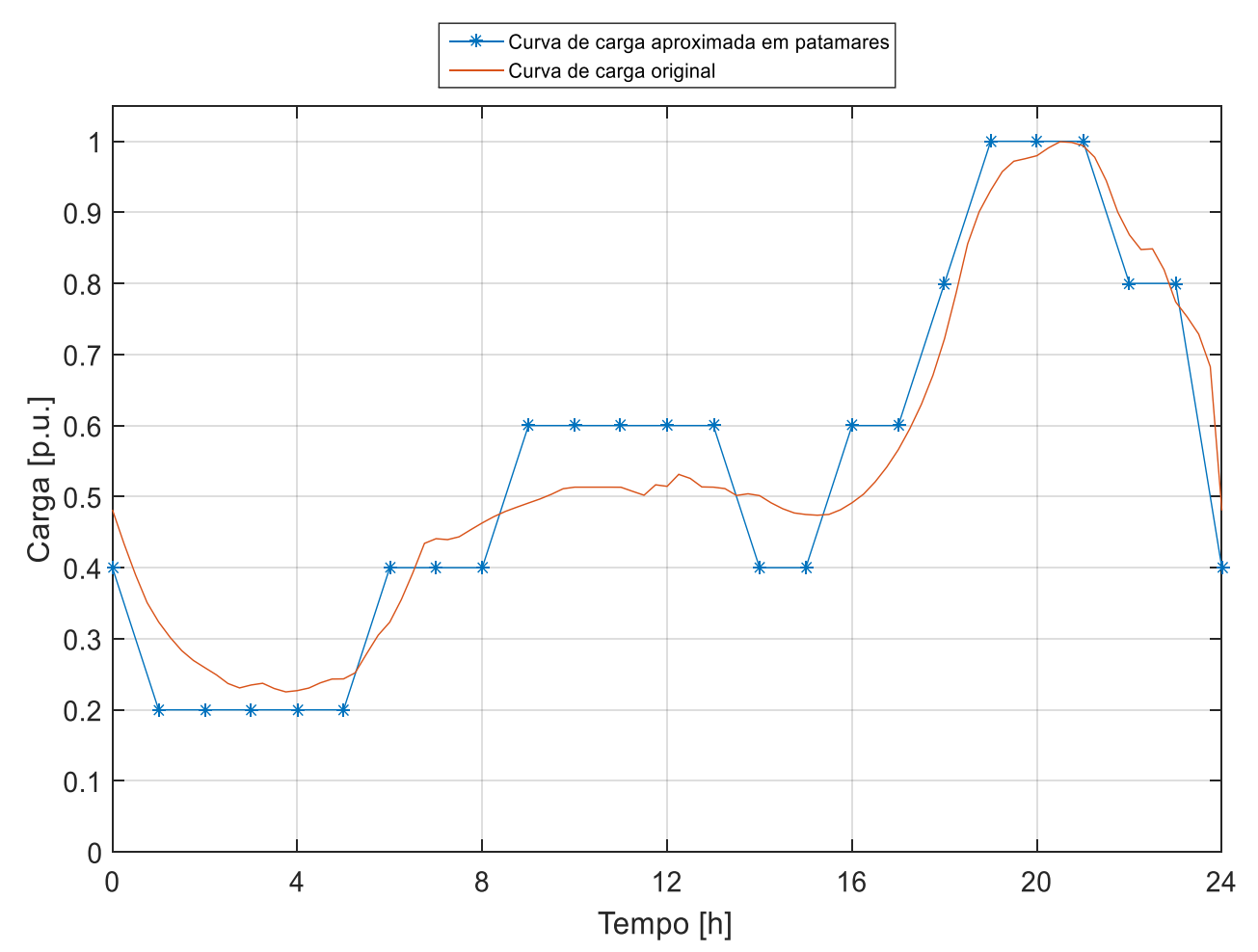

Figura 8 - Comparação entre a curva de carga original e a aproximada por patamares.

O AG utilizado possuía uma população composta por 2000 indivíduos, 600 deles eram selecionados como reprodutores em torneios com 40 indivíduos escolhidos ao acaso. 
Os 20 melhores indivíduos selecionados eram mantidos para a próxima iteração. Cada gene tinha $0,15 \%$ de chance de sofrer a mutação com valor completamente aleatório e $0,30 \%$ de chance de sofrer a mutação que adiciona ou subtrai um pequeno valor ao gene. Os pesos das funções objetivo tinham os seguintes valores: $\omega_{\text {Desconexão }}=10^{5}$, $\omega_{\text {Penalidade }}=10^{8}$ e $\omega_{\text {Tap }}=10^{-4}$.

\subsubsection{Cenário 1}

No Cenário 1, os dois geradores estão operando em CFP e cada gerador injeta 2,3 MW na rede, com o fator de potência unitário. No período de máxima demanda, a GD injeta $40,5 \%$ da potência ativa total consumida pelas unidades consumidoras localizadas a jusante do regulador de tensão (11,35 MW) e no período de baixa demanda (20\% da carga total), a GD supera o consumo desta porção do sistema em 2,33 MW, ocorrendo reversão do fluxo de potência no regulador de tensão. Há uma grande participação da GD no sistema, mas mesmo neste cenário, as violações de tensão, com ou sem a GD, foram totalmente eliminadas, ou seja, $\left(f_{\text {Desconexão }}\left(i_{\text {Min }}(x)\right)=f_{\text {Penalidade }}\left(i_{\text {Min }}(x)\right)=0\right)$ em todas as barras do sistema. Ocorrem 4 mudanças na posição dos taps do regulador de tensão, considerando 24 horas de operação $\left(f_{\text {Tap }}\left(i_{\text {Min }}(x)\right)=4\right)$, como pode ser observado na Figura 9. É possível observar que apenas no período de carga máxima foi necessário alterar a posição de tap do regulador de tensão

$\mathrm{Na}$ iteração 24, o AG não encontrou uma solução melhor do que na iteração 23 e gerou uma nova população inicial com o melhor resultado da última iteração. $\mathrm{O}$ método foi encerrado na iteração 31. Considerando os pesos das funções, o valor obtido da função objetivo foi $f_{\text {Objetivo }}\left(i_{\text {Min }}(x)\right)=0,0004$. Na Figura 10 são apresentadas as tensões com os geradores conectados e com eles desconectados ao longo de um dia típico na barra 12. É possível observar que a tensão sem a GD permanece dentro dos limites de tensão desejados ao longo do dia e com a GD, as tensões também estão dentro dos limites em todos os instantes da curva de carga. 


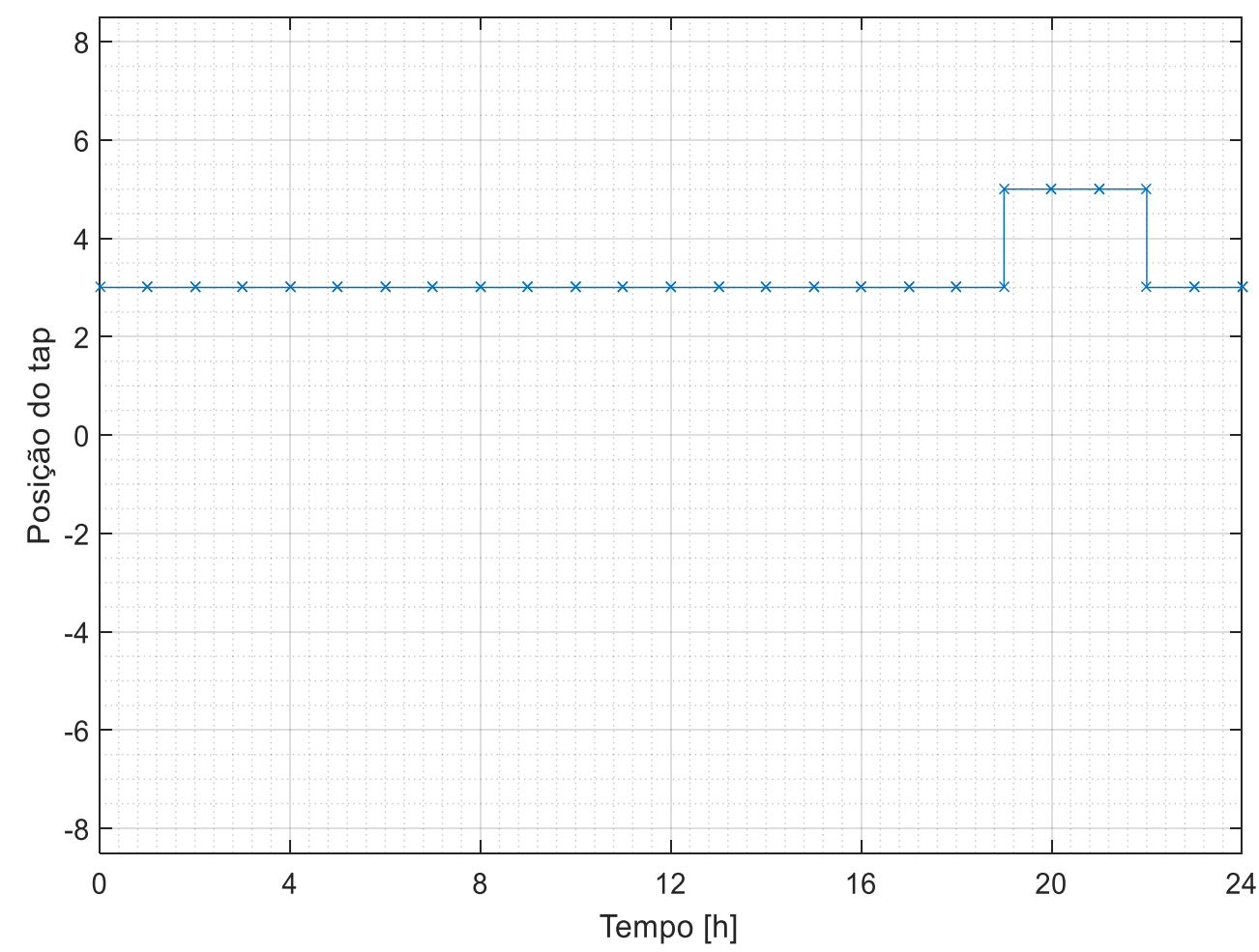

Figura 9 - Posições de tap obtidas pela otimização ao longo de um dia típico, representando por uma curva de carga residencial no Cenário 1.

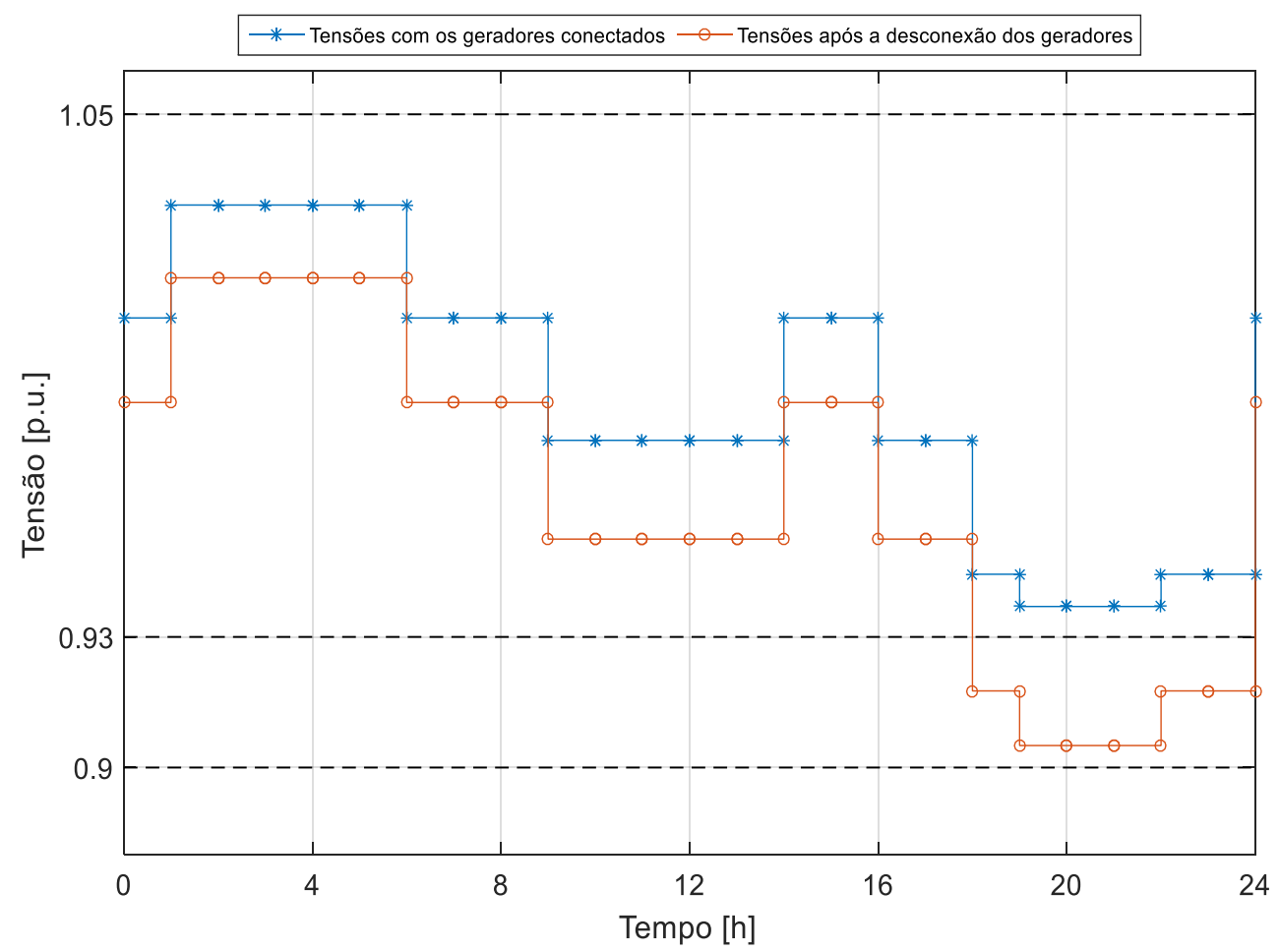

Figura 10 - As tensões com e sem a GD conectada na barra 12 ao longo de um dia típico, representando por uma curva de carga residencial no Cenário 1. 


\subsubsection{Cenário 2}

No Cenário 2 cada gerador injeta 4,6 MW, o dobro de potência ativa injetada no Cenário 1. No período de demanda máxima, os geradores injetam $81 \%$ da potência ativa consumida pelas cargas à jusante do regulador de tensão e no período de demanda mínima a geração de potência ativa supera o consumo das unidades consumidoras em 6,93 MW. Na solução encontrada, em todo o sistema não ocorrem violações de tensão, com ou sem a GD conectada $\left(f_{\text {Desconexão }}\left(i_{\text {Min }}(x)\right)=f_{\text {Penalidade }}\left(i_{\text {Min }}(x)\right)=0\right)$ e são necessárias 6 mudanças de tap $\left(f_{\text {Tap }}\left(i_{\text {Min }}(x)\right)=6\right)$ ao longo do dia, como pode ser observado na Figura 11.

$\mathrm{Na}$ iteração 23, não foi encontrada melhor solução do que a obtida na iteração anterior, então uma nova população inicial foi gerada. Na iteração 30 o método foi encerrado. A função objetivo encontrada foi $f_{\text {objetivo }}\left(i_{\text {Min }}(x)\right)=0,0006$, valor parecido ao obtido no Cenário 1. Neste cenário, foi necessário alterar a posição de tap no regulador de tensão quando a demanda foi e máxima e também quando a demanda foi mínima. $\mathrm{Na}$ Figura 12 é possível observar as tensões na barra 12, com e sem a GD conectada. Não há violações de tensão com a GD operando, em sua desconexão e nem na sua subsequente reconexão. Foi observado que mesmo dobrando a potência ativa injetada pelos geradores, fazendo assim os geradores possuírem uma grande participação no período de carga máxima e ocorrendo reversão de fluxo no período de carga mínima, o método conseguiu eliminar as violações de tensão variando um número parecido de vezes as posições de taps dos reguladores de tensão em relação ao Cenário 1. 


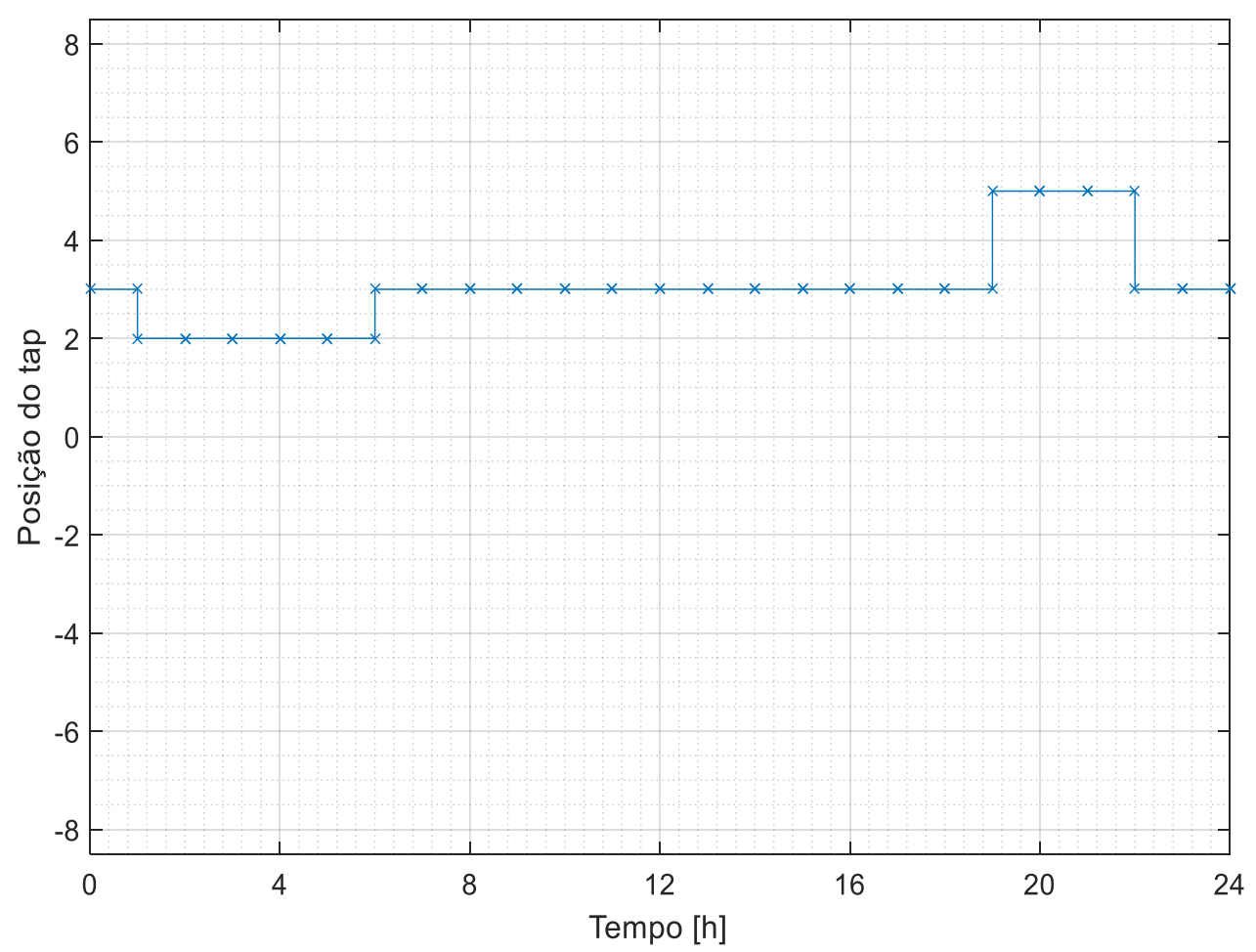

Figura 11 - Posições de tap obtidas pela otimização ao longo de um dia típico, representando por uma curva de carga residencial no Cenário 2.

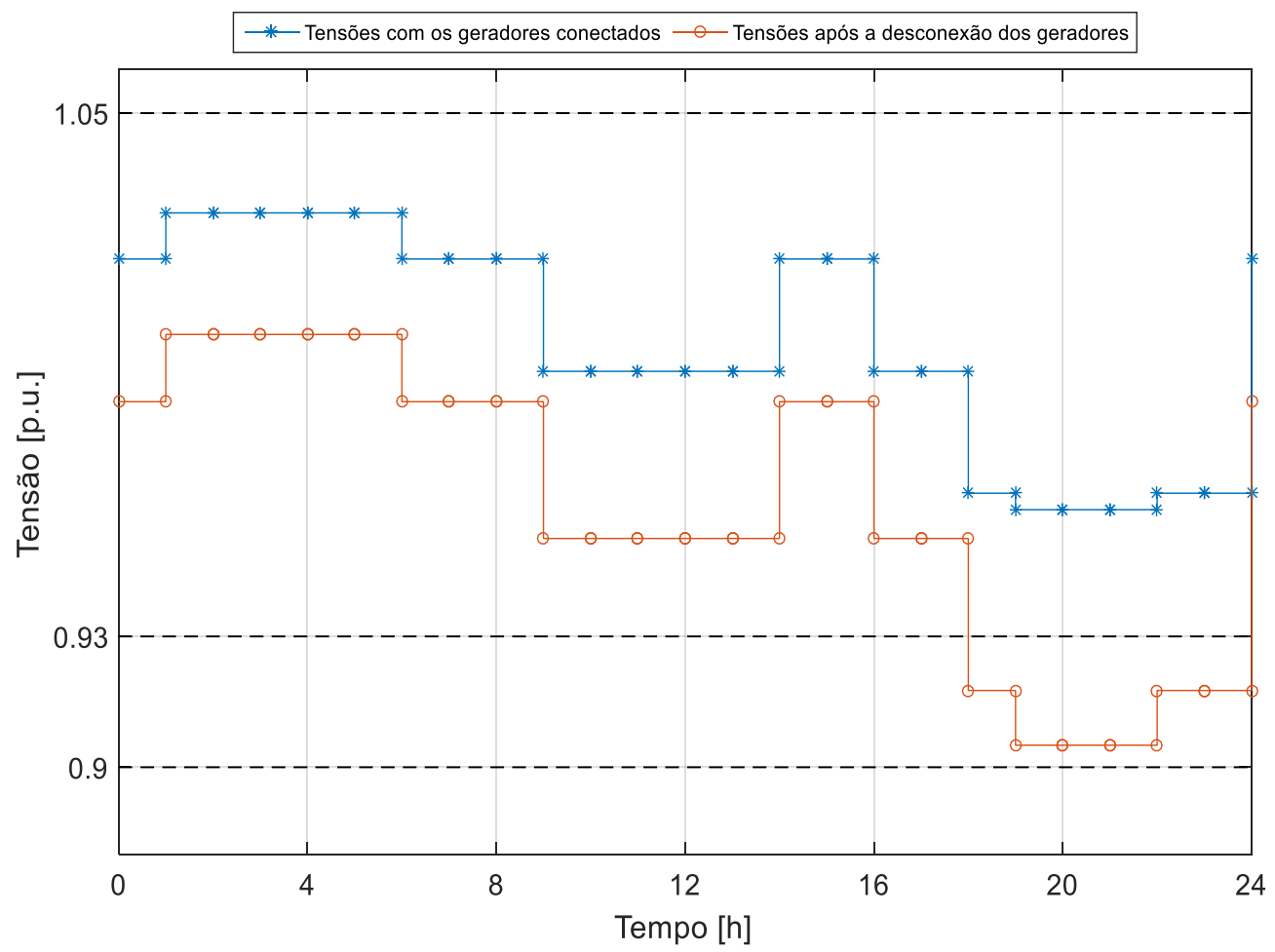

Figura 12 - As tensões com e sem a GD conectada na barra 12 ao longo de um dia típico, representando por uma curva de carga residencial no Cenário 2. 


\subsubsection{3 $\underline{\text { Cenário } 3}$}

O Cenário 3 é semelhante ao Cenário 1, porém os geradores também injetam potência reativa. Eles operam em CFP, gerando 2,3 MW e 0,9 Mvar (fator de potência igual a 0,93). As violações de tensão, com ou sem a GD foram eliminadas em todo o sistema $\left(f_{\text {Desconexão }}\left(i_{\text {Min }}(x)\right)=f_{\text {Penalidade }}\left(i_{\text {Min }}(x)\right)=0\right)$ e 8 mudanças de tap $\left(f_{\text {Tap }}\left(i_{\text {Min }}(x)\right)=8\right)$ são necessárias para regular a tensão do sistema, como pode ser observado na Figura 13.

$\mathrm{Na}$ iteração 27, não foi encontrada uma melhor solução que na iteração $26 . \mathrm{Na}$ iteração 32 o método foi encerrado. A função objetivo obtida foi $f_{\text {objetivo }}\left(i_{\text {Min }}(x)\right)=$ 0,0008. A GD pode ser desconectada e reconectada que não ocorrerá violações de tensão, como observado na Figura 14.

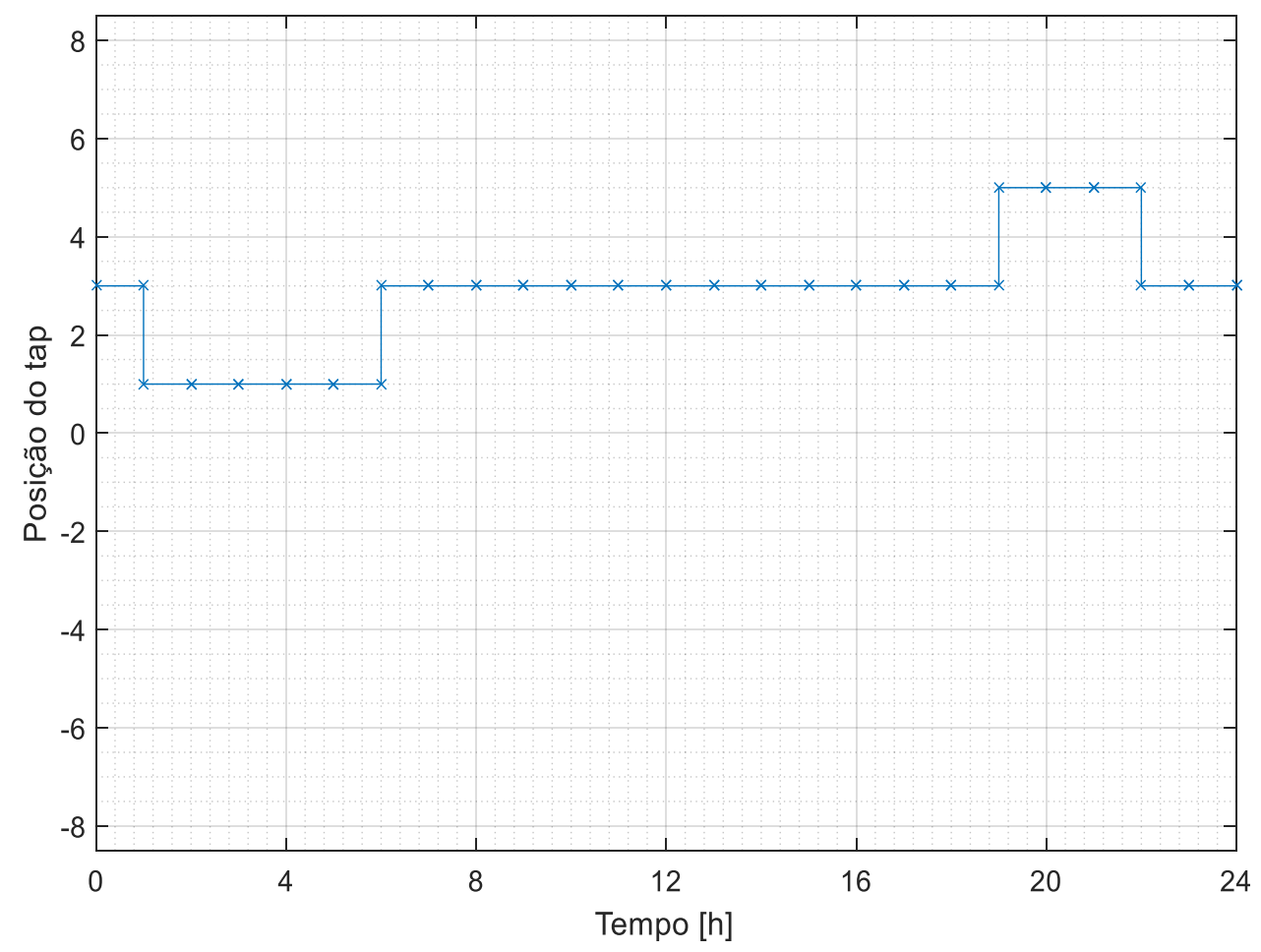

Figura 13 - Posições de tap obtidas pela otimização ao longo de um dia típico, representando por uma curva de carga residencial no Cenário 3. 


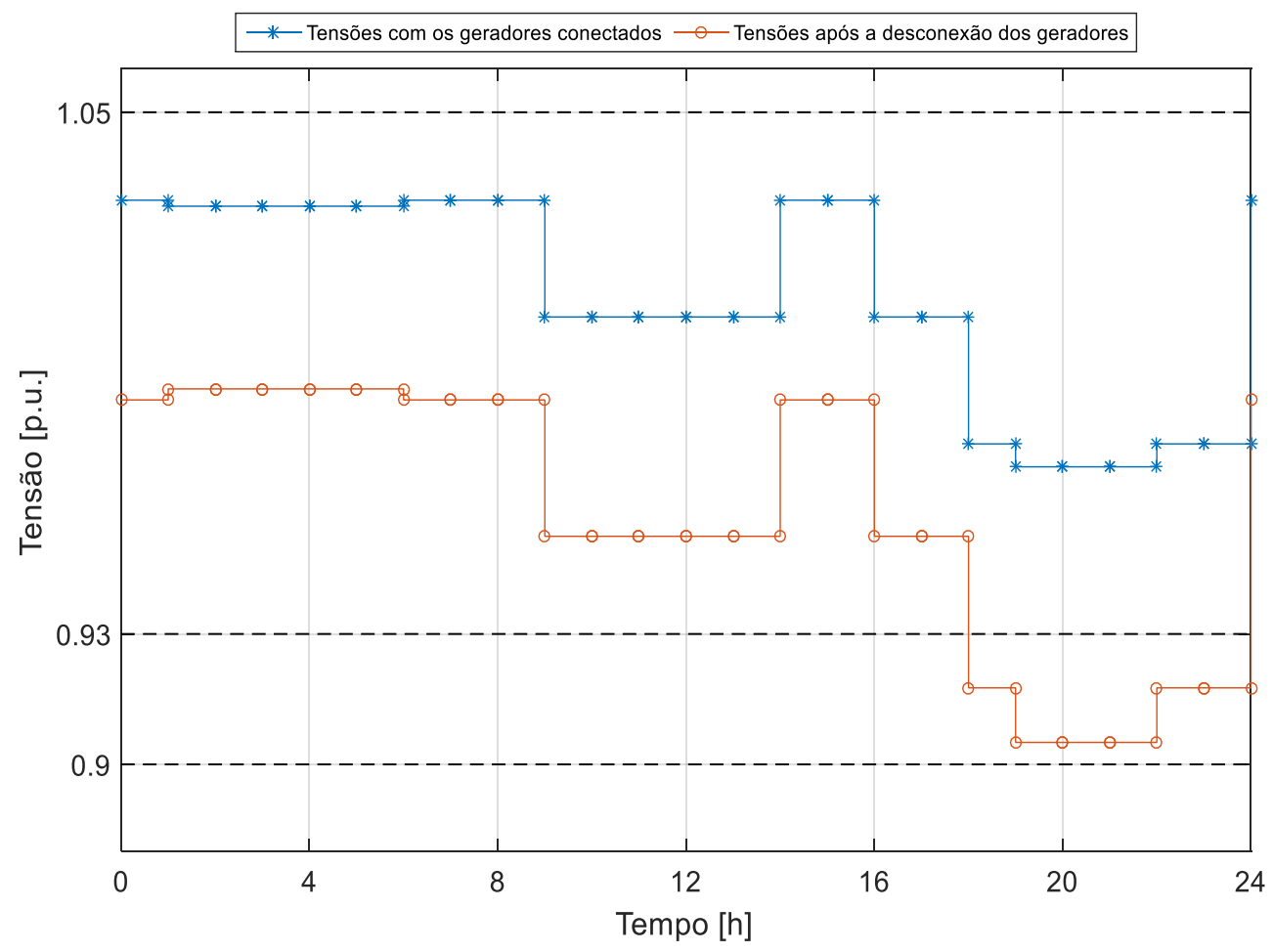

Figura 14 - As tensões com e sem a GD conectada na barra 12 ao longo de um dia típico, representando por uma curva de carga residencial no Cenário 3.

\subsubsection{Cenário 4}

O Cenário 4 é semelhante ao Cenário 2, porém há geração de potência reativa. No Cenário 4, os geradores operam em CFP e injetam 4,6 MW e 1,8 Mvar (fator de potência igual a 0,93). As violações de tensão com a GD conectada foram eliminadas $f_{\text {Penalidade }}\left(i_{\text {Min }}(x)\right)=0$, porém em sua desconexão, não foi possível encontrar posições de tap que evitassem violações de tensão $f_{\text {Desconexão }}\left(i_{\text {Min }}(x)\right)=6,7215$. Esse resultado vai ao encontro dos resultados parciais obtidos em [77], em que foi observado que quando o consumo desse sistema é máximo, a queda de tensão causada pela desconexão da GD considerada para este cenário é muito elevada. Isso ocorre, pois, além de uma quantidade significativa de potência ativa que está sendo gerada, há também uma injeção considerável de potência reativa, o que causa uma maior variação de tensão devido à maior participação da GD em relação aos outros cenários, de acordo com a equação (10). Foram obtidas 18 variações na posição de tap dos reguladores de tensão $\left(f_{\text {Tap }}\left(i_{\text {Min }}(x)\right)=\right.$ 18), como pode ser observado na Figura 15. 
$\mathrm{Na}$ iteração 29, a melhor solução não foi melhorada e na iteração 37 a nova população gerada também não obteve um indivíduo melhor, então o método foi encerrado. A função objetivo obtida foi $f_{\text {objetivo }}\left(i_{\text {Min }}(x)\right)=6,7215 \cdot 10^{5}$. Na Figura 16 é possível observar que ocorreu violação de tensão após a desconexão da GD entre as horas 19 e 22, sendo observada tensão de 0,8914 na barra 12. Contudo, antes da desconexão ou após a reconexão da GD não ocorrem violações de tensão em nenhum momento ao longo do dia.

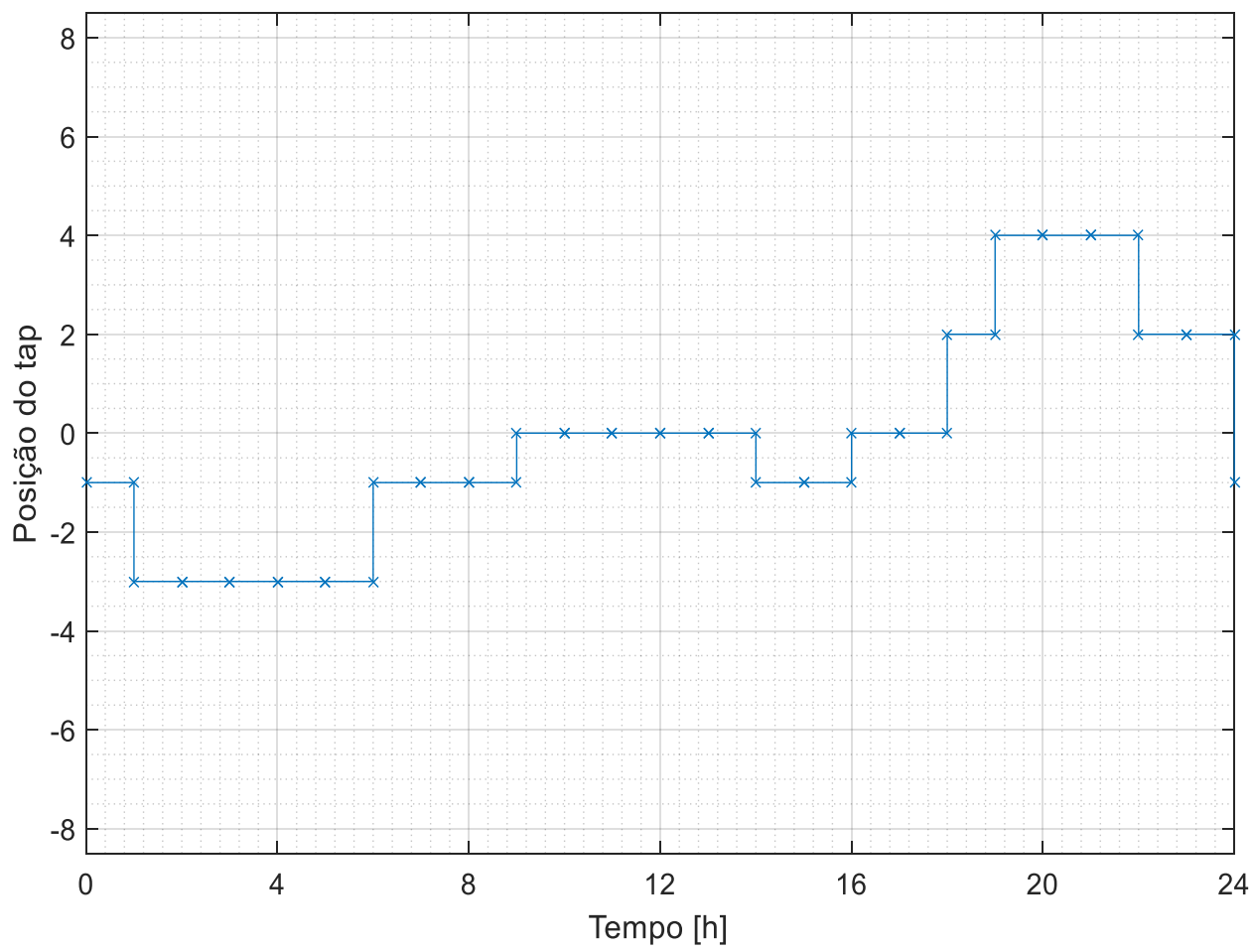

Figura 15 - Posições de tap obtidas pela otimização ao longo de um dia típico, representando por uma curva de carga residencial no Cenário 4. 


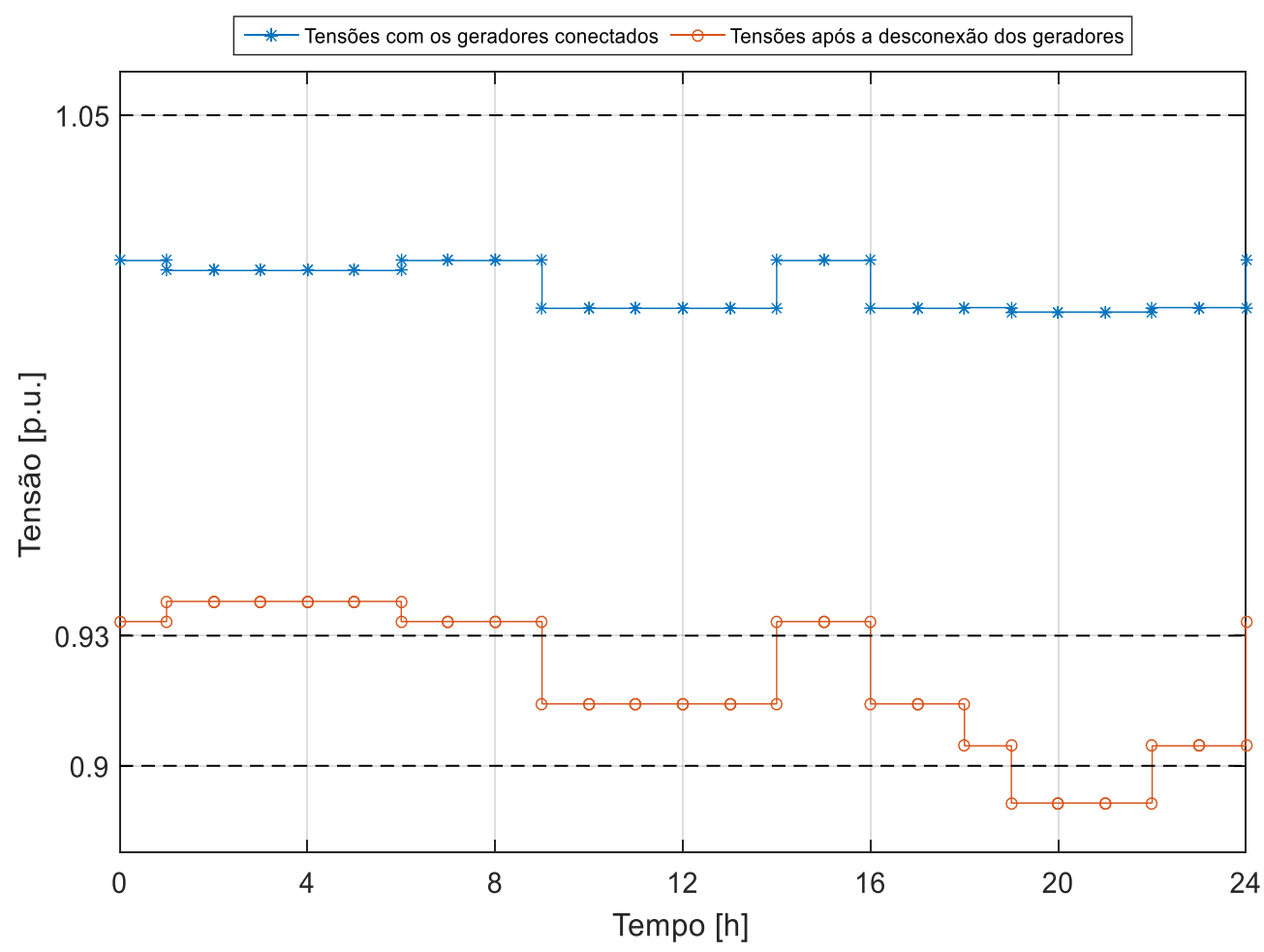

Figura 16 - As tensões com e sem a GD conectada na barra 12 ao longo de um dia típico, representando por uma curva de carga residencial no Cenário 4.

\subsubsection{Cenário 5}

No Cenário 5, os geradores estão operando em modo de controle da tensão terminal, injetando 2,3 MW e mantendo a tensão do PAC em 1,0 p.u.. As violações de tensão foram eliminadas, com ou sem a GD conectada $\left(f_{\text {Desconexão }}\left(i_{\text {Min }}(x)\right)=f_{\text {Penalidade }}\left(i_{\text {Min }}(x)\right)=0\right)$. Os reguladores de tensão mudam suas posições de tap 4 vezes ao longo do dia $\left(f_{\text {Tap }}\left(i_{\text {Min }}(x)\right)=4\right)$, como pode ser observado na Figura 17.

O método não encontrou solução melhor na iteração 32 . Na iteração 33, com a nova população inicial, também não houve melhora, então o método foi encerrado. A função objetivo obtida foi $f_{\text {Objetivo }}\left(i_{\text {Min }}(x)\right)=0,0004$. Na Figura 18, é possível observar um perfil diferente de tensão que nos outros cenários, variando pouco com a GD conectada e variando bastante após a sua desconexão. Como a GD está controlando a tensão em seu PAC, a tensão ao longo do dia oscilou menos. Foi observada grande oscilação na tensão ao longo do dia nos instantes após a desconexão da GD. Mesmo com essas grandes variações sem a GD, não ocorrem violações de tensão após a desconexão da GD. 


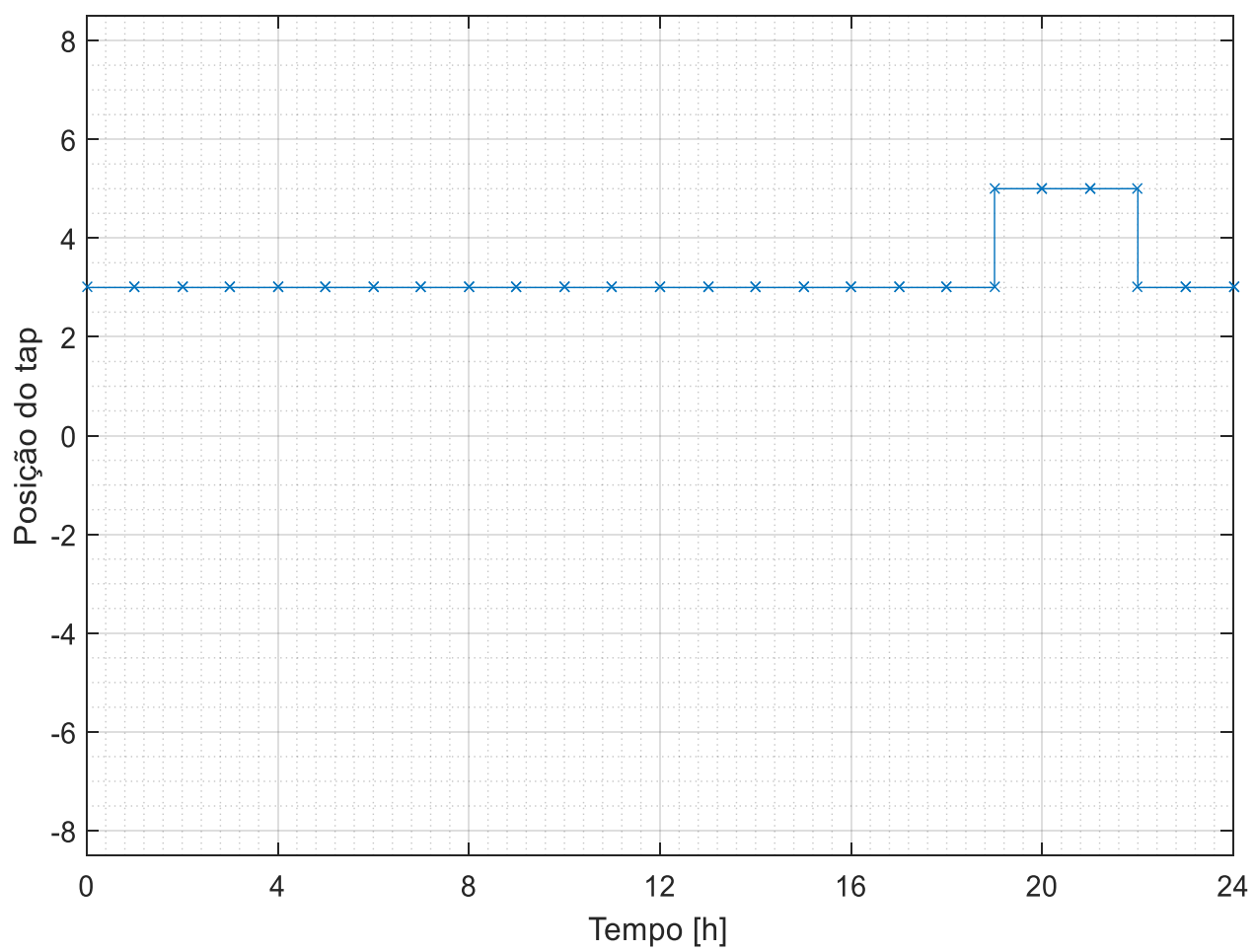

Figura 17 - Posições de tap obtidas pela otimização ao longo de um dia típico, representando por uma curva de carga residencial no Cenário 5.

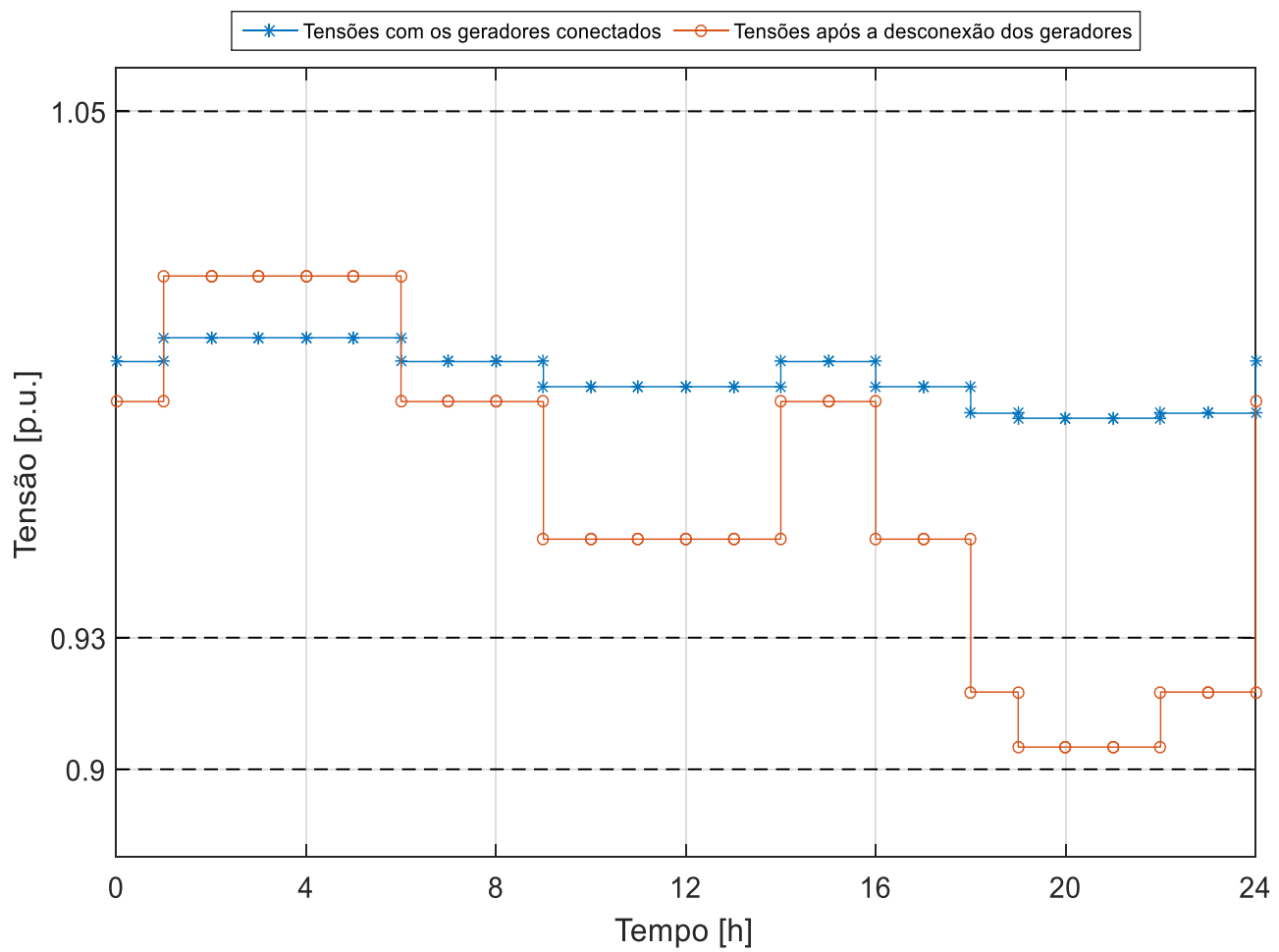

Figura 18 - As tensões com e sem a GD conectada na barra 12 ao longo de um dia típico, representando por uma curva de carga residencial no Cenário 5. 


\subsubsection{Cenário 6}

No Cenário 6 os geradores injetam cada um 4,6 MW e mantêm a tensão do PAC em 1 p.u., operando em CT. Nesse cenário, as violações de tensão, com ou sem a GD, também foram eliminadas $\left(f_{\text {Desconexão }}\left(i_{\text {Min }}(x)\right)=f_{\text {Penalidade }}\left(i_{\text {Min }}(x)\right)=0\right)$ e são necessárias 2 mudanças de $\operatorname{tap}\left(f_{\text {Tap }}\left(i_{\text {Min }}(x)\right)=2\right)$ ao longo do dia, como pode ser observado na Figura 19.

Na iteração 27, não ocorreu melhora no indivíduo mais apto. Na iteração 30 a nova população não gerou uma solução melhor, então o método foi encerrado. A função objetivo obtida foi $f_{\text {objetivo }}\left(i_{\text {Min }}(x)\right)=0,0002$. Na Figura 20, observa-se o mesmo fenômeno na tensão que ocorrida no Cenário 5, pois a GD também está controlando a tensão em seu PAC. A tensão com a GD é estável ao longo do dia, e caso ocorra desconexão ou reconexão da GD nenhuma violação ocorre.

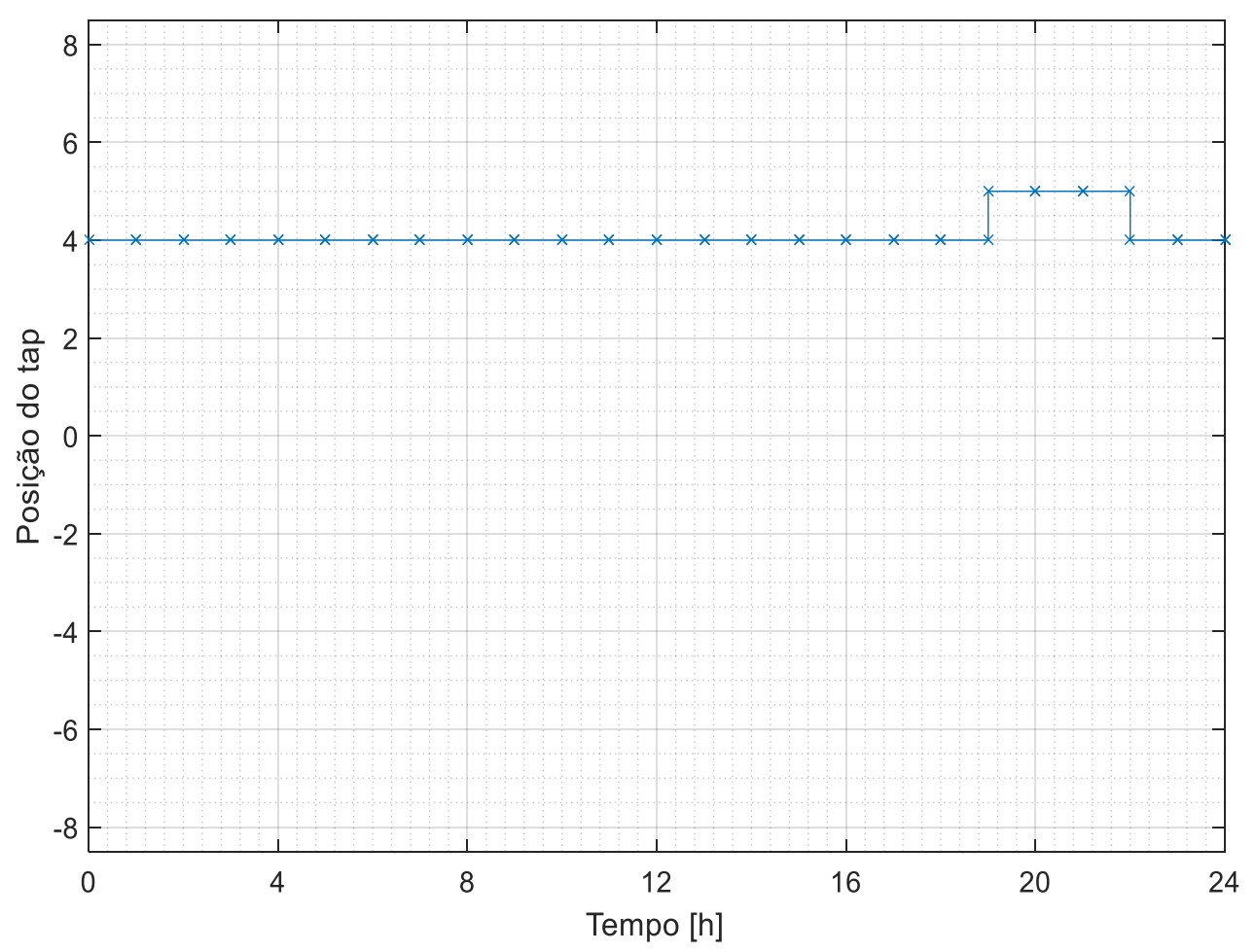

Figura 19 - Posições de tap obtidas pela otimização ao longo de um dia típico, representando por uma curva de carga residencial no Cenário 6. 


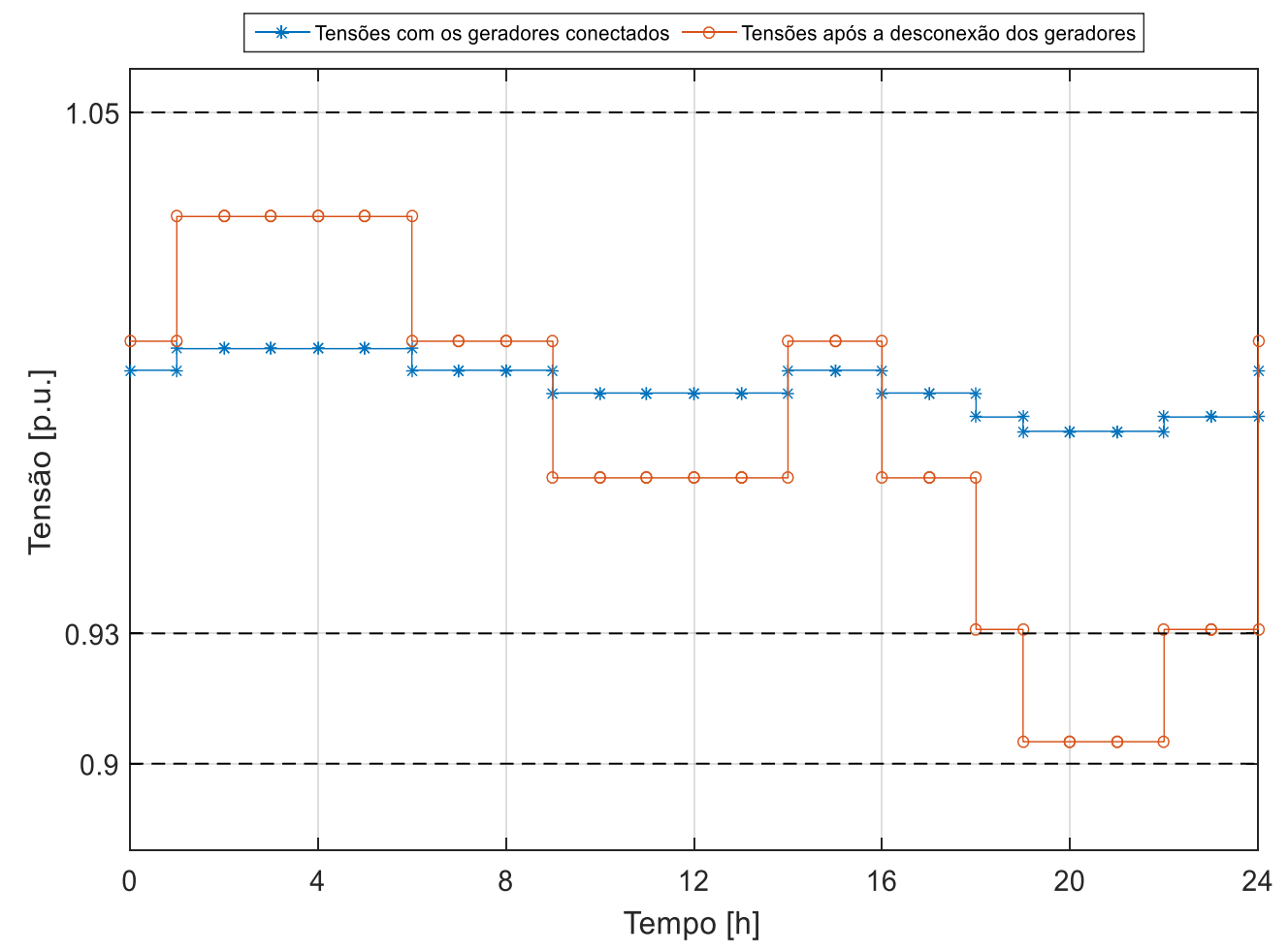

Figura 20 - As tensões com e sem a GD conectada na barra 12 ao longo de um dia típico, representando por uma curva de carga residencial no Cenário 6.

\subsubsection{Considerações Finais sobre os resultados obtidos no Sistema 1}

Observando os resultados obtidos para todos os cenários no Sistema 1, resumidos na Tabela 10, é possível observar que o método proposto conseguiu determinar com sucesso posições de tap dos reguladores de tensão para um dia inteiro que minimizem a ocorrência de violações de tensão com a GD conectada, após sua desconexão e ainda posteriormente em sua reconexão. As soluções obtidas resolveram satisfatoriamente a minimização das violações de tensão. O único cenário em que ocorrem violações aos a desconexão da GD foi o Cenário 4, porém, resultados anteriormente obtidos [77] já indicavam que para esse cenário, quando o consumo do sistema é máximo, é impossível evitar que ocorram violações de tensão após a desconexão da GD, mantendo a tensão antes da desconexão da GD dentro dos limites escolhidos. 
Tabela 10 Comparação dos resultados obtidos para o Sistema1.

\begin{tabular}{ccccccc}
\hline Funções objetivo & \multicolumn{7}{c}{ Cenário } \\
& $\mathbf{1}$ & $\mathbf{2}$ & $\mathbf{3}$ & $\mathbf{4}$ & $\mathbf{5}$ & $\mathbf{6}$ \\
$\boldsymbol{f}_{\text {Desconexão }}\left(\boldsymbol{i}_{\text {Min }}(\boldsymbol{x})\right)$ & 0 & 0 & 0 & 6,7215 & 0 & 0 \\
$\boldsymbol{f}_{\text {Tap }}\left(\boldsymbol{i}_{\text {Min }}(\boldsymbol{x})\right)$ & 4 & 6 & 8 & 18 & 4 & 2 \\
$\boldsymbol{f}_{\text {Penalidade }}\left(\boldsymbol{i}_{\text {Min }}(\boldsymbol{x})\right)$ & 0 & 0 & 0 & 0 & 0 & 0 \\
$\boldsymbol{f}_{\text {Objetivo }}\left(\boldsymbol{i}_{\text {Min }}(\boldsymbol{x})\right)$ & 0,0004 & 0,0006 & 0,0008 & $6,7215 \cdot 10^{5}$ & 0,0004 & 0,0002 \\
\hline
\end{tabular}

\subsection{Sistema IEEE 34 barras}

O SD IEEE 34 barras foi originalmente criado em $1992 \mathrm{com}$ a finalidade de avaliar e servir de referência para algoritmos que resolvam fluxo de potência de sistemas radiais e desbalanceados [78]. Esse SD é baseado em um sistema real localizado no Arizona (EUA), com a tensão nominal de $24,9 \mathrm{kV}$. O sistema é longo, apresenta baixo carregamento, possui dois reguladores de tensão que controlam as fases separadamente, um transformador que reduz a tensão em seção para $4,16 \mathrm{kV}$, cargas desbalanceadas, trechos de linha monofásica e dois bancos de capacitores. Os reguladores de tensão utilizados possuem 33 posições possíveis de tap, sendo que cada tap ajusta o valor de tensão em 0,00625 p.u.. A topologia do sistema pode ser observada na Figura 21 e as informações do SD original relacionadas aos tipos de cabos, comprimento das linhas, parâmetros dos reguladores de tensão, das cargas e dos bancos de capacitores são apresentados entre as Tabela 11 a Tabela 17 Cargas distribuídas.. O sistema foi modelado no software OpenDSS [79], sendo que nele é necessário que as cargas distribuídas ao longo das linhas sejam concentradas nas pontas e no meio das linhas, pois essa é a maneira que o software modela cargas distribuídas. Usar o OpenDSS em conjunto com o Matlab permitiu calcular diversos fluxos de potência importantes para o método de maneira simplificada e eficiente.

Algumas mudanças foram feitas no sistema, para assim permitir cenários em que a variação de tensão causada pela desconexão da GD cause problemas de QEE. A carga localizada na barra 890 foi concentrada na barra em que o transformador redutor XFM-1 está localizado (barra 832), no lado de alta. Os reguladores de tensão foram modificados para regular a tensão em seus respectivos barramentos (814 para o Regulador 1 e 852 
para o Regulador 2), pois a adição da GD poderia afetar o seu funcionamento pelo método tradicional de regulação da tensão, uma vez que o método não considera a potência injetada pela GD. O transformador localizado na subestação foi alterado para um regulador de tensão, permitindo assim maior flexibilidade na operação do IEEE 34 barras com diferentes níveis de carregamento. Todas as cargas foram modificadas para manter a potência ativa e reativa consumidas constantes e, como o sistema apresenta baixo carregamento, a carga da barra 840 foi aumentada para $270 \mathrm{~kW}$ e $131 \mathrm{kVAr}$, sendo ela equilibrada nas três fases. Por fim, foram adicionados geradores conectados diretamente nas barras 840, 844 e 848, que representam injeção de potência no SD, podendo representar qualquer tipo de gerador para o problema estudado. Em cada cenário considerado, os geradores possuem valores de potência nominal diferente. Nessa pesquisa, são considerados geradores com diferentes capacidades e características, permitindo assim uma maior empregabilidade de método proposto. Quando o consumo é máximo, a potência ativa consumida no SD é de $2333 \mathrm{~kW}$ e a potência reativa consumida é de 421 kvar.

Tabela 11 Configuração dos cabos.

\begin{tabular}{ccccc}
\hline Configuração & Fases & Fase ACSR & Neutro ACSR & $\begin{array}{c}\text { Tipo de } \\
\text { Espaçamento }\end{array}$ \\
300 & B A C N & $1 / 0$ & $1 / 0$ & 500 \\
301 & B A C N & $\# 26 / 1$ & $\# 26 / 1$ & 500 \\
302 & A N & $\# 46 / 1$ & $\# 46 / 1$ & 510 \\
303 & B N & $\# 46 / 1$ & $\# 46 / 1$ & 510 \\
304 & B N & $\# 26 / 1$ & $\# 26 / 1$ & 510 \\
\hline
\end{tabular}

Tabela 12 Parâmetros dos transformadores.

\begin{tabular}{cccccc}
\hline Localização & [kVA] & Alta [kV] & Baixa [kV] & R [\%] & X [\%] \\
Subestação & 2500 & 250 & $24,9-$ Estrela aterrada & 1,00 & 8,00 \\
XFM-1 & 500 & $24,9-$ Estrela aterrada & $4,16-$ Estrela aterrada & 1,90 & 4,08 \\
\hline
\end{tabular}


Tabela 13 Parâmetros dos segmentos de linha.

\begin{tabular}{|c|c|c|c|}
\hline Barra A & Barra B & Comprimento [ft] & Configuração \\
\hline 800 & 802 & 2580 & 300 \\
\hline 802 & 806 & 1730 & 300 \\
\hline 806 & 808 & 32230 & 300 \\
\hline 808 & 810 & 5804 & 303 \\
\hline 808 & 812 & 37500 & 300 \\
\hline 812 & 814 & 29730 & 300 \\
\hline 814 & 850 & 10 & 301 \\
\hline 816 & 818 & 1710 & 302 \\
\hline 816 & 824 & 10210 & 301 \\
\hline 818 & 820 & 48150 & 302 \\
\hline 820 & 822 & 13740 & 302 \\
\hline 824 & 826 & 3030 & 303 \\
\hline 824 & 828 & 840 & 301 \\
\hline 828 & 830 & 20440 & 301 \\
\hline 830 & 854 & 520 & 301 \\
\hline 832 & 858 & 4900 & 301 \\
\hline 832 & 888 & 0 & XFM-1 \\
\hline 834 & 860 & 2020 & 301 \\
\hline 834 & 842 & 280 & 301 \\
\hline 836 & 840 & 860 & 301 \\
\hline 836 & 862 & 280 & 301 \\
\hline 842 & 844 & 1350 & 301 \\
\hline 844 & 846 & 3640 & 301 \\
\hline 846 & 848 & 530 & 301 \\
\hline 850 & 816 & 310 & 301 \\
\hline 852 & 832 & 10 & 301 \\
\hline 854 & 856 & 23330 & 303 \\
\hline 854 & 852 & 36830 & 301 \\
\hline 858 & 864 & 1620 & 302 \\
\hline 858 & 834 & 5830 & 301 \\
\hline 860 & 836 & 2680 & 301 \\
\hline 862 & 838 & 4860 & 304 \\
\hline
\end{tabular}

Tabela 14 Bancos de Capacitores.

\begin{tabular}{cccc}
\hline Barra & $\begin{array}{c}\text { Fase A } \\
{[\text { kvar] }}\end{array}$ & $\begin{array}{c}\text { Fase B } \\
{[\text { kvar] }}\end{array}$ & $\begin{array}{c}\text { Fase C } \\
{[\mathrm{kvar}]}\end{array}$ \\
844 & 100 & 100 & 100 \\
848 & 150 & 150 & 150 \\
Total & 250 & 250 & $\mathbf{2 5 0}$ \\
\hline
\end{tabular}


Tabela 15 Cargas concentradas.

\begin{tabular}{cccccccc}
\hline \multirow{2}{*}{ Barra } & \multirow{2}{*}{ Conexão / Modelo } & \multicolumn{2}{c}{ Fase A } & \multicolumn{2}{c}{ Fase B } & \multicolumn{2}{c}{ Fase C } \\
& [kW] & {$[\mathrm{kvar}]$} & {$[\mathrm{kW}]$} & {$[\mathrm{kvar}]$} & {$[\mathrm{kW}]$} & [kvar] \\
860 & Estrela / PQ & 20 & 16 & 20 & 16 & 20 & 16 \\
840 & Estrela / I & 9 & 7 & 9 & 7 & 9 & 7 \\
844 & Estrela / Z & 135 & 105 & 135 & 105 & 135 & 105 \\
848 & Delta / PQ & 20 & 16 & 20 & 16 & 20 & 16 \\
890 & Delta / I & 150 & 75 & 150 & 75 & 150 & 75 \\
830 & Delta / Z & 10 & 5 & 10 & 5 & 25 & 10 \\
Total & & 344 & $\mathbf{2 2 4}$ & 344 & $\mathbf{2 2 4}$ & 359 & 229 \\
\hline
\end{tabular}

Tabela 16 Parâmetros dos reguladores de tensão.

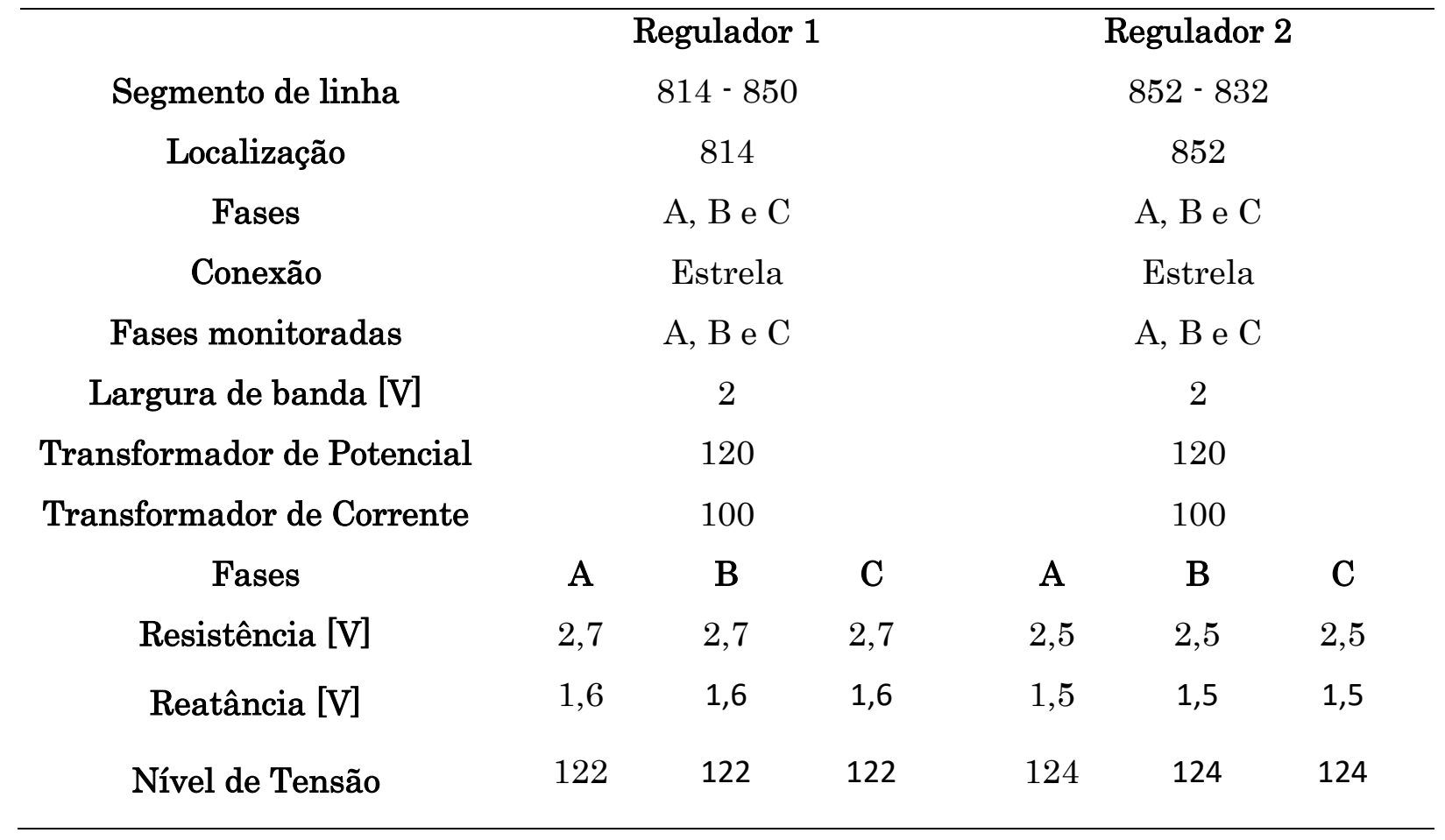


Tabela 17 Cargas distribuídas.

\begin{tabular}{|c|c|c|c|c|c|c|c|c|}
\hline Barra & Barra & Conexão / & \multicolumn{2}{|c|}{ Fase A } & \multicolumn{2}{|c|}{ Fase B } & \multicolumn{2}{|c|}{ Fase C } \\
\hline $\mathrm{A}$ & B & Modelo & {$[\mathrm{kW}]$} & [kvar] & [kW] & [kvar] & {$[\mathrm{kW}]$} & [kvar] \\
\hline 802 & 806 & Estrela / PQ & 0 & 0 & 30 & 15 & 25 & 14 \\
\hline 808 & 810 & Estrela / I & 0 & 0 & 16 & 8 & 0 & 0 \\
\hline 818 & 820 & Estrela / Z & 34 & 17 & 0 & 0 & 0 & 0 \\
\hline 820 & 822 & Estrela / PQ & 135 & 70 & 0 & 0 & 0 & 0 \\
\hline 816 & 824 & Delta / I & 0 & 0 & 5 & 2 & 0 & 0 \\
\hline 824 & 826 & Estrela / I & 0 & 0 & 40 & 20 & 0 & 0 \\
\hline 824 & 828 & Estrela / PQ & 0 & 0 & 0 & 0 & 4 & 2 \\
\hline 828 & 830 & Estrela / PQ & 7 & 3 & 0 & 0 & 0 & 0 \\
\hline 854 & 856 & Estrela / PQ & 0 & 0 & 4 & 2 & 0 & 0 \\
\hline 832 & 858 & Delta / Z & 7 & 3 & 2 & 1 & 6 & 3 \\
\hline 858 & 864 & Estrela / PQ & 2 & 1 & 0 & 0 & 0 & 0 \\
\hline 858 & 834 & Delta / PQ & 4 & 2 & 15 & 8 & 13 & 7 \\
\hline 834 & 860 & Delta / Z & 16 & 8 & 20 & 10 & 110 & 55 \\
\hline 860 & 836 & Delta / PQ & 30 & 15 & 10 & 6 & 42 & 22 \\
\hline 836 & 840 & Delta / I & 18 & 9 & 22 & 11 & 0 & 0 \\
\hline 862 & 838 & Estrela / PQ & 0 & 0 & 28 & 14 & 0 & 0 \\
\hline 842 & 844 & Estrela / PQ & 9 & 5 & 0 & 0 & 0 & 0 \\
\hline 844 & 846 & Estrela / PQ & 0 & 0 & 25 & 12 & 20 & 11 \\
\hline 846 & 848 & Estrela / PQ & 0 & 0 & 23 & 11 & 0 & 0 \\
\hline Total & & & 262 & 133 & 240 & 120 & 220 & 114 \\
\hline
\end{tabular}

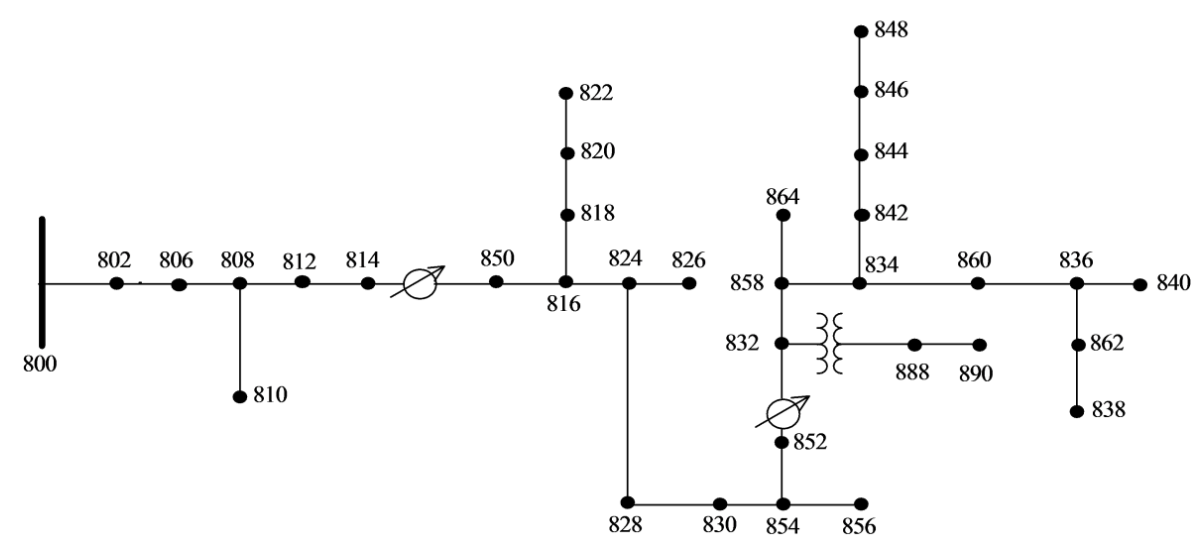

Figura 21 - Topologia do IEEE 34 barras. 


\subsubsection{Resultados obtidos no Sistema IEEE 34 barras}

O sistema IEEE 34 barras foi utilizado para realizar análises de sensibilidade no método. O sistema possui dois reguladores de tensão que regulam as fases independentemente uma da outra, o que é necessário, pois o sistema é altamente desiquilibrado. O sistema é longo, característica que aumenta as quedas de tensão ao longo das linhas, tornando a eliminação das violações de tensão causadas pela desconexão e reconexão da GD um problema ainda mais difícil de ser resolvido. Existe um modelo disponível do sistema no OpenDSS, que possui interface com o Matlab. Essas características facilitaram o seu uso nesta pesquisa.

Assim como no Sistema 1, foram considerados diversos cenários de operação, sendo eles:

Cenário 1. Geradores operando em modo de controle de fator de potência (CFP). O geradores nas barras 840, 844 e 848, geram, respectivamente $400 \mathrm{~kW}, 300 \mathrm{~kW}$ e $300 \mathrm{~kW}$.

Cenário 2. Sem geradores conectados ao sistema.

Cenário 3. Similar ao Cenário 1, porém utilizando uma curva de carga aproximada em 5 patamares de carga.

Cenário 4. Similar ao Cenário 1, porém utilizando uma curva de carga aproximada em 10 patamares de carga.

Cenário 5. Geradores operando em modo de controle de fator de potência (CFP). O geradores nas barras 840, 844 e 848, geram, respectivamente $400 \mathrm{~kW}$ e 131,5 kvar, $300 \mathrm{~kW}$ e 98,6 kvar e, por fim, $300 \mathrm{~kW}$ e $98,6 \mathrm{kvar}$.

Cenário 6. Geradores operando em modo de controle de tensão (CT), mantendo a tensão em 1 p.u.. O geradores nas barras 840, 844 e 848, geram, respectivamente $400 \mathrm{~kW}, 300 \mathrm{~kW}$ e $300 \mathrm{~kW}$.

O Cenário 1 foi utilizado como base para comparar o desempenho do método nos outros cenários. Quando o sistema está consumindo a carga máxima, neste cenário os geradores geram metade da potência ativa consumida pelas cargas. O Cenário 2 permitiu avaliar o método em seu cenário mais simples, sem GD adicionada nele. Os Cenários 3 e 4 mostram o impacto no método de aproximar a curva de carga para patamares, aproximando em 5 no Cenário 3 e 10 no Cenário 4. No Cenário 5, os geradores injetam potência reativa, aumentando a variação de tensão e dificultando a resolução do 
problema pelo método proposto. Os geradores controlaram a tensão em seus PAC no Cenário 6. Em todos os cenários são feitas comparações do método tradicional de controle de tensão dos reguladores de tensão para regular a tensão em seus respectivos barramentos, com o método proposto. As funções objetivo também foram aplicadas nas posições de tap dos reguladores de tensão quando o regulador opera pelo método tradicional, regulando a tensão da barra de seu secundário ao longo do dia. O método tradicional consiste na regulação da tensão na barra em que o regulador de tensão está conectado ou utilizando a compensação de queda de tensão na linha (line drop compensation) [80]. Nesta pesquisa, será considerada regulação tradicional quando o regulador de tensão regula a tensão na barra em que ele está conectado, tendo como parâmetros a tensão de referência (1,02 p.u.) e a banda morta (0,02 p.u.) . Com esses valores da função objetivo pelo método tradicional, é possível comparar as soluções obtidas para o problema utilizando o método proposto ou o método tradicional de regular a barra do secundário. Para o método tradicional, por não existirem iterações $(x)$ nem melhor solução $i_{\text {Min }}(x)$, as posições de tap obtidas em sua operação são usadas para realizar os cálculos de fluxo de potência.

Os mesmos limites de tensão utilizados no Sistema 1 foram utilizados no IEEE 34 barras $\left(L_{C o m G D \text { min }}=0,93, L_{\text {Com GD máx }}=1,05, L_{S e m G D \text { min }}=0,90\right.$ e $\left.L_{S e m ~ G D \text { máx }}=1,05\right)$. Foi utilizada a mesma curva de carga residencial [76] utilizada no Sistema 1 para representar um dia típico, sendo que algumas outras cargas foram escolhidas para possuírem curva de carga comercial ou um dos três diferentes tipos de curva de carga industrial disponível em [76], apresentadas na Figura 22. Foram escolhidas as maiores cargas concentradas (Tabela 15) para possuírem um perfil de consumo diferente, como pode ser observado na Tabela 18. As curvas de carga foram discretizadas em 24 pontos para todos os cenários.

Tabela 18 Barras que possuem perfil de consumo diferente do Residencial.

\begin{tabular}{cc}
\hline Barra & Perfil de consumo \\
840 & Industrial 1 \\
844 & Industrial 2 \\
860 & Industrial 3 \\
848 & Industrial 3 \\
890 & Comercial \\
\hline
\end{tabular}


Nos resultados a seguir, serão apresentadas as tensões trifásicas na barra 840, com e sem a GD conectada, pois essa barra possui o maior gerador conectado e, portanto, a maior variação de tensão no sistema ocorre nessa barra após a desconexão da GD. Observar a tensão nesta barra não garante que não há violações de tensão ao longo de todo o sistema, porém ela foi escolhida para padronizar a apresentação dos resultados. Quando não ocorrem violações de tensão no sistema inteiro com a GD conectada, a função $f_{\text {Penalidade }}(i)$ é zerada, e quando não há violações de tensão em todas as barras do sistema após a desconexão da GD, a função $f_{\text {Desconexão }}(i)$ é zerada.

Como cada um dos dois reguladores de tensão controla as fases de maneira independente, o método terá que escolher posições de tap para cada um, como se fossem 6 reguladores de tensão independentes. Ainda, foi adicionado um regulador na saída da subestação, o qual utiliza a mesma posição de tap para as três fases, então o método terá que controlar 7 reguladores de tensão no total. Nos resultados a seguir, os reguladores de tensão foram denominados de acordo com a Tabela 19, atribuindo-lhes um índice para a sua representação matemática. Os reguladores "1A", "1B", e "1C" estão localizados na barra 814 e cada um regula uma de suas respectivas fases. Os reguladores " $2 \mathrm{~A}$ ", "2B", e " $2 \mathrm{C}$ " estão localizados na barra 852 e também regulam suas respectivas fases. O regulador "tsub" está localizado na subestação, a barra 800, e regula as três fases juntas, usando uma mesma posição de tap para as três fases.

Tabela 19 Denominação dos reguladores de tensão nos gráficos e suas respectivas representações na modelagem matemática empregada.

\begin{tabular}{ccc}
\hline $\boldsymbol{R}$ & Denominação \\
1 & $1 \mathrm{~A}$ \\
2 & $1 \mathrm{~B}$ \\
3 & $1 \mathrm{C}$ \\
4 & $2 \mathrm{~A}$ \\
5 & $2 \mathrm{~B}$ \\
6 & $2 \mathrm{C}$ \\
7 & tsub \\
\hline
\end{tabular}


(a) Perfil Residencial

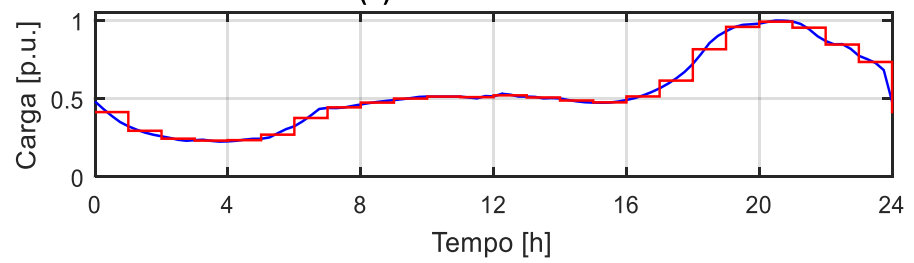

(b) Perfil Comercial

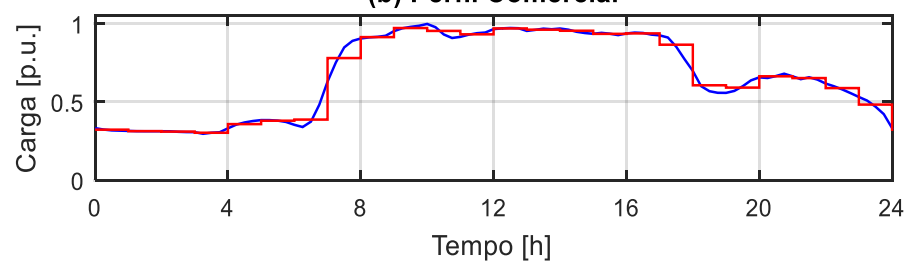

(c) Perfil Industrial 1

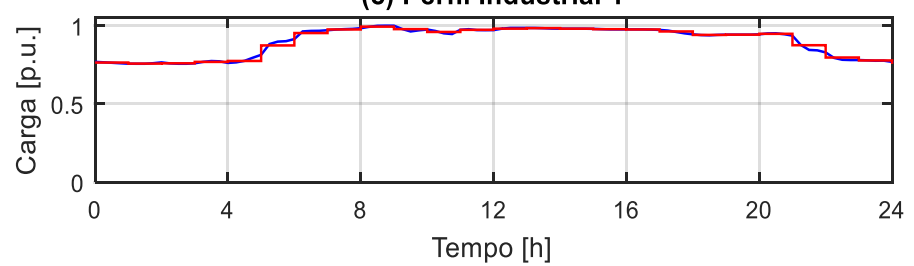

(d) Perfil Industrial 2

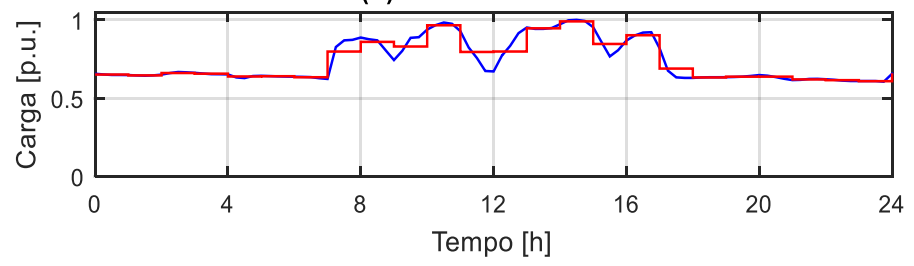

(e) Perfil Industrial 3

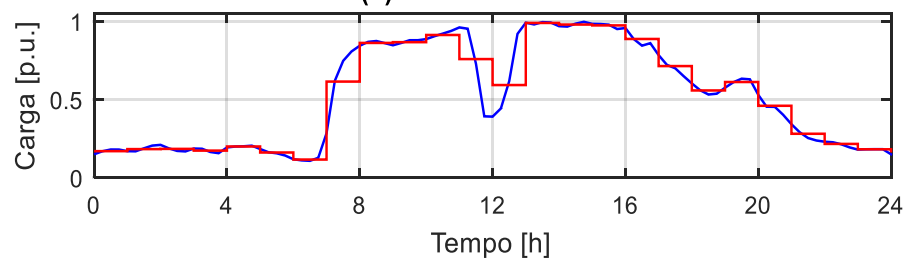

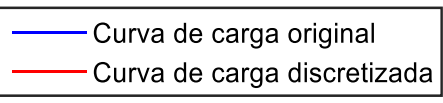

- Curva de carga original Curva de carga discretizada

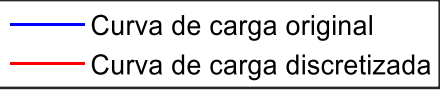

Curva de carga original Curva de carga discretizada

- Curva de carga original Curva de carga discretizada

Figura 22 - Comparação entre as curvas de carga originais e as curvas discretizadas.

Devido ao maior esforço computacional para aplicar o método em um sistema com muitos regulares de tensão, optou-se por reduzir o número de indivíduos da população do AG para 200. Em torneios de 4 indivíduos escolhidos ao acaso, foram selecionados 60 indivíduos para a reprodução. As duas melhores soluções foram mantidas para a próxima iteração. As chances de mutação foram as mesmas para o Sistema 1: 0,15\% para a mutação com valor completamente aleatório e $0,30 \%$ para a mutação que varia um valor entre -3 e 3 . Os pesos das funções objetivos também são os mesmos, sendo eles $\omega_{\text {Desconexão }}=10^{5}, \omega_{\text {Penalidade }}=10^{8}$ e $\omega_{\text {Tap }}=10^{-4}$. 


\subsubsection{Cenário 1}

No Cenário 1, a GD tem uma grande participação no sistema. Os geradores operam com fator de potência unitário, que é a situação mais comum e a mais desejada pelos autoprodutores. Os resultados obtidos para esse cenário, utilizando o método proposto e a regulação tradicional no secundário do regulador de tensão, são apresentados na Tabela 20. É possível observar que o método proposto conseguiu eliminar as violações de tensão antes da desconexão e após a reconexão da GD para todas as barras no sistema $\left(f_{\text {Desconexão }}\left(i_{\text {Min }}(x)\right)=f_{\text {Penalidade }}\left(i_{\text {Min }}(x)\right)=0\right)$, ao passo que a regulação tradicional não conseguiu evitar violações de tensão em nenhum dos casos $\left(f_{\text {Desconexão }}\left(i_{\text {Min }}(x)\right)=\right.$ 24,3986 e $\left.f_{\text {Penalidade }}\left(i_{\text {Min }}(x)\right)=3,5721\right)$. Ocorreu uma diminuição nas mudanças totais, considerando os 7 reguladores de tensão ao longo do dia e as três fases, de $f_{\text {Tap }}\left(i_{\text {Min }}(x)\right)=$ 86 para $f_{\text {Tap }}\left(i_{\text {Min }}(x)\right)=36$.

$\mathrm{Na}$ segunda iteração, não foi obtida melhor solução do que a da primeira iteração. Após a nova população inicial ser criada, por cerca de cinquenta iterações o método conseguiu encontrar soluções melhores, alternando entre soluções obtidas por cruzamento ou por uma população nova até que o método foi encerrado na iteração 190 . Na Figura 23, observa-se as posições de tap obtidas para os reguladores de tensão ao longo de um dia típico. Foi observado que o regulador localizado na subestação ("tsub") operou mais vezes para regular a tensão no sistema. A Figura 24 apresenta as tensões trifásicas na barra 840, com e sem a GD conectada. Observa-se que as tensões estão dentro da faixa de tensão desejada. 
Tabela 20 Comparação entre o método proposto e a regulação tradicional, no Cenário 1.

\begin{tabular}{|c|c|c|}
\hline & Regulação Tradicional & Método proposto \\
\hline $\boldsymbol{f}_{\text {Desconexão }}\left(\boldsymbol{i}_{\text {Min }}(\boldsymbol{x})\right)$ & 24,3986 & 0 \\
\hline$h_{T a p}\left(i_{M i n}(x), 1\right), " 1 A^{\prime}$ & 4 & 4 \\
\hline$h_{\text {Tap }}\left(i_{\text {Min }}(x), 2\right)$, “1B" & 10 & 0 \\
\hline$h_{T a p}\left(i_{M i n}(x), 3\right)$, “1C" & 10 & 0 \\
\hline$h_{T a p}\left(i_{M i n}(x), 4\right), " 2 A "$ & 12 & 2 \\
\hline$h_{T a p}\left(i_{M i n}(x), 5\right)$, “2B" & 12 & 0 \\
\hline$h_{T a p}\left(i_{M i n}(x), 6\right)$, “3C" & 12 & 2 \\
\hline$h_{\text {Tap }}\left(i_{\text {Min }}(x), 7\right)$, "tsub" & 26 & 28 \\
\hline $\boldsymbol{f}_{\text {Tap }}\left(\boldsymbol{i}_{\text {Min }}(\boldsymbol{x})\right)$ & 86 & 36 \\
\hline$f_{\text {Penalidade }}\left(\boldsymbol{i}_{\text {Min }}(\boldsymbol{x})\right)$ & 3,5721 & 0 \\
\hline$f_{\text {objetivo }}\left(i_{\text {Min }}(x)\right)$ & $3,5965 \cdot 10^{8}$ & 0,0036 \\
\hline
\end{tabular}

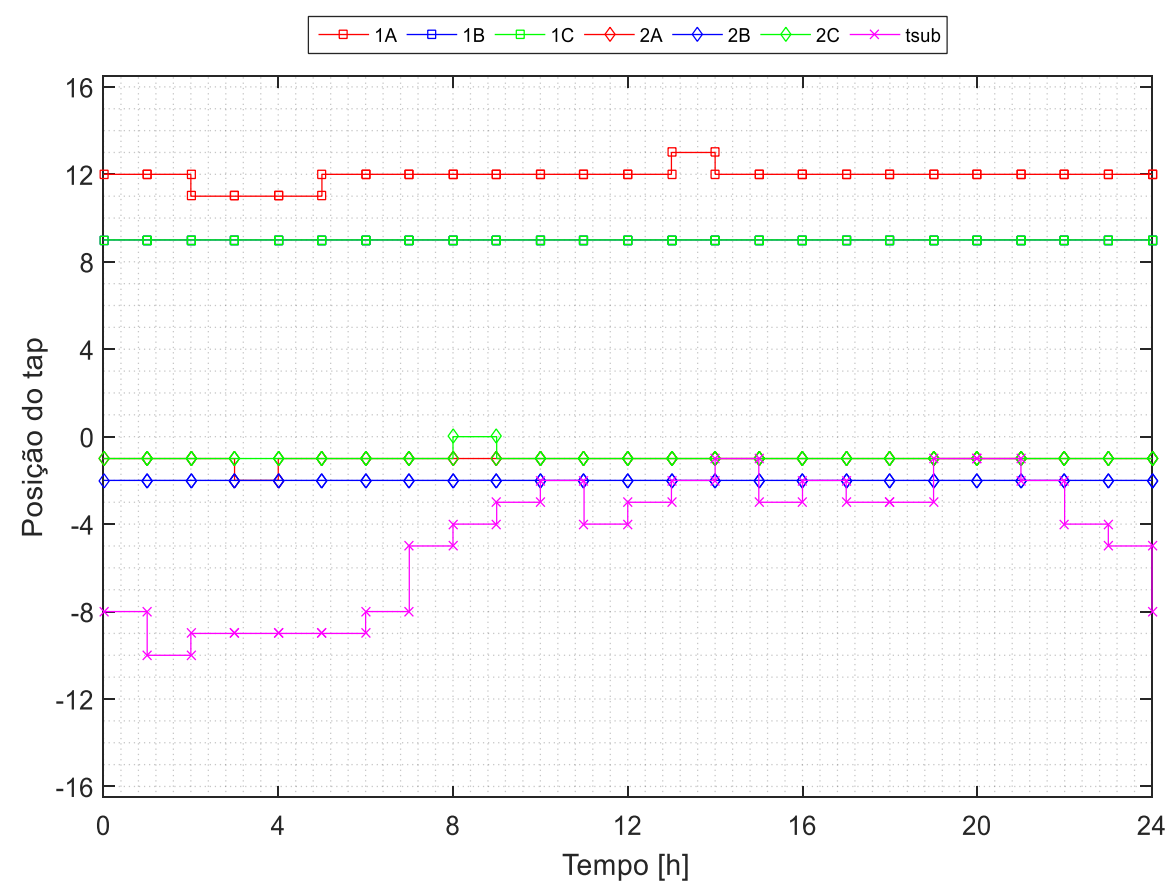

Figura 23 - Posições de tap obtidas pela otimização ao longo de um dia típico para todos os reguladores de tensão, no Cenário 1. 


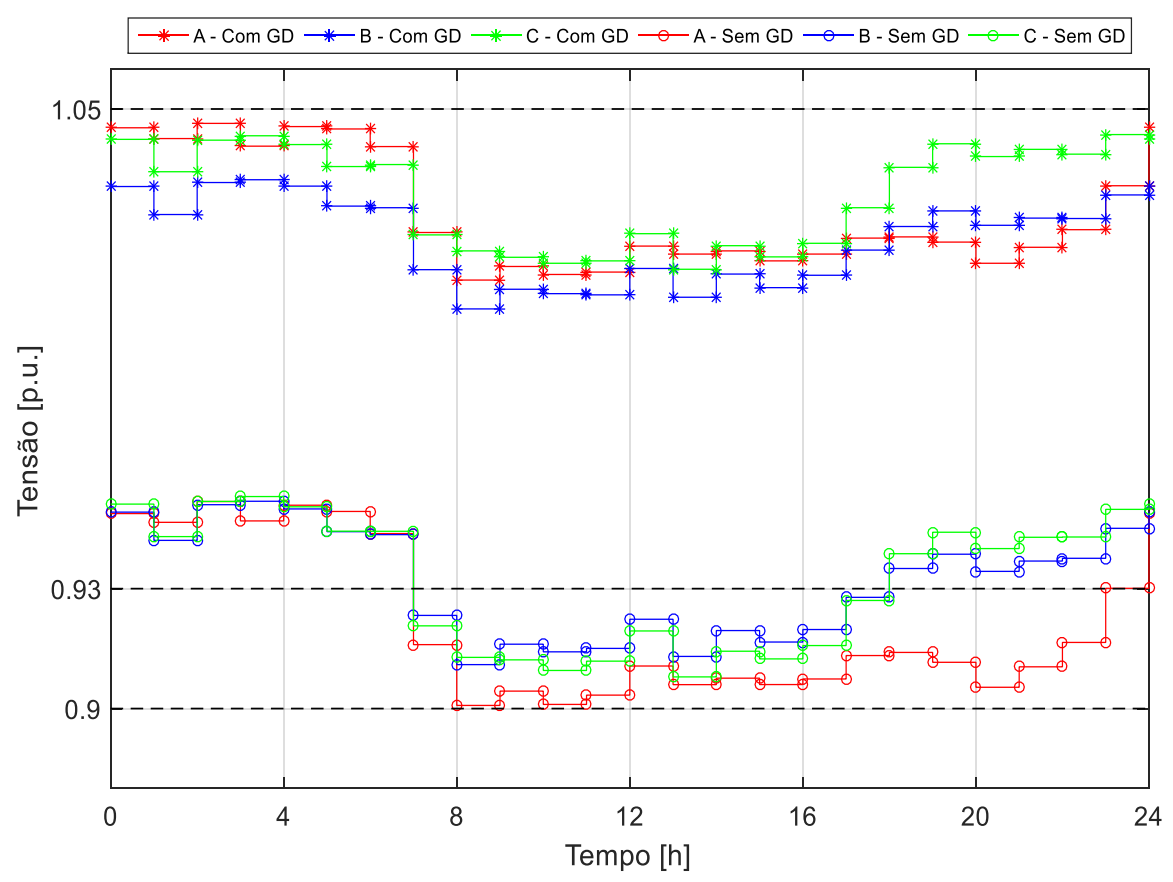

Figura 24 - As tensões trifásicas com e sem a GD conectada na barra 840 ao longo de um dia típico, no Cenário 1.

\subsubsection{Cenário 2}

Apesar de não existirem geradores conectados ao sistema no Cenário 2, o método foi aplicado para avaliar seu desempenho em um cenário mais simples. Nesse cenário foi observado na Tabela 21 que o método conseguiu reduzir as mudanças de posição de tap de $f_{\text {Tap }}\left(i_{\text {Min }}(x)\right)=118$ para $f_{\text {Tap }}\left(i_{\text {Min }}(x)\right)=34$.

Novamente, o método não encontrou solução melhor na segunda iteração, precisando gerar uma nova população inicial. Isso ocorreu diversas vezes, assim o método alternou entre gerar novos indivíduos pelo cruzamento ou gerando uma nova população inicial. Na iteração 153 o método foi encerrado. A Figura 25 apresenta as posições de tap dos reguladores ao longo de um dia típico. As tensões trifásicas na barra 840 são apresentadas na Figura 26. 
Tabela 21 Comparação entre o método proposto e a regulação tradicional, no Cenário 2.

$\begin{array}{ccc}\boldsymbol{f}_{\text {Desconexão }}\left(\boldsymbol{i}_{\text {Min }}(\boldsymbol{x})\right) & \text { Regulação Tradicional } & \text { Método proposto } \\ \boldsymbol{h}_{\text {Tap }}\left(\boldsymbol{i}_{\text {Min }}(\boldsymbol{x}), \mathbf{1}\right), \text { "1A" } & 0 & 0 \\ \boldsymbol{h}_{\text {Tap }}\left(\boldsymbol{i}_{\text {Min }}(\boldsymbol{x}), \mathbf{2}\right), \text { "1B" } & 16 & 4 \\ \boldsymbol{h}_{\text {Tap }}\left(\boldsymbol{i}_{\text {Min }}(\boldsymbol{x}), \mathbf{3}\right), \text { "1C" } & 12 & 0 \\ \boldsymbol{h}_{\text {Tap }}\left(\boldsymbol{i}_{\text {Min }}(\boldsymbol{x}), \mathbf{4}\right), \text { "2A" } & 12 & 4 \\ \boldsymbol{h}_{\text {Tap }}\left(\boldsymbol{i}_{\text {Min }}(\boldsymbol{x}), \mathbf{5}\right), \text { "2B" } & 18 & 4 \\ \boldsymbol{h}_{\text {Tap }}\left(\boldsymbol{i}_{\text {Min }}(\boldsymbol{x}), \mathbf{6}\right), \text { "3C" } & 18 & 2 \\ \boldsymbol{h}_{\text {Tap }}\left(\boldsymbol{i}_{\text {Min }}(\boldsymbol{x}), \mathbf{7}\right), \text { "tsub” } & 18 & 18 \\ \boldsymbol{f}_{\text {Tap }}\left(\boldsymbol{i}_{\text {Min }}(\boldsymbol{x})\right) & 24 & 34 \\ \boldsymbol{f}_{\text {Penalidade }}\left(\boldsymbol{i}_{\text {Min }}(\boldsymbol{x})\right) & 118 & 0 \\ \boldsymbol{f}_{\text {Objetivo }}\left(\boldsymbol{i}_{\text {Min }}(\boldsymbol{x})\right) & 0 & 0,0034\end{array}$

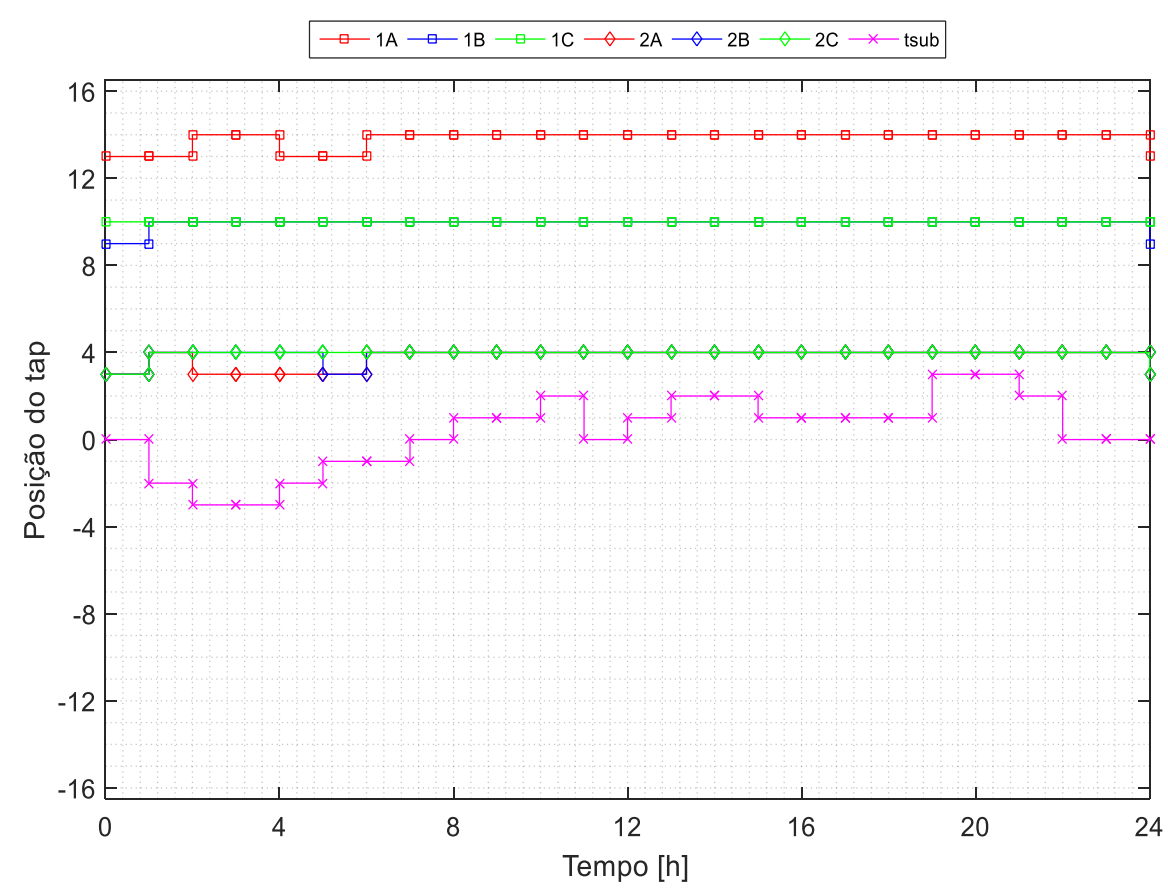

Figura 25 - Posições de tap obtidas pela otimização ao longo de um dia típico para todos os reguladores de tensão, no Cenário 2. 


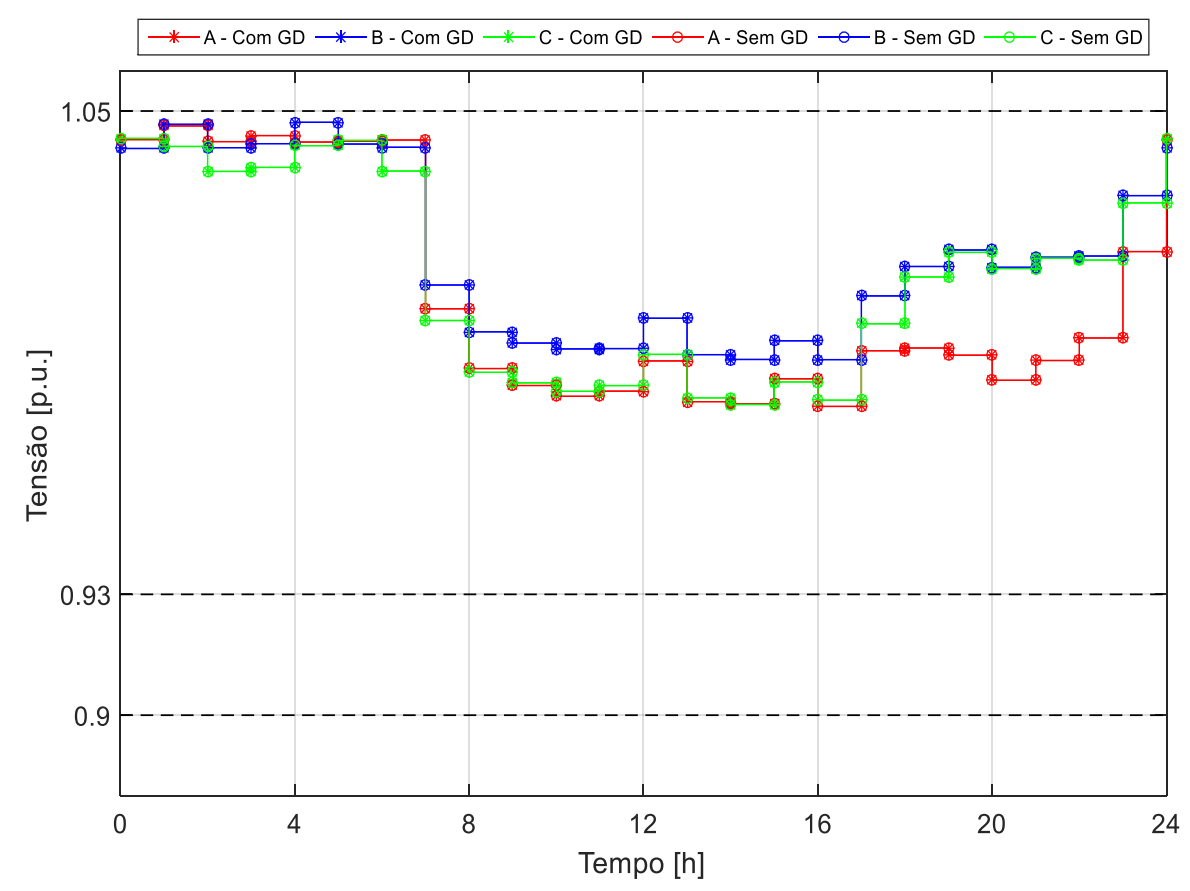

Figura 26 - As tensões trifásicas com e sem a GD conectada na barra 840 ao longo de um dia típico, no Cenário 2.

\subsubsection{3 $\underline{\text { Cenário } 3}$}

Este cenário tem como objetivo analisar a influência da aproximação das curvas de carga em patamares no método. Os geradores operam de maneira similar ao Cenário 1 , sendo que a única diferença são as curvas de carga aproximadas na Figura 27. Foi observada na Tabela 22 uma diferença significativa nas funções objetivo entre os resultados obtidos neste cenário e no Cenário 1, porém, o método conseguiu eliminar as variações de tensão em todo o sistema, com ou sem a GD conectada. Em comparação ao Cenário 1, ocorreu um aumento nas variações de posição dos taps dos reguladores de tensão obtidas pelo método proposto $\left(\operatorname{de} f_{\text {Tap }}\left(i_{\text {Min }}(x)\right)=36\right.$ para $\left.f_{\text {Tap }}\left(i_{\text {Min }}(x)\right)=54\right)$ e também pela regulação tradicional dos reguladores de tensão $\left(\operatorname{de} f_{\text {Tap }}\left(i_{\text {Min }}(x)\right)=86\right.$ para $\left.f_{\text {Tap }}\left(i_{\text {Min }}(x)\right)=108\right)$.

O método teve dificuldade em encontrar melhores soluções apenas por meio do cruzamento, como em AGs tradicionais, porém a nova população inicial introduzida auxiliou na busca da melhor solução. Todas as posições de tap dos reguladores de tensão são apresentadas na Figura 28 e as tensões trifásicas da barra 840 são apresentadas na Figura 29. 
(a) Perfil Residencial

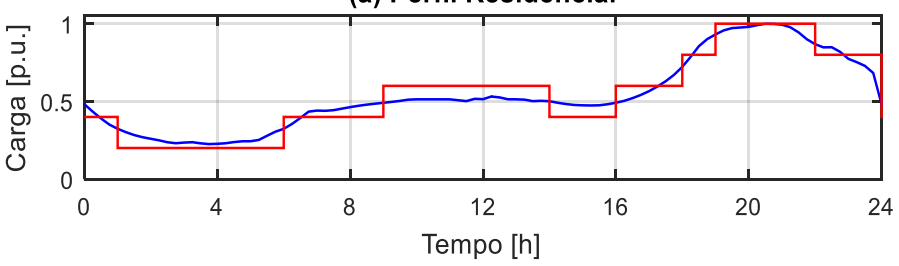

- Curva de carga original

Curva de carga discretizada

(b) Perfil Comercial

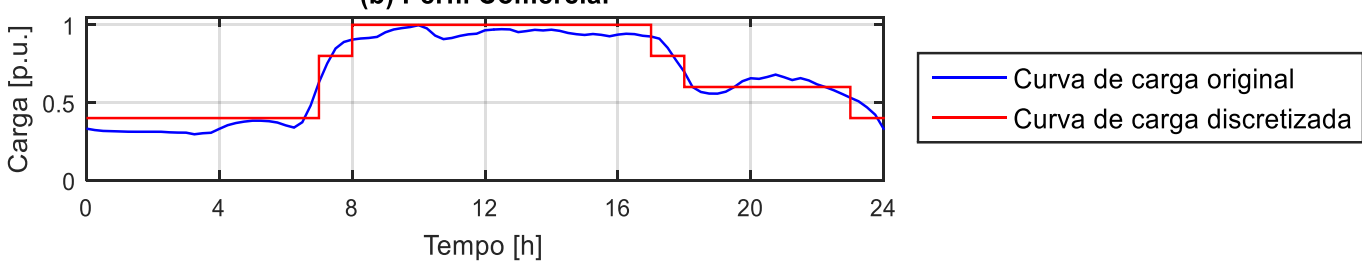

(c) Perfil Industrial 1

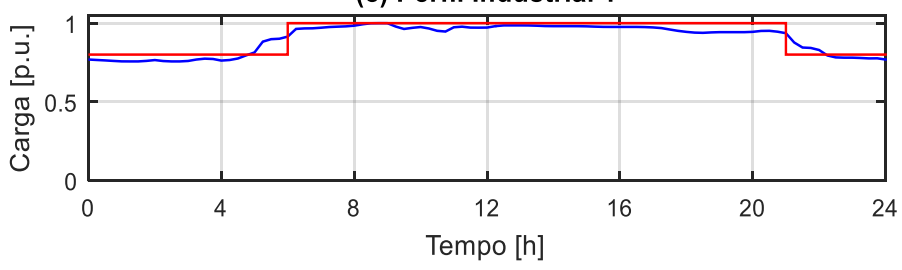

Curva de carga original

Curva de carga discretizada

(d) Perfil Industrial 2

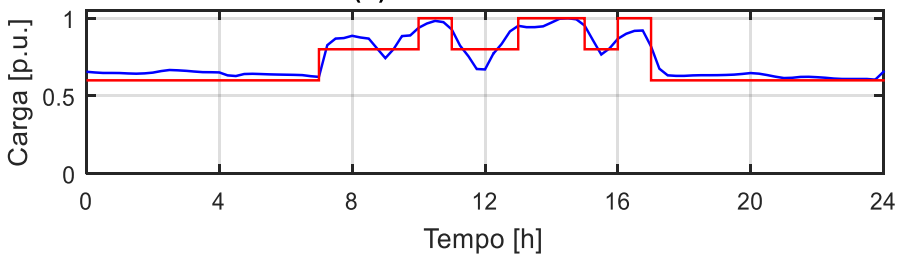

- Curva de carga original

Curva de carga discretizada

(e) Perfil Industrial 3

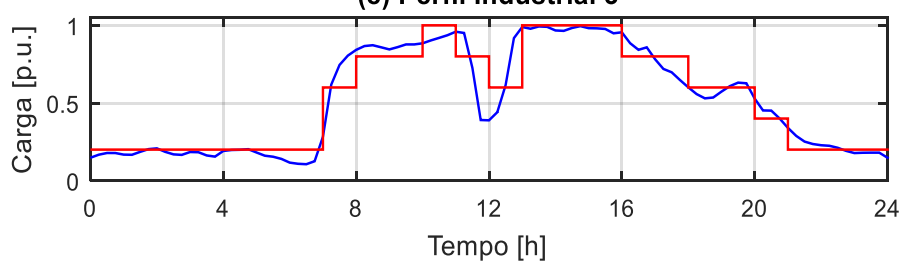

Curva de carga original

Curva de carga discretizada

Figura 27 - Comparação entre as curvas de carga originais e as curvas discretizadas em 5 patamares. 
Tabela 22 Comparação entre o método proposto e a regulação tradicional, no Cenário 3.

\begin{tabular}{ccc}
\hline & Regulação Tradicional & Método proposto \\
$\boldsymbol{f}_{\text {Desconexão }}\left(\boldsymbol{i}_{\text {Min }}(\boldsymbol{x})\right)$ & 29,5730 & 0 \\
$\boldsymbol{h}_{\text {Tap }}\left(\boldsymbol{i}_{\text {Min }}(\boldsymbol{x}), \mathbf{1}\right)$, "1A" & 12 & 12 \\
$\boldsymbol{h}_{\text {Tap }}\left(\boldsymbol{i}_{\text {Min }}(\boldsymbol{x}), \mathbf{2}\right)$, "1B" & 14 & 0 \\
$\boldsymbol{h}_{\text {Tap }}\left(\boldsymbol{i}_{\text {Min }}(\boldsymbol{x}), \mathbf{3}\right)$, "1C" & 16 & 4 \\
$\boldsymbol{h}_{\text {Tap }}\left(\boldsymbol{i}_{\text {Min }}(\boldsymbol{x}), \mathbf{4}\right)$, "2A" & 10 & 0 \\
$\boldsymbol{h}_{\text {Tap }}\left(\boldsymbol{i}_{\text {Min }}(\boldsymbol{x}), \mathbf{5}\right)$, "2B" & 10 & 0 \\
$\boldsymbol{h}_{\text {Tap }}\left(\boldsymbol{i}_{\text {Min }}(\boldsymbol{x}), \mathbf{6}\right)$, "3C" & 10 & 2 \\
$\boldsymbol{h}_{\text {Tap }}\left(\boldsymbol{i}_{\text {Min }}(\boldsymbol{x}), \mathbf{7}\right)$, "tsub" & 36 & 36 \\
$\boldsymbol{f}_{\text {Tap }}\left(\boldsymbol{i}_{\text {Min }}(\boldsymbol{x})\right)$ & 108 & 54 \\
$\boldsymbol{f}_{\text {Penalidade }}\left(\boldsymbol{i}_{\text {Min }}(\boldsymbol{x})\right)$ & 4,4641 & 0 \\
$\boldsymbol{f}_{\text {Objetivo }}\left(\boldsymbol{i}_{\text {Min }}(\boldsymbol{x})\right)$ & $4,4937 \cdot 10^{8}$ & 0,0054
\end{tabular}

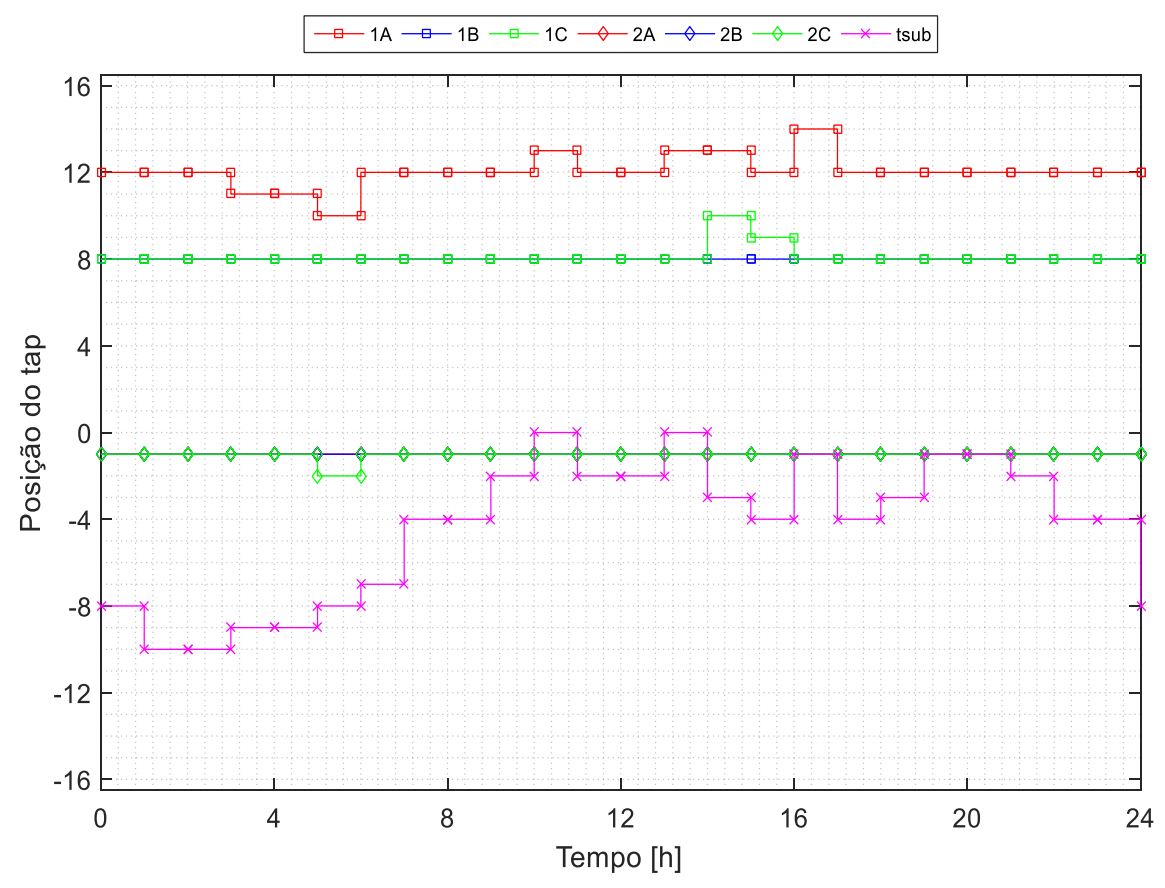

Figura 28 - Posições de tap obtidas pela otimização ao longo de um dia típico para todos os reguladores de tensão, no Cenário 3. 


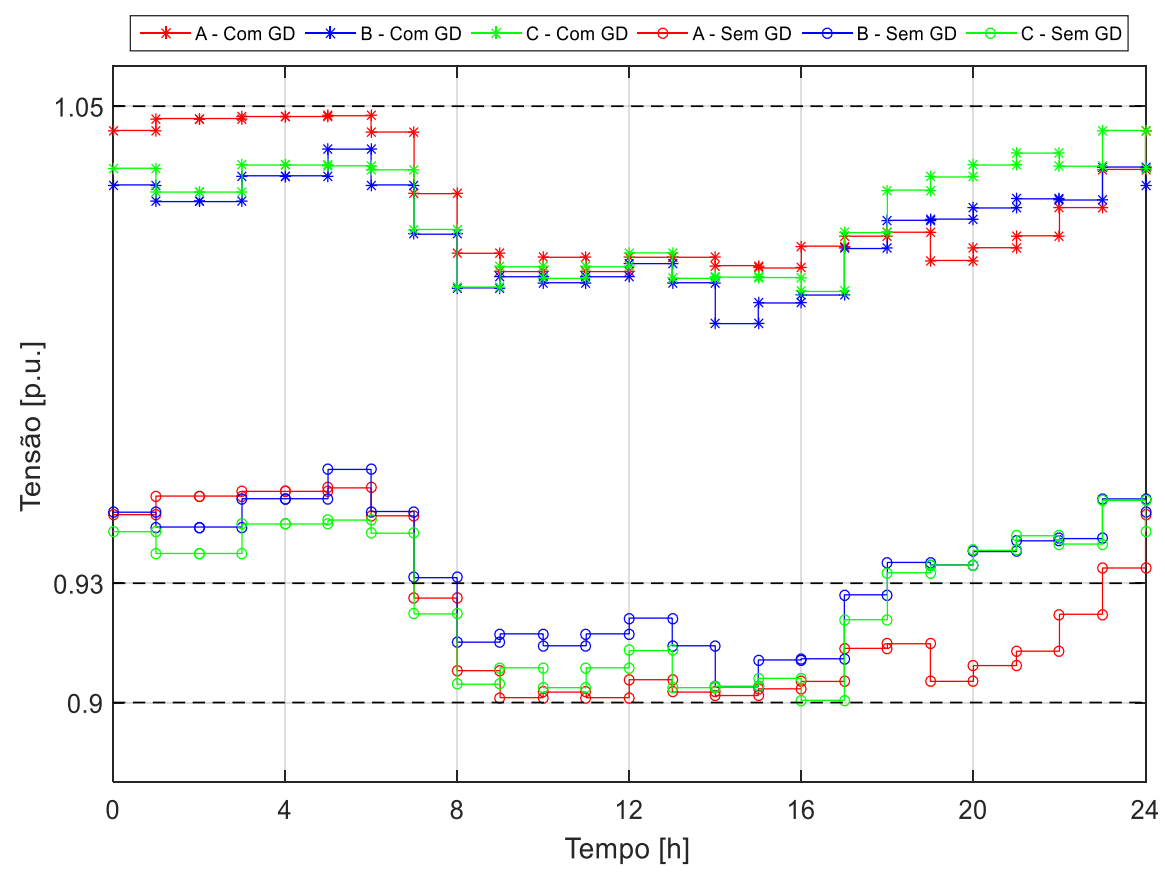

Figura 29 - As tensões trifásicas com e sem a GD conectada na barra 840 ao longo de um dia típico, no Cenário 3.

\subsubsection{Cenário 4}

O Cenário 4 também utiliza curvas de carga aproximadas em patamares, porém 10 patamares são utilizados, como pode ser observado na Figura 30. Na Tabela 23, foi observado que os resultados obtidos se aproximaram mais dos observados no Cenário 1. As violações de tensão também foram eliminadas em todas as barras do sistema, com a GD conectada ou não. As mudanças na posição de tap obtidas $\left(f_{\text {Tap }}\left(i_{\text {Min }}(x)\right)=92\right.$ para o método tradicional e $f_{\text {Tap }}\left(i_{\text {Min }}(x)\right)=40$ para o método proposto) se aproximam mais dos valores observados no Cenário 1 do que o obtido no Cenário 3, apesar de ainda serem maiores do que no Cenário 1.

O método alternou entre gerar uma nova população por meio da reprodução ou pela nova população inicial, sendo finalizado na iteração 189. As posições de tap obtidas são apresentadas na Figura 31 e as tensões trifásicas da barra 840 são apresentadas na Figura 32. 
(a) Perfil Residencial

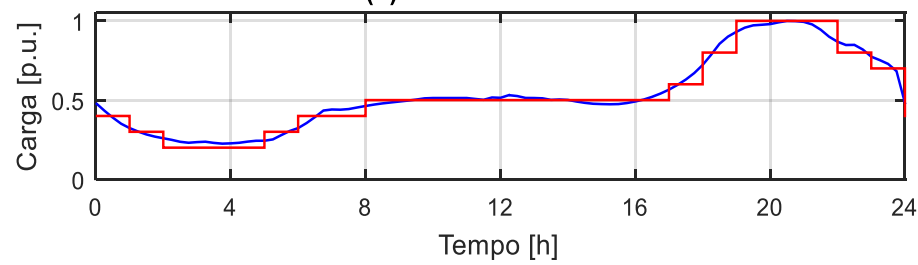

- Curva de carga original Curva de carga discretizada

(b) Perfil Comercial

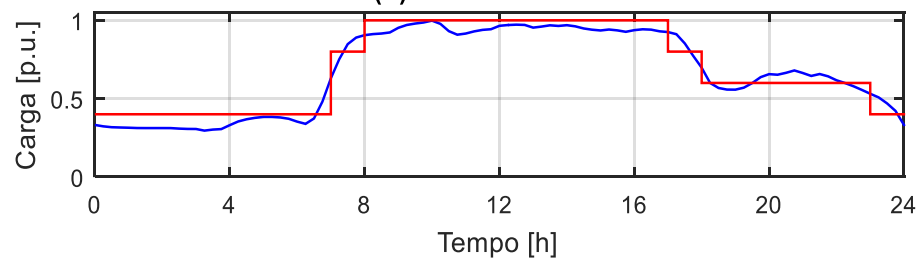

- Curva de carga original Curva de carga discretizada

(c) Perfil Industrial 1

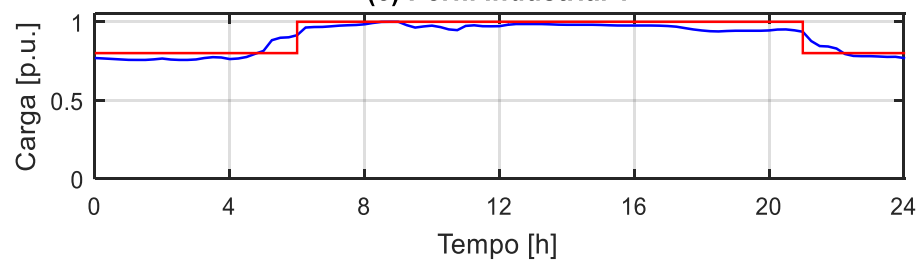

- Curva de carga original

Curva de carga discretizada

(d) Perfil Industrial 2

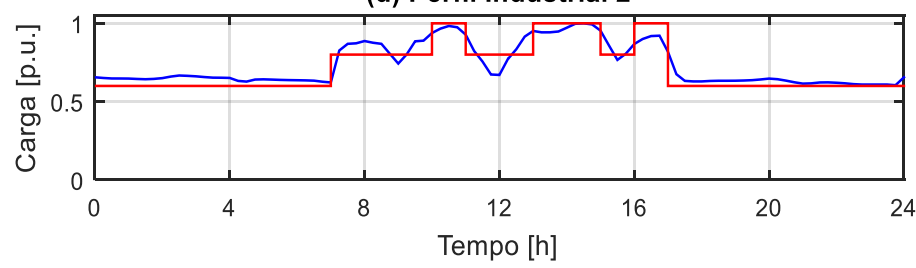

- Curva de carga original

Curva de carga discretizada

(e) Perfil Industrial 3

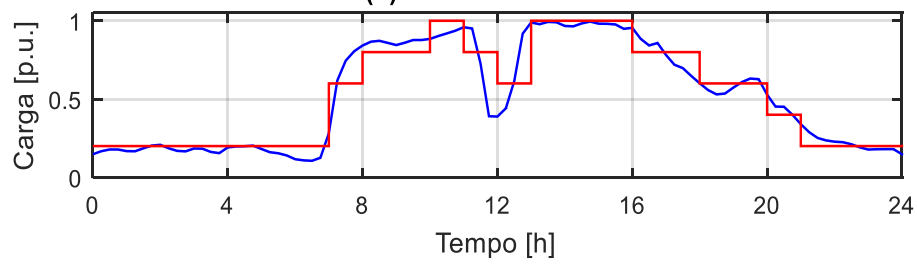

- Curva de carga original

Curva de carga discretizada

Figura 30 - Comparação entre as curvas de carga originais e as curvas discretizadas em 10 patamares. 
Tabela 23 Comparação entre o método proposto e a regulação tradicional, no Cenário 4.

\begin{tabular}{|c|c|c|}
\hline & Regulação Tradicional & Método proposto \\
\hline$f_{\text {Desconexão }}\left(i_{\text {Min }}(x)\right)$ & 25,7675 & 0 \\
\hline$h_{T a p}\left(i_{M i n}(x), 1\right), " 1 A^{\prime \prime}$ & 10 & 8 \\
\hline$h_{T a p}\left(i_{M i n}(x), 2\right), “ 1 \mathrm{~B} "$ & 14 & 0 \\
\hline$h_{T a p}\left(i_{M i n}(x), 3\right), " 1 C^{\prime \prime}$ & 12 & 2 \\
\hline$h_{T a p}\left(i_{M i n}(x), 4\right), “ 2 A^{\prime \prime}$ & 10 & 0 \\
\hline$h_{T a p}\left(i_{M i n}(x), 5\right)$, "2B" & 10 & 0 \\
\hline$h_{T a p}\left(i_{M i n}(x), 6\right)$, "3C" & 10 & 0 \\
\hline$h_{\text {Tap }}\left(i_{\text {Min }}(x), 7\right)$, "tsub" & 26 & 30 \\
\hline $\boldsymbol{f}_{\text {Tap }}\left(\boldsymbol{i}_{\text {Min }}(\boldsymbol{x})\right)$ & 92 & 40 \\
\hline $\boldsymbol{f}_{\text {Penalidade }}\left(\boldsymbol{i}_{\text {Min }}(\boldsymbol{x})\right)$ & 3,5719 & 0 \\
\hline$f_{\text {Objetivo }}\left(\boldsymbol{i}_{\text {Min }}(x)\right)$ & $3,5977 \cdot 10^{8}$ & 0,0040 \\
\hline
\end{tabular}

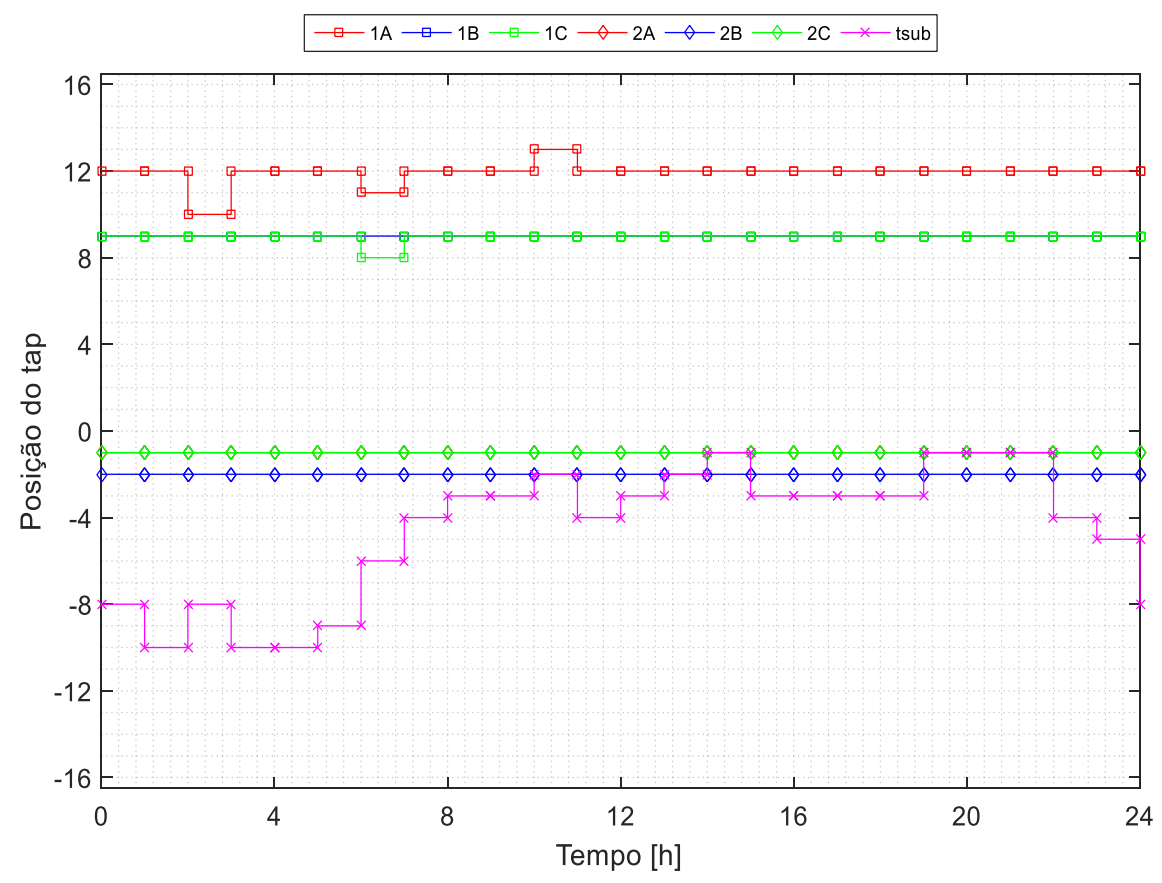

Figura 31 - Posições de tap obtidas pela otimização ao longo de um dia típico para todos os reguladores de tensão, no Cenário 4. 


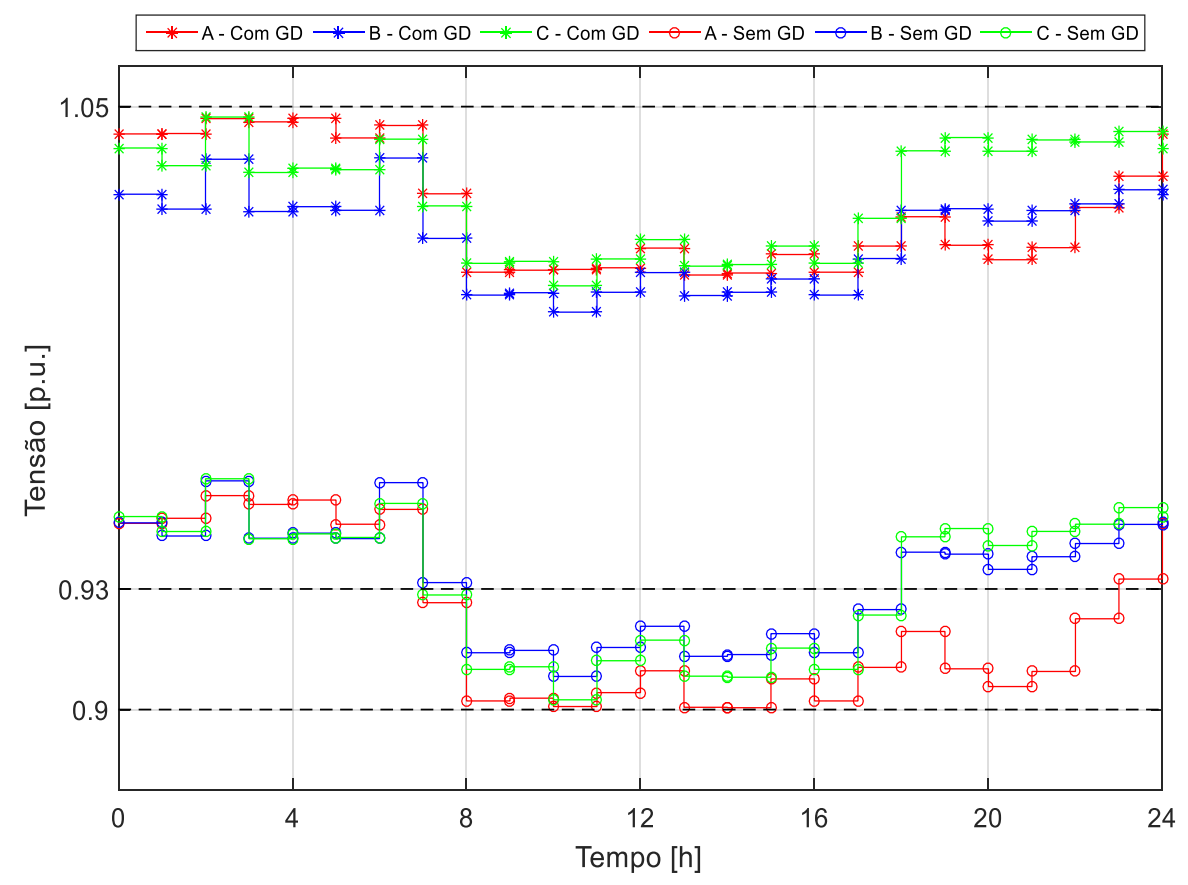

Figura 32 - As tensões trifásicas com e sem a GD conectada na barra 840 ao longo de um dia típico, no Cenário 4.

\subsubsection{Cenário 5}

Neste cenário, o fator de potência dos geradores foi mantido em 0,95. Devido à injeção de potência reativa, a variação de tensão causada pela desconexão da GD é maior do que no Cenário 1. Do ponto de vista do esforço computacional, essa injeção de potência reativa torna este cenário mais custoso para ser resolvido, pois ocorre uma variação de tensão maior, reduzindo as possibilidades de tap que não causem violação de tensão para o método encontrar. Mesmo assim, o método encontrou posições de tap que não causam violações de tensão após a desconexão da GD e em sua reconexão em todo sistema, como pode ser observado na Tabela 24 . As variações na posição de tap obtidas pelo método proposto $\left(f_{\text {Tap }}\left(i_{\text {Min }}(x)\right)=50\right)$ foram reduzidas em comparação com a regulação tradicional dos reguladores de tensão de $\left(f_{\text {Tap }}\left(i_{\text {Min }}(x)\right)=126\right)$.

O método também alternou entre gerar populações pela reprodução ou usando o melhor individuo da ultima iteração, sendo encerrado na iteração 175 . As posições de tap obtidas pelo método para os reguladores são apresentadas na Figura 33 e a tensões trifásicas, com e sem a GD, na barra 840 são apresentadas na Figura 34. 
Tabela 24 Comparação entre o método proposto e a regulação tradicional, no Cenário 5.

\begin{tabular}{|c|c|c|}
\hline & Regulação Tradicional & Método proposto \\
\hline$f_{\text {Desconexão }}\left(i_{\text {Min }}(x)\right)$ & 132,5956 & 0 \\
\hline$h_{T a p}\left(i_{M i n}(x), 1\right), " 1 A^{\prime \prime}$ & 10 & 8 \\
\hline$h_{T a p}\left(i_{M i n}(x), 2\right), “ 1 \mathrm{~B} "$ & 14 & 2 \\
\hline$h_{T a p}\left(i_{M i n}(x), 3\right), " 1 C^{\prime \prime}$ & 18 & 8 \\
\hline$h_{T a p}\left(i_{M i n}(x), 4\right), “ 2 A^{\prime \prime}$ & 20 & 2 \\
\hline$h_{T a p}\left(i_{M i n}(x), 5\right)$, "2B" & 20 & 0 \\
\hline$h_{T a p}\left(i_{M i n}(x), 6\right)$, "3C" & 20 & 0 \\
\hline$h_{\text {Tap }}\left(i_{\text {Min }}(x), 7\right)$, "tsub" & 24 & 30 \\
\hline $\boldsymbol{f}_{\text {Tap }}\left(\boldsymbol{i}_{\text {Min }}(\boldsymbol{x})\right)$ & 126 & 50 \\
\hline $\boldsymbol{f}_{\text {Penalidade }}\left(\boldsymbol{i}_{\text {Min }}(\boldsymbol{x})\right)$ & 7,2586 & 0 \\
\hline$f_{\text {Objetivo }}\left(\boldsymbol{i}_{\text {Min }}(x)\right)$ & $7,3912 \cdot 10^{8}$ & 0,0050 \\
\hline
\end{tabular}

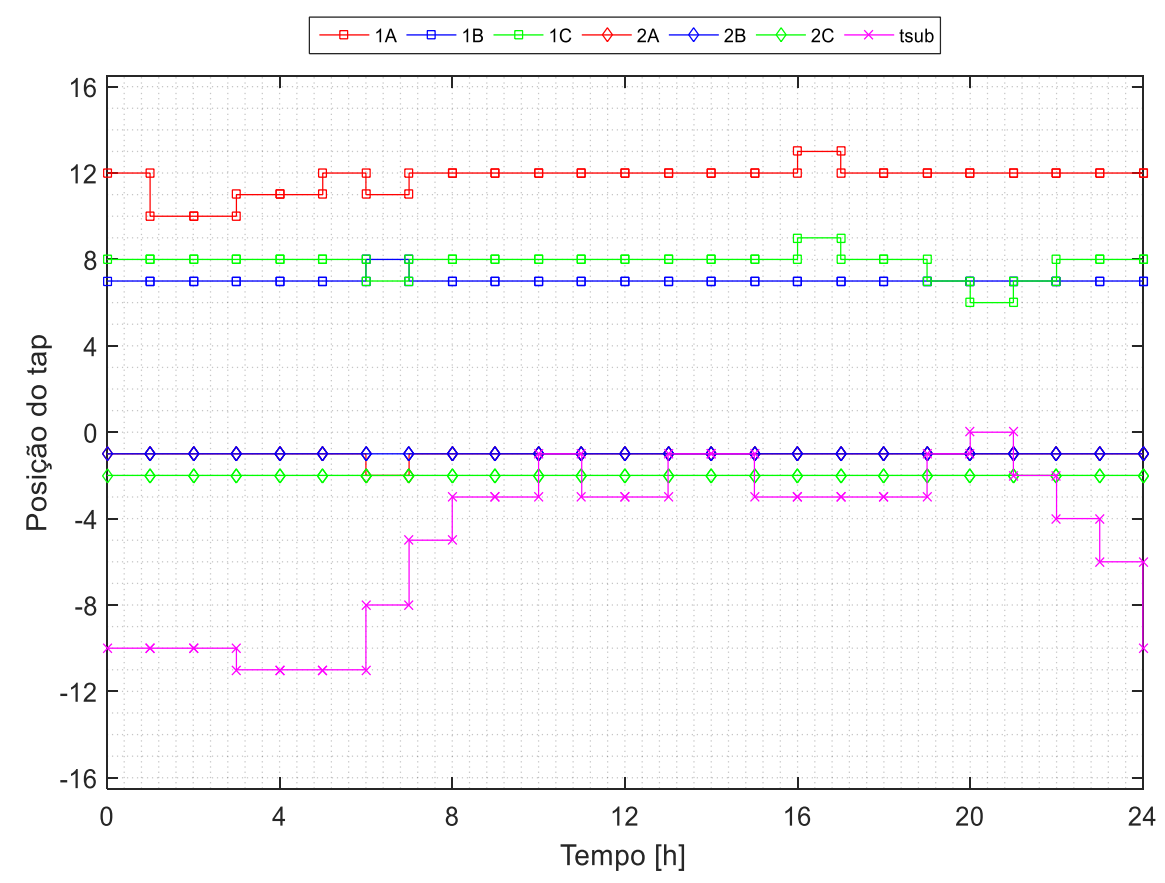

Figura 33 - Posições de tap obtidas pela otimização ao longo de um dia típico para todos os reguladores de tensão, no Cenário 5. 


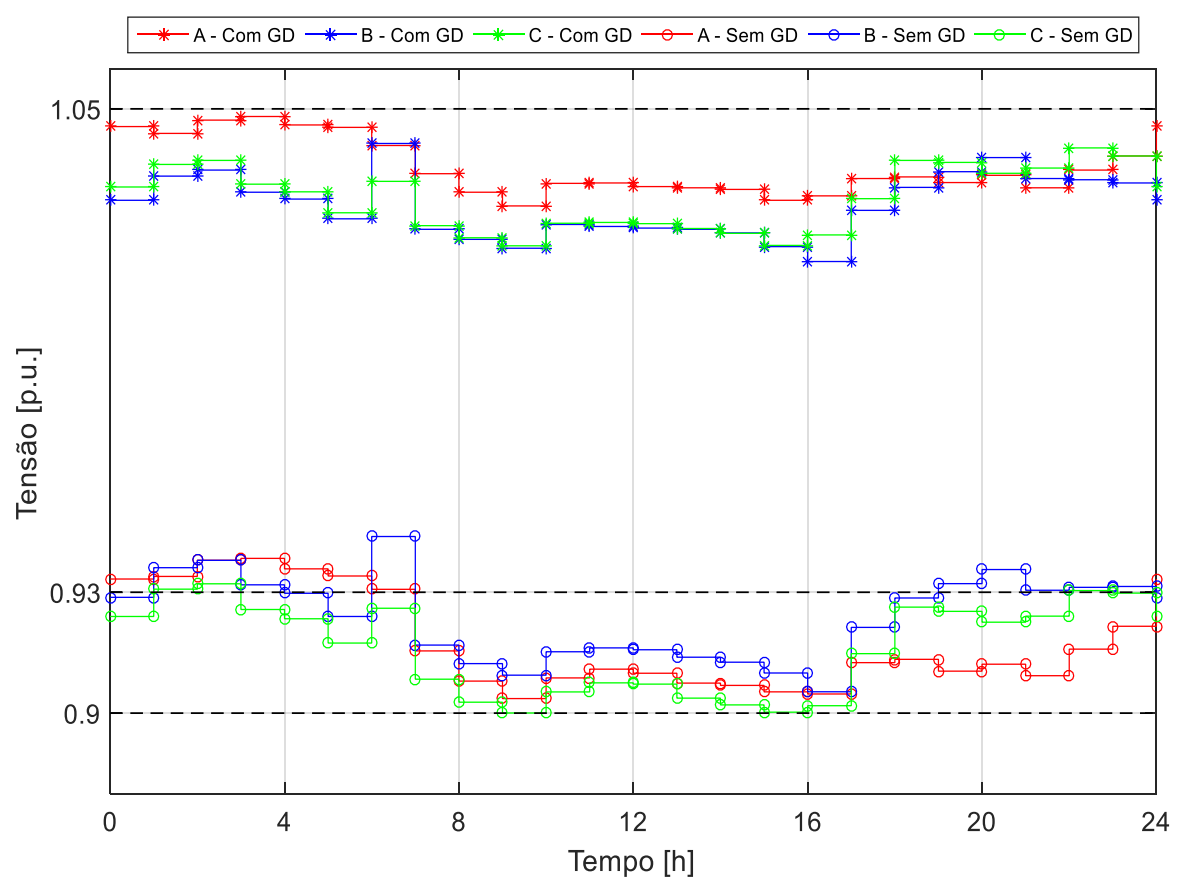

Figura 34 - As tensões trifásicas com e sem a GD conectada na barra 840 ao longo de um dia típico, no Cenário 5.

\subsubsection{6 $\underline{\text { Cenário } 6}$}

Neste cenário, a GD está controlando a tensão em seu PAC e o fator de potência pode oscilar entre 0,9 capacitivo e indutivo. O controle da tensão auxilia a evitar violações de tensão enquanto os geradores estão conectados, porém esse controle não leva em consideração a variação de tensão que ocorre na desconexão dos geradores. Como o controle de tensão é feito por meio da potência reativa, é de se esperar que o controle aumente as variações de tensão após a desconexão dos geradores. Este fato pode ser observado no grande valor de $f_{\text {Desconexão }}\left(i_{\text {Min }}(x)\right)$ obtido na regulação tradicional, indicando que a variação de tensão após a desconexão dos geradores causa violações pelo SD. Ainda sim, na Tabela 25 é possível observar que o método proposto conseguiu eliminar essas violações de tensão e manter as variações de posição de tap em um valor relativamente baixo $\left(f_{\text {Tap }}\left(i_{\text {Min }}(x)\right)=62\right)$, em comparação com a regulação tradicional dos reguladores de tensão ou o Cenário 1.

Novamente, o método proposto necessitou gerar novas populações iniciais com frequência, porém, diversas iterações seguidas conseguiram gerar melhores soluções pelo cruzamento. As posições de tap obtidas são apresentadas na Figura 35 e as tensões trifásicas, com e sem a GD na barra 840 são apresentadas na Figura 36. 
Tabela 25 Comparação entre o método proposto e a regulação tradicional, no Cenário 6.

\begin{tabular}{|c|c|c|}
\hline & Regulação Tradicional & Método proposto \\
\hline$f_{\text {Desconexão }}\left(i_{\text {Min }}(x)\right)$ & 177,7927 & 0 \\
\hline$h_{T a p}\left(i_{M i n}(x), 1\right), " 1 A^{\prime \prime}$ & 6 & 10 \\
\hline$h_{T a p}\left(i_{M i n}(x), 2\right), “ 1 \mathrm{~B} "$ & 12 & 2 \\
\hline$h_{T a p}\left(i_{M i n}(x), 3\right), " 1 C^{\prime \prime}$ & 12 & 10 \\
\hline$h_{T a p}\left(i_{M i n}(x), 4\right), “ 2 A "$ & 16 & 6 \\
\hline$h_{T a p}\left(i_{M i n}(x), 5\right)$, "2B" & 16 & 0 \\
\hline$h_{T a p}\left(i_{M i n}(x), 6\right)$, "3C" & 16 & 6 \\
\hline$h_{\text {Tap }}\left(i_{\text {Min }}(x), 7\right)$, "tsub" & 26 & 28 \\
\hline $\boldsymbol{f}_{\text {Tap }}\left(\boldsymbol{i}_{\text {Min }}(\boldsymbol{x})\right)$ & 104 & 62 \\
\hline $\boldsymbol{f}_{\text {Penalidade }}\left(\boldsymbol{i}_{\text {Min }}(\boldsymbol{x})\right)$ & 8,4818 & 0 \\
\hline$f_{\text {Objetivo }}\left(\boldsymbol{i}_{\text {Min }}(x)\right)$ & $8,6596 \cdot 10^{8}$ & 0,0062 \\
\hline
\end{tabular}

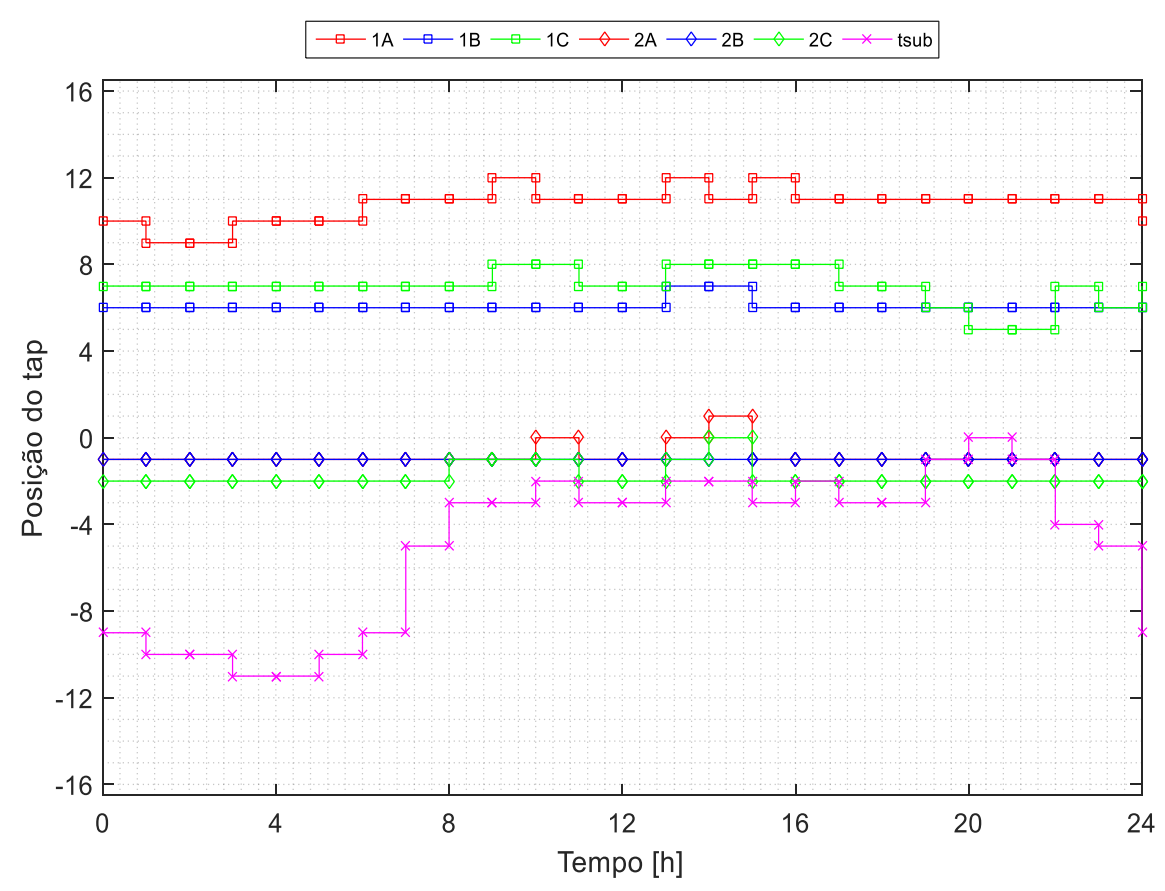

Figura 35 - Posições de tap obtidas pela otimização ao longo de um dia típico para todos os reguladores de tensão, no Cenário 6. 


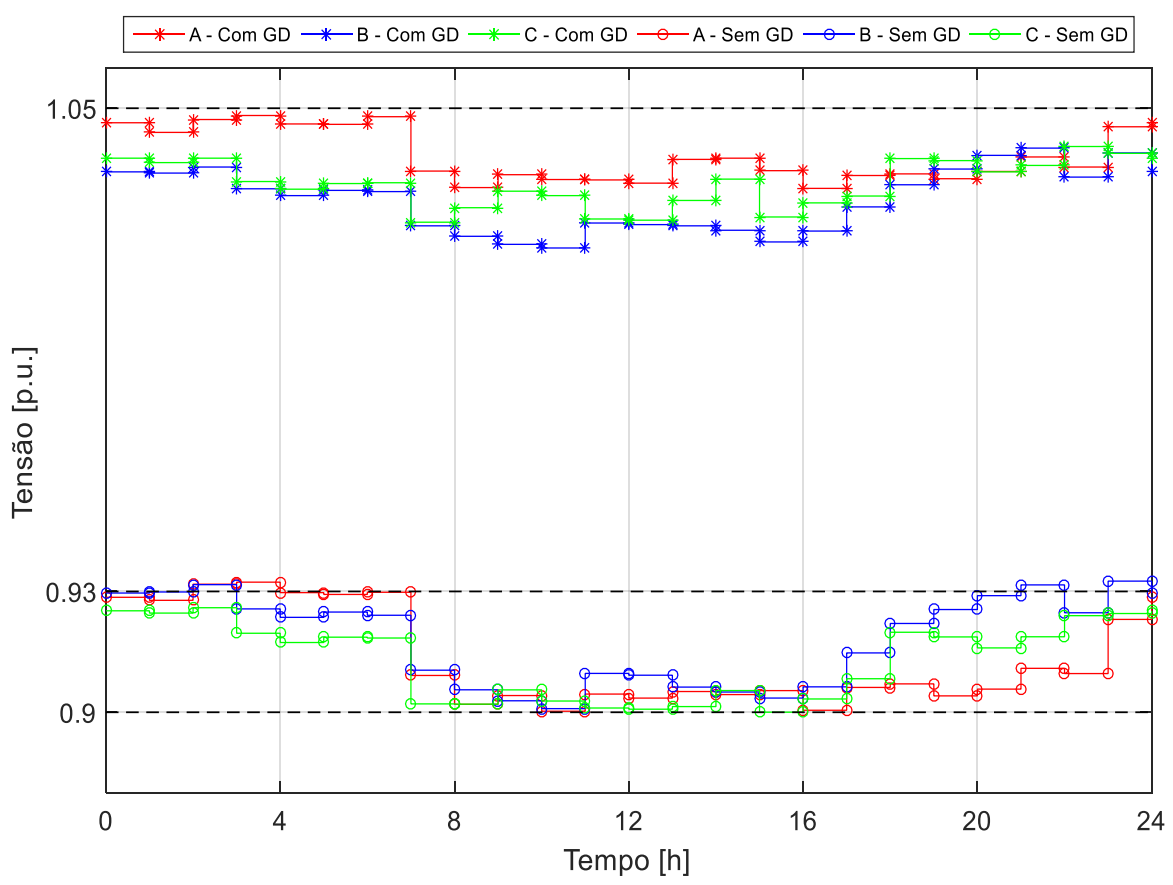

Figura 36 - As tensões trifásicas com e sem a GD conectada na barra 840 ao longo de um dia típico, no Cenário 6.

\subsubsection{Considerações finais sobres os resultados obtidos no IEEE 34 barras}

Os resultados obtidos aplicando o método proposto no IEEE 34 barras estão resumidos na Tabela 26. Nos cenários em que havia a presença da GD, o método tradicional de regulação de tensão não conseguiu evitar violações de tensão após a desconexão da GD. Por outro lado, em cenários bem distintos entre si, foi possível observar que o método proposto conseguiu minimizar as violações de tensão com e sem a GD conectada, ou seja, uma mesma configuração de posições de tap dos reguladores de tensão não causam violações de tensão enquanto a GD está conectada, após sua desconexão e em sua posterior reconexão. As mudanças de posições dos taps foram minimizadas, porém, em comparação ao método tradicional de operação dos reguladores de tensão, aumentou, exceto no Cenário 5. Isso ocorreu, pois a otimização tem como objetivo principal regular a tensão com a GD conectada e ao mesmo tempo após a sua desconexão, enquanto que na regulação tradicional a desconexão da GD não é considerada.

Comparando a regulação tradicional e o método proposto, nos Cenários 3 e 4 ocorreu um aumento significativo entre as mudanças de tap, o que indica que esta função objetivo pode ser afetada quando a curva de carga é aproximada em patamares. Essas aproximações não afetaram o objetivo principal de eliminar as violações de tensão. Nos 
cenários em que a curva de carga não foi aproximada em patamares, o método conseguiu eliminar as violações de tensão e reduzir as mudanças de tap, o que o método pode ser empregado e diminuir de maneira significativa o desgaste mecânico dos reguladores de tensão.

Tabela 26 Comparação dos resultados obtidos para o Sistema1.

\begin{tabular}{ccccccc}
\hline Funções objetivo & \multicolumn{7}{c}{ Cenário } \\
$\boldsymbol{f}_{\text {Desconexão }}\left(\boldsymbol{i}_{\text {Min }}(\boldsymbol{x})\right)$ & 0 & 0 & 0 & 0 & $\mathbf{5}$ & $\mathbf{6}$ \\
$\boldsymbol{f}_{\text {Tap }}\left(\boldsymbol{i}_{\text {Min }}(\boldsymbol{x})\right)$ & 36 & 34 & 54 & 40 & 50 & 62 \\
$\boldsymbol{f}_{\text {Penalidade }}\left(\boldsymbol{i}_{\text {Min }}(\boldsymbol{x})\right)$ & 0 & 0 & 0 & 0 & 0 & 0 \\
$\boldsymbol{f}_{\text {Objetivo }}\left(\boldsymbol{i}_{\text {Min }}(\boldsymbol{x})\right)$ & 0,0036 & 0,0034 & 0,0054 & 0,0040 & 0,0050 & 0,0062 \\
\hline
\end{tabular}

\subsection{Considerações finais sobre capítulo}

Este capítulo apresentou os resultados obtidos em dois sistemas de distribuição pelo método proposto. Cada sistema precisou de parâmetros específicos para o AG. O Sistema 1 já tinha sido utilizado em pesquisas anteriores e ele foi importante para validar a Solução 5 e fornecer uma familiarização com o problema. O sistema IEEE 34 barras permitiu diversos testes de sensibilidade e mostrou que o método proposto consegue, em diversos cenários, atingir o objetivo proposto. A aproximação da curva de carga em patamares pode alterar os resultados obtidos se poucos patamares forem utilizados, porém ainda sim foi possível aplicar o método nesses casos e obter os resultados desejados, que é a eliminação das violações de tensão.

No Sistema 1, no Cenário 4 não foi possível eliminar as violações de tensão após a desconexão da GD. Isso já era esperado, pois não são todos os cenários em que essa violação pode ser eliminada. Ainda sim, o método conseguiu minimizar essas violações de tensão.

Foi observado que quanto mais potência reativa era injetada, maior era a dificuldade do método em eliminar as violações de tensão. Isto ocorre, pois a injeção de potência reativa aumenta a variação de tensão causada pela conexão da GD, aumentando a possibilidade de ocorrer uma violação após a desconexão da GD. 


\section{Capítulo 6}

\section{Conclusões}

O método proposto nesta dissertação conseguiu determinar posições de tap dos reguladores de tensão em que a GD pode operar, mesmo que se repentinamente desconectada e em sua posterior reconexão. As violações de tensões no SD são minimizadas ou não ocorrem. Como o método busca posições de tap que não violem a tensão com e sem a GD conectada, esses mesmos taps, se mantidos após uma desconexão repentina da GD, minimizarão ou eliminarão as violações de tensão na reconexão da GD ao sistema.

O método foi aplicado em cenários com grande participação de GD. Centrais geradoras de capacidade semelhante às usadas neste trabalho, se conectadas a um SD de alguma distribuidora estudadas no Capítulo 2, seriam obrigadas a possuir sistemas de comunicação com o COD, então um método de controle centralizado poderia ser utilizado sem que sejam necessários grandes investimentos em melhorias na rede.

O método proposto neste trabalho é capaz de minimizar as violações de tensão com e sem a GD conectada, ou seja, o método minimiza a violação de tensão logo após a desconexão da GD e também a sua posterior reconexão, pois os valores de taps obtidos já foram escolhidos visando minimizar essas violações de tensão.

A função objetivo definida permite uma seleção de qual posição de tap o regulador de tensão deve operar, considerando os objetivos da otimização. A formulação utilizada permite ainda planejar a operação de bancos de capacitores, a potência entregue pelos geradores, a tensão controlada pelos geradores se estiverem operando em CT, entre outras possibilidades. 
O problema é de natureza combinatória, principalmente se forem considerados outros reguladores de tensão e bancos capacitores. Um AG tradicional apresenta dificuldades para resolver este problema, pois uma população grande é necessária para abranger mais possibilidades de solução. Isso tem um alto custo computacional, pois são necessários diversos cálculos de fluxo de potência para cada indivíduo. Foi observado que no Sistema 1, em que apenas um regulador de tensão estava presente e uma população de 2000 indivíduos foi usada, o método resolveu o problema como um AG tradicional, criando a população das iterações pela reprodução dos indivíduos selecionados. Porém, no Sistema IEEE 34 barras, mais reguladores de tensão estavam presentes, o que aumentava o esforço computacional. Nesse sistema, o método teve que ser utilizado com uma população menor. Nesta aplicação, a reprodução tradicional não se mostrou suficiente para resolver o problema. Para resolver esta barreira, foi utilizado conhecimento prévio do problema, de que posições de tap parecidas possuem comportamento parecido. A criação de indivíduos similares, porém com pequenas diferenças auxiliou significativamente na minimização das variações de tap. A criação de novas populações iniciais auxiliou o método a não se limitar a soluções que são mínimos locais, porém mesmo assim não há garantia que a solução obtida também seja um outro mínimo local.

Em cinco cenários do IEEE 34 barras foram observadas que as variações de tap aumentaram com a utilização do método proposto. Vale ressaltar que a redução dessas mudanças era um objetivo secundário, sendo o objetivo principal reduzir as violações de tensão causadas pela desconexão e reconexão da GD, o que foi alcançado. Mesmo aumentando as variações da posição de tap, o aumento não foi excessivo, o que significa que o método conseguiu eliminar as violações de tensão sem causar um impacto significativo na vida útil do regulador de tensão. A injeção de potência reativa aumenta o esforço computacional do método, assim como a participação da potência ativa injetada em relação a potência consumida pelo sistema. As posições de tap obtidas podem ser utilizadas como ferramenta de suporte ao planejamento da operação.

Para trabalhos futuros, propõem-se:

- Diferentes maneiras de criar a população do AG podem ser utilizadas.

- Outros tipos de mutações que possam gerar indivíduos melhores para este tipo de problema podem ser estudados.

- Técnicas de otimização diferentes podem ser estudadas pra resolver este problema. É desejável evitar obter mínimos locais. 
- Mais variáveis de controle podem ser incluídas, como as tensões dos geradores quando operam em CT, a potência reativa injetada pelos geradores, o uso de bancos de capacitores, a potência ativa injetada pelos geradores, entre outras.

- Pode ser estudado obter uma solução que não dependesse de comunicação entre a subestação e os reguladores de tensão ou também que não necessitasse da curva de carga do sistema.

- Um método analítico também pode ser estudado para resolver este problema. A modelagem matemática desenvolvida pode auxiliar na comparação de diferentes soluções. 



\section{Referências Bibliográficas}

[1] N. Jenkins, R. Allan, P. Crossley, D. Kirschen, and G. Strbac, Embedded Generation, vol. 31. 2000.

[2] Working Group 37.23, "Impact of increasing contribution of dispersed generation on the power system," CIGRÉ, no. Final Report, 1999.

[3] Working Group 4, "Dispersed Generation,” CIGRÉ, no. Final Report, 1999.

[4] A. Saidian, M. Heidari, and D. Mirabbasi, "Improvement of voltage unbalance and voltage sag in radial distribution systems using DG," 2010 th IEEE Conf. Ind. Electron. Appl., pp. 835-839, 2010.

[5] H. B. Püttgen, P. R. Macgregor, and F. C. Lambert, "Distributed Generation: Semantic Hype or the Dawn of a New Era?," IEEE Power Energy Mag., vol. 1, no. 1, pp. 22-29, 2003.

[6] C. Bommareddy and E. Makram, "Power Quality Studies in the Presence of DG," in 2006 Power Systems Conference: Advanced Metering, Protection, Control, Communication, and Distributed Resources, 2006, pp. 224-229.

[7] C. L. Masters, "Voltage rise: the big issue when connecting embedded generation to long $11 \mathrm{kV}$ overhead lines," Power Engineering Journal, vol. 16, no. 1. p. 5, 2002.

[8] W. Freitas, J. C. M. Vieira, A. Morelato, L. C. P. DaSilva, V. F. da Costa, and F. A. B. Lemos, "Comparative Analysis Between Synchronous and Induction Machines for Distributed Generation Applications," IEEE Trans. Power Syst., vol. 21, no. 1, pp. 301-311, Feb. 2006.

[9] D. Petean, J. C. M. Vieira, and R. Q. Machado, "Influence of inverter-based distributed generator interface control on the performance of power distribution systems," in 2010 IREP Symposium Bulk Power System Dynamics and Control VIII (IREP), 2010, pp. 1-8.

[10] W. Freitas, J. C. M. Vieira, A. Morelato, and W. Xu, "Influence of Excitation System Control Modes on the Allowable Penetration Level of Distributed Synchronous Generators," IEEE Trans. Energy Convers., vol. 20, no. 2, pp. 474- 
480, Jun. 2005.

[11] K. J. P. Macken, M. H. J. Bollen, and R. J. M. Belmans, "Mitigation of Voltage Dips Through Distributed Generation Systems," IEEE Trans. Ind. Appl., vol. 40, no. 6, pp. 1686-1693, Nov. 2004.

[12] J. C. Gómez and M. M. Morcos, "Coordination of voltage sag and overcurrent protection in DG systems," IEEE Trans. Power Deliv., vol. 20, no. 1, pp. 214-218, 2005.

[13] E. R. Collins and J. Jiang, "Voltage sags and the response of a synchronous distributed generator: A case study," IEEE Trans. Power Deliv., vol. 23, no. 1, pp. 442-448, 2008.

[14] L. N. Padilha, "Análise Comparativa De Estratégias Para Regulação De Tensão Em Sistemas De Distribuição De Energia Elétrica Na Presença De Geradores Distribuídos," USP, 2010.

[15] IEEE standards Coordinating Committee 21, "1547 IEEE Standard for Interconnecting Distributed Resources with Electric Power Systems,” no. July, 2003.

[16] ANEEL, "PRODIST Módulo 3 - Acesso ao Sistema de Distribuição," Guia, 2012.

[17] COPEL, "NTC 605100 ACESSO DE GERAÇÃO DISTRIBUÍDA AO SISTEMA DA COPEL (com comercialização de energia)," Guia, no. Dezembro, 2013, p. 101, 2013.

[18] COPEL, "NTC 905200 ACESSO DE MICRO E MINIGERAÇÃO DISTRIBUÍDA AO SISTEMA DA COPEL," Guia, 2016.

[19] CPFL, "GED-33 Ligação de Autoprodutores em Paralelo com o Sistema de Distribuição da CPFL," Guia, pp. 1-33, 2002.

[20] CPFL, "GED-15303 Conexão de Micro e Minigeração Distribuída sob Sistema de Compensação de Energia Elétrica," Guia, pp. 1-41, 2013.

[21] Alberta Energy, “Alberta Distributed Generation Inteconnection Guide," Standard, 2002.

[22] Hydro One, "Distributed Generation Technical Interconnection Requirements Interconnections at Voltages 50kV and Below," Guia, vol. 3, p. 183, 2013.

[23] R. C. Dugan, M. F. McGranaghan, S. Santoso, and H. Wayne Beaty, Electrical Power Systems Quality, 2. McGraw-Hill, 2003.

[24] IEEE standards Coordinating Committee 21, "IEEE Application Guide for IEEE Std 1547(TM), IEEE Standard for Interconnecting Distributed Resources with Electric Power Systems," Guia, no. April, pp. 1-217, 2009.

[25] F. C. L. Trindade, K. V. do Nascimento, and J. C. M. Vieira, "Investigation on 
Voltage Sags Caused by DG Anti-Islanding Protection," IEEE Trans. Power Deliv., vol. 28, no. 2, pp. 972-980, Apr. 2013.

[26] K. Vieira do Nascimento, "Metodologia de Análise de Variações de Tensão Causadas pela Proteção Anti-Ilhamento de Geradores Síncronos Distribuídos,” Dissertação, no. USP, p. 132, 2013.

[27] F. C. L. Trindade, J. C. M. Vieira, and W. Freitas, "Potential Solutions for Minimizing Voltage Sags Caused by DG Anti-Islanding Protection,” IEEE Trans. Power Deliv., vol. 30, no. 5, pp. 2242-2251, Oct. 2015.

[28] ANEEL, "Resolução Normativa n 482," p. 9, 2016.

[29] ANEEL, "Resolução Normativa n 687," p. 25, 2015.

[30] ANEEL, "PRODIST Módulo 1 - Introdução," Guia, 2016.

[31] ANEEL, "Novas regras para geração distribuída entram em vigor," 2016. [Online]. Available: http://www2.aneel.gov.br/aplicacoes/noticias/Output_Noticias.cfm?Identidade=908 6\&id_area=90. [Accessed: 04-May-2017].

[32] ANEEL, "ANEEL amplia possibilidades para micro e minigeração distribuída," 2015. [Online]. Available: http://www2.aneel.gov.br/aplicacoes/noticias/Output_Noticias.cfm?Identidade=895 5\&id_area=90. [Accessed: 04-May-2017].

[33] ANEEL, “Outorgas e Registros de Geração,” 2017. [Online]. Available: http://www.aneel.gov.br/outorgas/geracao//asset_publisher/mJhnKIi7qcJG/content/registro-de-central-geradora-decapacidadereduzida/655808?inheritRedirect=false\&redirect=http $\% 3 \mathrm{~A} \% 2 \mathrm{~F} \% 2 \mathrm{Fwww}$.aneel.gov .br\%2Foutorgas\%2Fgeracao\%3Fp_p_id\%3D101_INSTANCE_mJhnKIi7qc. [Accessed: 04-May-2017].

[34] F. C. L. Trindade, T. S. D. Ferreira, M. G. Lopes, and W. Freitas, "Mitigation of Fast Voltage Variations During Cloud Transients in Distribution Systems With PV Solar Farms," IEEE Trans. Power Deliv., vol. 32, no. 2, pp. 921-932, Apr. 2017.

[35] S. Pukhrem, M. Basu, M. F. Conlon, and K. Sunderland, "Enhanced Network Voltage Management Techniques Under the Proliferation of Rooftop Solar PV Installation in Low-Voltage Distribution Network," IEEE J. Emerg. Sel. Top. Power Electron., vol. 5, no. 2, pp. 681-694, Jun. 2017.

[36] D. R. D. Rufino, "Processo 48500.004924/2010-51,” 2011. 
[37] ANEEL, "Resolução Normativa n² 235," 2006.

[38] ANEEL, "PRODIST Módulo 4 - Procedimentos Operativos do Sistema de Distribuição,” p. 27, 2010.

[39] ANEEL, "PRODIST Módulo 8 - Qualidade da Energia Elétrica," Guia, 2014.

[40] ONS, "Submódulo 1.1 - O Operador Nacional do Sistema Elétrico e os Procedimentos de Rede: visão geral,” Procedimentos Rede, vol. 0, pp. 1-23, 2009.

[41] IEEE standards Coordinating Committee 21, "1547 IEEE Standard for Interconnecting Distributed Resources with Electric Power Systems Amendment $1, ” 2014$.

[42] P. M. S. Carvalho, P. F. Correia, and L. a. F. Ferreira, "Distributed Reactive Power Generation Control for Voltage Rise Mitigation in Distribution Networks," IEEE Trans. Power Syst., vol. 23, no. 2, pp. 766-772, May 2008.

[43] P. N. Vovos, A. E. Kiprakis, A. R. Wallace, and G. P. Harrison, "Centralized and Distributed Voltage Control: Impact on Distributed Generation Penetration," IEEE Trans. Power Syst., vol. 22, no. 1, pp. 476-483, Feb. 2007.

[44] S. N. Liew and G. Strbac, "Maximising penetration of wind generation in existing distribution networks," IEE Proc. - Gener. Transm. Distrib., vol. 149, no. 3, p. 256, 2002.

[45] A. Shafiu, T. Bopp, I. Chilvers, G. Strbac, N. Jenkins, and Haiyu Li, "Active management and protection of distribution networks with distributed generation," in IEEE Power Engineering Society General Meeting, 2004., 2004, vol. 2, pp. 1098-1103.

[46] A. E. Kiprakis and A. R. Wallace, "Maximising energy capture from distributed generators in weak networks," IEE Proc. - Gener. Transm. Distrib., vol. 151, no. 5, p. $611,2004$.

[47] M. Castilla, M. Velasco, J. Miret, P. Martí, and A. Momeneh, "Comparative study of reactive power control methods for photovoltaic inverters in low-voltage grids," IET Renew. Power Gener., vol. 10, no. 3, pp. 310-318, 2016.

[48] H. Kazari, A. Abbaspour-Tehrani Fard, A. S. Dobakhshari, and A. M. Ranjbar, "Voltage stability improvement through centralized reactive power management on the Smart Grid," in 2012 IEEE PES Innovative Smart Grid Technologies (ISGT), 2012, pp. 1-7.

[49] K. T. Tan, X. Y. Peng, P. L. So, Y. C. Chu, and M. Z. Q. Chen, "Centralized Control for Parallel Operation of Distributed Generation Inverters in Microgrids," IEEE Trans. Smart Grid, vol. 3, no. 4, pp. 1977-1987, Dec. 2012. 
[50] X. Liu, A. Aichhorn, L. Liu, and H. Li, "Coordinated control of distributed energy storage system with tap changer transformers for voltage rise mitigation under high photovoltaic penetration," IEEE Trans. Smart Grid, vol. 3, no. 2, pp. 897-906, 2012.

[51] S. Deshmukh, B. Natarajan, and A. Pahwa, "Voltage/VAR control in distribution networks via reactive power injection through distributed generators," IEEE Trans. Smart Grid, vol. 3, no. 3, pp. 1226-1234, 2012.

[52] L. Z. Zhu, N. Chen, W. Wang, and X. D. Zhu, "Reactive control strategy for wind farm considering reactive power command," in 2009 International Conference on Sustainable Power Generation and Supply, 2009, pp. 1-5.

[53] A. R. Dalmau, D. M. Perez, I. Diaz, D. C. Mendaza, and J. R. Pillai, "Decentralized Voltage Control Coordination of On-Load Tap Changer Transformers, Distributed Generation Units and Flexible Loads," Smart Grid Technol. - Asia (ISGT ASIA), 2015 IEEE Innov., 2015.

[54] W. Zhang, W. Liu, X. Wang, L. Liu, and F. Ferrese, "Distributed Multiple Agent System Based Online Optimal Reactive Power Control for Smart Grids," IEEE Trans. Smart Grid, vol. 5, no. 5, pp. 2421-2431, Sep. 2014.

[55] M. E. Baran and I. M. El-Markabi, "A multiagent-based dispatching scheme for distributed generators for voltage support on distribution feeders," IEEE Trans. Power Syst., vol. 22, no. 1, pp. 52-59, 2007.

[56] J. Faiz and B. Sjahkolah, Electronic Tap-changer for Distribution Transformers, Series: Power System. Berlin Srpinger, 2011.

[57] T. Sansawatt, J. O’Donnell, L. F. Ochoa, and G. P. Harrison, "Decentralised voltage control for active distribution networks," Univ. Power Eng. Conf. (UPEC), 2009 Proc. 44th Int., pp. 1-5, 2009.

[58] T. Yang and Y. Yu, "Static Voltage Security Region-based Coordinated Voltage Control in Smart Distribution Grids," IEEE Trans. Smart Grid, vol. 31, no. 3, Jun. 2017.

[59] K. M. Muttaqi, A. D. T. Le, M. Negnevitsky, and G. Ledwich, “A Coordinated Voltage Control Approach for Coordination of OLTC, Voltage Regulator, and DG to Regulate Voltage in a Distribution Feeder," IEEE Trans. Ind. Appl., vol. 51, no. 2, pp. 1239-1248, 2015.

[60] D. R. Rallage, "Online coordinated voltage control in distribution systems subjected to structural changes and DG availability," IEEE Trans. Smart Grid, 
vol. 7, no. 2, pp. 580-591, 2016.

[61] G. W. Kim and K. Y. Lee, "Coordination Control of ULTC Transformer and STATCOM Based on an Artificial Neural Network," IEEE Trans. Power Syst., vol. 20, no. 2, pp. 580-586, May 2005.

[62] C. J. Dent, L. F. Ochoa, and G. P. Harrison, "Network distributed generation capacity analysis using OPF with voltage step constraints," IEEE Trans. Power Syst., vol. 25, no. 1, pp. 296-304, 2010.

[63] D. E. Goldberg, "Genetic Algorithms in Search, Optimization, and Machine Learning," Mach. Learn., no. ISBN 0-201-15767-5, p. 412, 1989.

[64] D. C. Lucas, Algoritmos Genéticos: uma Introdução. UFRGS, 2002.

[65] D. Chikouche, K. Boudjelaba, and F. Ros, "Adaptive genetic algorithm-based approach to improve the synthesis of two-dimensional finite impulse response filters," IET Signal Process., vol. 8, no. 5, pp. 429-446, Jul. 2014.

[66] C. Wang and Y. Gao, "Determination of Power Distribution Network Configuration Using Non-Revisiting Genetic Algorithm," IEEE Trans. Power Syst., vol. 28, no. 4, pp. 3638-3648, Nov. 2013.

[67] A. M. Eldurssi and R. M. O’Connell, "A Fast Nondominated Sorting Guided Genetic Algorithm for Multi-Objective Power Distribution System Reconfiguration Problem," IEEE Trans. Power Syst., vol. 30, no. 2, pp. 593-601, Mar. 2015.

[68] Y.-Y. Hong and Y.-F. Luo, "Optimal VAR Control Considering Wind Farms Using Probabilistic Load-Flow and Gray-Based Genetic Algorithms," IEEE Trans. Power Deliv., vol. 24, no. 3, pp. 1441-1449, Jul. 2009.

[69] B. R. Pereira, G. R. M. Martins da Costa, J. Contreras, and J. R. S. Mantovani, "Optimal Distributed Generation and Reactive Power Allocation in Electrical Distribution Systems," IEEE Trans. Sustain. Energy, vol. 7, no. 3, pp. 975-984, Jul. 2016.

[70] M. Vatani, G. B. Gharehpetian, M. J. Sanjari, and D. Solati Alkaran, "Multiple distributed generation units allocation in distribution network for loss reduction based on a combination of analytical and genetic algorithm methods," IET Gener. Transm. Distrib., vol. 10, no. 1, pp. 66-72, Jan. 2016.

[71] X. Wu, X. Wang, and C. Qu, "A Hierarchical Framework for Generation Scheduling of Microgrids," IEEE Trans. Power Deliv., vol. 29, no. 6, pp. 24482457, Dec. 2014.

[72] J. M. Lujano-Rojas, R. Dufo-Lopez, J. L. Bernal-Agustin, and J. P. S. Catalao, "Optimizing Daily Operation of Battery Energy Storage Systems Under Real-Time 
Pricing Schemes," IEEE Trans. Smart Grid, vol. 8, no. 1, pp. 316-330, Jan. 2017.

[73] L. A. Wolsey, Integer Programming. New York: John Wiley \& Sons, 1998.

[74] The MathWorks, "SimPowerSystems for use with Simulink,” pp. 1-620, 2013.

[75] R. D. Oliveira; F. C. L. Trindade;J. C. M. Vieira, "Mitigação de variações de tensão causadas pela proteção anti-ilhamento de geradores distribuídos," XX Congr. Bras. Automática, 2014.

[76] J. A. Jardini, C. M. V. Tahan, M. R. Gouvea, S. U. Ahn, and F. M. Figueiredo, "Daily load profiles for residential, commercial and industrial low voltage consumers," IEEE Trans. Power Deliv., vol. 15, no. 1, pp. 375-380, 2000.

[77] D. F. Lima and J. C. M. Vieira, "Mitigation of voltage violations caused by the disconnection of distributed generation by using a centralized control of the stepvoltage regulator," in 2016 12th IEEE International Conference on Industry Applications (INDUSCON), 2016, pp. 1-5.

[78] IEEE PES Distribution System Analysis Subcommittee's Distribution Test Feeder Working Group, “34-bus Feeder,” 2013. [Online]. Available: https://ewh.ieee.org/soc/pes/dsacom/testfeeders/. [Accessed: 29-May-2017].

[79] R. C. Dugan, "Reference Guide: The Open Distribution System Simulator (OpenDSS)," Electr. Power Res. Institute, Inc., no. November, pp. 1-177, 2013.

[80] R. C. Dugan, M. F. McGranaghan, S. Santoso, and H. Wayne Beaty, Electrical Power Systems Quality. 2003.

[81] Mathworks, "SimPowerSystems - Model and Simulate Electrical Power Systems." [Online]. Available: http://www.mathworks.com/products/simpower/. 



\section{Apêndice}

Este apêndice justificará as decisões tomadas entre os Passos 1 e 4 do método apresentado na Solução 5 [27] na Seção 3. Posteriormente, apresentará e analisará os resultados obtidos entre os Passos 5 a 9, os quais constituem as etapas finais do método apresentado na Solução 5 [27]. O SD utilizado foi o Sistema 1, apresentado no Capítulo 5. A curva de carga do sistema não estava disponível, então foram definidos cinco patamares de carga, sendo eles: 100\%, 80\%, 60\%, 40\% e 20\% da carga máxima.

A seguir, serão apresentados os resultados obtidos nos Passos 5 a 9, que consistem em cálculos de fluxo de potência e avaliação das tensões no sistema. Os Passos 5 e 7 são parecidos, sendo que no Passo 5 a GD está conectada ao SD e no Passo 7 ela está desconectada. Em ambos, cálculos de fluxo de potência foram efetuados para todas as posições de tap dos reguladores de tensão, os cinco patamares de carga definidos no Passo 2 e todos os cenários definidos no Passo 3. Os cálculos foram efetuados com auxílio da toolbox SimPowerSystems do Matlab [81]. Os Passos 6 e 8 são comparações dos valores de tensão obtidos nos cálculos de fluxo de potência com os valores definidos pelo Passo 4. Os limites de tensão para o Passo 4 são os mesmos utilizados na seção 5.1.1. Por fim, o Passo 9 se resume a reunir as posições de tap obtidas tanto no Passo 6 como no Passo 8.

Com o objetivo de tornar possível uma melhor análise dos resultados obtidos e auxiliar a proposta de otimização, serão apresentados os módulos das variações máximas de tensão, que são as maiores variações de tensão que ocorreram em alguma barra do $\mathrm{SD}$, de todos os cálculos de fluxo realizados. Também serão apresentado, para cada cenário de geração, o módulo da variação mínima de tensão que ocorreu em alguma barra do SD para uma posição de tap selecionada pelo método. No Passo 3 foram definidos 6 cenários de operação da GD, então, com o objetivo de melhorar a organização deste documento, os resultados de cada cenário serão apresentados separados. 


\section{Cenário 1}

O método encontrou várias posições de tap em que os geradores podem operar e serem desconectados repentinamente sem causar nenhuma violação de tensão, como pode ser observado na Tabela 27. Nesta tabela, as células destacadas em verde representam os módulos das variações máximas de tensão após a desconexão de ambos os geradores referentes às posições de tap indicadas na primeira coluna. As variações de tensão são apresentadas em módulo, pois desde que estas variações de tensão ocorram dentro dos limites de tensão esperados, não faz diferença para a aplicação do método se a variação de tensão foi positiva ou negativa.

Quando a demanda é máxima foram obtidas quatro posições de tap, enquanto que no período de baixa demanda foram obtidas nove posições de tap, o que indica que a operação do regulador de tensão possui maior flexibilidade em períodos de menor demanda.

Na Tabela 27 é possível observar que em um mesmo patamar de carga a queda de tensão varia muito pouco, mesmo nas diferentes posições do tap. As maiores quedas de tensão ocorreram no período de maior demanda, a maior obtida em uma posição de tap selecionada pelo método foi de 3,21\%, diminuindo nos períodos de menor demanda. $\mathrm{O}$ módulo da variação mínima de tensão ocorreu no período de demanda mínima e foi de $0,16 \%$.

Qualquer posição de tap correspondente às marcações em verde poderia ser empregada em seu respectivo nível de carregamento. De acordo com a Tabela 27, se a carga não variar excessivamente, o método poderia diminuir a quantidade de alterações da posição do tap, pois a posição de tap “ +5 ” pode ser utilizada em quatro dos cinco patamares de carga. 
Tabela 27 Módulo das variações máximas de tensão que ocorreram no sistema e posições de tap obtidas finais no Cenário 1 (CFP em 2,3 MW e 0,0 Mvar).

\begin{tabular}{c|c|c|c|c|c}
\hline \multirow{2}{*}{$\begin{array}{c}\text { Posição } \\
\text { do tap }\end{array}$} & \multicolumn{4}{|c}{ Módulo da Variaça Máxima de Tensão (\%) } \\
\cline { 2 - 6 } carga & $\begin{array}{c}\text { 80\% da } \\
\text { carga }\end{array}$ & $\begin{array}{c}\text { 60\% da } \\
\text { carga }\end{array}$ & $\begin{array}{c}40 \% \text { da } \\
\text { carga }\end{array}$ & $\begin{array}{c}20 \% \text { da } \\
\text { carga }\end{array}$ \\
\hline+8 & 3,17 & 2,66 & 2,27 & 1,95 & 1,69 \\
\hline+7 & 3,18 & 2,67 & 2,27 & 1,95 & 1,69 \\
\hline+6 & 3,19 & 2,67 & 2,27 & 1,95 & 1,69 \\
\hline+5 & 3,21 & 2,68 & 2,28 & 1,95 & 1,68 \\
\hline+4 & 3,22 & 2,69 & 2,28 & 1,95 & 1,68 \\
\hline+3 & 3,23 & 2,69 & 2,28 & 1,95 & 1,68 \\
\hline+2 & 3,25 & 2,70 & 2,29 & 1,96 & 1,68 \\
\hline+1 & 3,26 & 2,71 & 2,29 & 1,96 & 1,68 \\
\hline 0 & 3,28 & 2,72 & 2,29 & 1,96 & 1,68 \\
\hline-1 & 3,30 & 2,73 & 2,30 & 1,96 & 1,68 \\
\hline-2 & 3,32 & 2,74 & 2,30 & 1,96 & 1,68 \\
\hline-3 & 3,34 & 2,75 & 2,31 & 1,97 & 1,69 \\
\hline-4 & 3,36 & 2,76 & 2,31 & 1,97 & 1,69 \\
\hline-5 & 3,38 & 2,77 & 2,32 & 1,97 & 1,69 \\
\hline-6 & 3,40 & 2,78 & 2,33 & 1,97 & 1,69 \\
\hline-7 & 3,42 & 2,79 & 2,33 & 1,98 & 1,69 \\
\hline-8 & 3,45 & 2,80 & 2,34 & 1,98 & 1,69 \\
\hline
\end{tabular}

\section{Cenário 2}

Novamente, observa-se na Tabela 28 que as maiores quedas de tensão ocorrem nos períodos de maior demanda, sendo que no período de demanda máxima a maior queda de tensão foi de 5,43\%. O módulo da variação mínima de tensão foi de $0,06 \%$ e ocorreu no período de menor demanda. A maior participação da GD no sistema aumentou os módulos das variações máximas de tensão, porém, o método conseguiu encontrar várias posições de tap que não violam os limites de tensão estabelecidos no Passo 4. 
Tabela 28 Módulo das variações máximas de tensão que ocorreram no sistema e posições de tap obtidas finais no Cenário 2 (CFP em 4,6 MW e 0,0 Mvar).

\begin{tabular}{c|c|c|c|c|c}
\hline \multirow{2}{*}{$\begin{array}{c}\text { Posição } \\
\text { do tap }\end{array}$} & \multicolumn{4}{|c}{ Módulo da Variação Máxima de Tensão (\%) } \\
\cline { 2 - 6 } carga & $\begin{array}{c}\text { 80\% da } \\
\text { carga }\end{array}$ & $\begin{array}{c}\text { 60\% da } \\
\text { carga }\end{array}$ & $\begin{array}{c}40 \% \text { da } \\
\text { carga }\end{array}$ & $\begin{array}{c}\text { 20\% da } \\
\text { carga }\end{array}$ \\
\hline+8 & 5,43 & 4,58 & 3,91 & 3,35 & 2,88 \\
\hline+7 & 5,43 & 4,57 & 3,90 & 3,34 & 2,87 \\
\hline+6 & 5,43 & 4,56 & 3,89 & 3,33 & 2,86 \\
\hline+5 & 5,43 & 4,56 & 3,88 & 3,32 & 2,85 \\
\hline+4 & 5,43 & 4,55 & 3,87 & 3,31 & 2,84 \\
\hline+3 & 5,44 & 4,55 & 3,86 & 3,30 & 2,82 \\
\hline+2 & 5,44 & 4,55 & 3,85 & 3,29 & 2,81 \\
\hline+1 & 5,45 & 4,54 & 3,84 & 3,28 & 2,80 \\
\hline 0 & 5,45 & 4,54 & 3,84 & 3,27 & 2,79 \\
\hline-1 & 5,46 & 4,54 & 3,83 & 3,26 & 2,78 \\
\hline-2 & 5,47 & 4,54 & 3,83 & 3,25 & 2,77 \\
\hline-3 & 5,49 & 4,54 & 3,82 & 3,24 & 2,76 \\
\hline-4 & 5,50 & 4,54 & 3,82 & 3,23 & 2,75 \\
\hline-5 & 5,51 & 4,54 & 3,81 & 3,22 & 2,74 \\
\hline-6 & 5,53 & 4,55 & 3,81 & 3,22 & 2,73 \\
\hline-7 & 5,54 & 4,55 & 3,80 & 3,21 & 2,72 \\
\hline-8 & 5,56 & 4,55 & 3,80 & 3,20 & 2,71 \\
\hline
\end{tabular}

\section{Cenário 3}

Comparando com o Cenário 1, os resultados da aplicação do método (Tabela 29) foram parecidos, porém, os módulos das variações máximas de tensão foram maiores, sendo que a maior variação de tensão foi de $6,35 \%$. O módulo da variação mínima de tensão foi de $0,85 \%$. 
Tabela 29 Módulo das variações máximas de tensão que ocorreram no sistema e posições de tap obtidas finais no Cenário 3 (CFP em 2,3 MW e 0,9 Mvar).

\begin{tabular}{c|c|c|c|c|c}
\hline \multirow{2}{*}{$\begin{array}{c}\text { Posição } \\
\text { do tap }\end{array}$} & \multicolumn{4}{|c}{ Módulo da Variaça Máxima de Tensão (\%) } \\
\cline { 2 - 6 } carga & $\begin{array}{c}\text { 80\% da } \\
\text { carga }\end{array}$ & $\begin{array}{c}\text { 60\% da } \\
\text { carga }\end{array}$ & $\begin{array}{c}40 \% \text { da } \\
\text { carga }\end{array}$ & $\begin{array}{c}20 \% \text { da } \\
\text { carga }\end{array}$ \\
\hline+8 & 6,34 & 5,64 & 5,10 & 4,66 & 4,30 \\
\hline+7 & 6,35 & 5,64 & 5,09 & 4,65 & 4,28 \\
\hline+6 & 6,35 & 5,63 & 5,08 & 4,64 & 4,27 \\
\hline+5 & 6,35 & 5,63 & 5,07 & 4,63 & 4,26 \\
\hline+4 & 6,36 & 5,63 & 5,07 & 4,62 & 4,25 \\
\hline+3 & 6,37 & 5,63 & 5,06 & 4,61 & 4,24 \\
\hline+2 & 6,38 & 5,63 & 5,06 & 4,60 & 4,23 \\
\hline+1 & 6,39 & 5,63 & 5,05 & 4,59 & 4,22 \\
\hline 0 & 6,40 & 5,63 & 5,05 & 4,59 & 4,21 \\
\hline-1 & 6,42 & 5,64 & 5,05 & 4,58 & 4,20 \\
\hline-2 & 6,44 & 5,64 & 5,05 & 4,58 & 4,20 \\
\hline-3 & 6,46 & 5,65 & 5,05 & 4,58 & 4,19 \\
\hline-4 & 6,48 & 5,66 & 5,05 & 4,57 & 4,19 \\
\hline-5 & 6,50 & 5,67 & 5,05 & 4,57 & 4,18 \\
\hline-6 & 6,53 & 5,68 & 5,06 & 4,57 & 4,18 \\
\hline-7 & 6,55 & 5,69 & 5,06 & 4,57 & 4,17 \\
\hline-8 & 6,58 & 5,71 & 5,07 & 4,57 & 4,17 \\
\hline
\end{tabular}

\section{Cenário 4}

O resultado obtido pela aplicação do método, encontrados na Tabela 30, mostram que neste cenário, poucas posições de tap podem garantir que não ocorram violações de tensão após a desconexão da GD. Também ocorreu um aumento no módulo da variação máxima de tensão, sendo que a maior variação observada foi de 10,13\%. O módulo da variação mínima de tensão foi de $1,44 \%$. No período de máxima demanda não foram encontradas posições de tap que garantam que não ocorram violações de tensão após a desconexão da GD. 
Tabela 30 Módulo das variações máximas de tensão que ocorreram no sistema e posições de tap obtidas finais no Cenário 4 (CFP em 4,6 MW e 1,8 Mvar).

\begin{tabular}{c|c|c|c|c|c}
\hline \multirow{2}{*}{$\begin{array}{c}\text { Posição } \\
\text { do tap }\end{array}$} & \multicolumn{4}{|c}{ Módulo da Variação Máxima de Tensão (\%) } \\
\cline { 2 - 6 } carga & $\begin{array}{c}\text { 80\% da } \\
\text { carga }\end{array}$ & $\begin{array}{c}\text { 60\% da } \\
\text { carga }\end{array}$ & $\begin{array}{c}40 \% \text { da } \\
\text { carga }\end{array}$ & $\begin{array}{c}20 \% \text { da } \\
\text { carga }\end{array}$ \\
\hline+8 & 11,41 & 10,27 & 9,37 & 8,62 & 7,98 \\
\hline+7 & 11,39 & 10,24 & 9,33 & 8,58 & 7,95 \\
\hline+6 & 11,38 & 10,22 & 9,30 & 8,55 & 7,91 \\
\hline+5 & 11,36 & 10,19 & 9,27 & 8,51 & 7,88 \\
\hline+4 & 11,35 & 10,17 & 9,24 & 8,48 & 7,84 \\
\hline+3 & 11,34 & 10,15 & 9,22 & 8,45 & 7,81 \\
\hline+2 & 11,34 & 10,13 & 9,19 & 8,43 & 7,78 \\
\hline+1 & 11,33 & 10,12 & 9,17 & 8,40 & 7,76 \\
\hline 0 & 11,33 & 10,11 & 9,15 & 8,38 & 7,73 \\
\hline-1 & 11,34 & 10,10 & 9,13 & 8,36 & 7,71 \\
\hline-2 & 11,34 & 10,09 & 9,12 & 8,34 & 7,68 \\
\hline-3 & 11,35 & 10,08 & 9,11 & 8,32 & 7,66 \\
\hline-4 & 11,37 & 10,08 & 9,09 & 8,30 & 7,64 \\
\hline-5 & 11,38 & 10,08 & 9,08 & 8,28 & 7,62 \\
\hline-6 & 11,40 & 10,08 & 9,07 & 8,27 & 7,60 \\
\hline-7 & 11,42 & 10,08 & 9,06 & 8,25 & 7,58 \\
\hline-8 & 11,44 & 10,08 & 9,06 & 8,24 & 7,57 \\
\hline
\end{tabular}

\section{Cenário 5}

Para o Cenário 5, os resultados são apresentados na Tabela 31. Em comparação com os Cenários 1 e 3, em que os geradores também injetam 2,3 MW na rede, foram obtidas menos posições de tap para operação dos reguladores de tensão com geradores conectados ao SD, porém, o objetivo do método foi alcançado, pois ainda sim posições de tap foram obtidas. Diferentemente dos outros cenários, a queda de tensão variou bastante nos diferentes valores de tap. Tal fato pode ter ocorrido, pois quando a GD mantém a tensão do PAC em 1 p.u., a quantidade de potência reativa que ela injeta varia nas diferentes posições de tap do regulador de tensão. $\mathrm{O}$ módulo da variação máxima de tensão foi de 6,38\% no período de máxima demanda. Em diferentes demandas do sistema, a tensão em algumas barras não foi alterada, tendo variação de $0,0 \%$. 
Tabela 31 Módulo das variações máximas de tensão que ocorreram no sistema e posições de tap obtidas finais no Cenário 5 (CT em 2,3 MW e 1,0 p.u.).

\begin{tabular}{c|c|c|c|c|c}
\hline \multirow{2}{*}{$\begin{array}{c}\text { Posição } \\
\text { do tap }\end{array}$} & \multicolumn{4}{|c}{ Módulo da Variação Máxima de Tensão (\%) } \\
\cline { 2 - 6 } & $\begin{array}{c}\text { carga da } \\
\text { 80\% da } \\
\text { carga }\end{array}$ & $\begin{array}{c}\text { 60\% da } \\
\text { carga }\end{array}$ & $\begin{array}{c}40 \% \text { da } \\
\text { carga }\end{array}$ & $\begin{array}{c}20 \% \text { da } \\
\text { carga }\end{array}$ \\
\hline+8 & 3,99 & 0,66 & 2,36 & 4,94 & 7,31 \\
\hline+7 & 5,20 & 1,88 & 1,25 & 3,72 & 6,06 \\
\hline+6 & 6,38 & 3,06 & 0,32 & 2,54 & 4,85 \\
\hline+5 & 7,51 & 4,20 & 1,30 & 1,47 & 3,70 \\
\hline+4 & 8,62 & 5,30 & 2,41 & 0,59 & 2,59 \\
\hline+3 & 9,69 & 6,37 & 3,49 & 0,92 & 1,58 \\
\hline+2 & 10,72 & 7,41 & 4,54 & 1,98 & 0,75 \\
\hline+1 & 11,73 & 8,42 & 5,55 & 3,00 & 0,70 \\
\hline 0 & 12,71 & 9,40 & 6,53 & 3,99 & 1,70 \\
\hline-1 & 13,67 & 10,35 & 7,48 & 4,95 & 2,67 \\
\hline-2 & 14,60 & 11,27 & 8,41 & 5,88 & 3,61 \\
\hline-3 & 15,50 & 12,17 & 9,31 & 6,79 & 4,52 \\
\hline-4 & 16,38 & 13,04 & 10,18 & 7,67 & 5,41 \\
\hline-5 & 17,24 & 13,89 & 11,03 & 8,52 & 6,26 \\
\hline-6 & 18,07 & 14,72 & 11,86 & 9,34 & 7,10 \\
\hline-7 & 18,89 & 15,52 & 12,66 & 10,15 & 7,91 \\
\hline-8 & 19,68 & 16,30 & 13,43 & 10,93 & 8,69 \\
\hline
\end{tabular}

\section{Cenário 6}

Comparando com os Cenários 2 e 4 que também injetam 4,6 MW, este foi o cenário em que mais posições de tap foram obtidas, como pode ser observado na Tabela 32 . Tal fato ocorreu, pois os geradores possuem grande participação da geração de potência ativa e regulam a tensão, permitindo maior flexibilidade para a operação do regulador de tensão. Assim como no Cenário 5, o módulo da variação máxima de tensão variou junto com as diferentes posições de tap e a maior variação $(7,18 \%)$ ocorreu no período de demanda máxima. Também ocorreram casos em que não houve variação de tensão $(0,0 \%)$. 
Tabela 32 Módulo das variações máximas de tensão que ocorreram no sistema e posições de tap obtidas finais no Cenário 6 (CT em 4,6 MW e 1,0 p.u.).

\begin{tabular}{c|c|c|c|c|c}
\hline \multirow{2}{*}{$\begin{array}{c}\text { Posição } \\
\text { do tap }\end{array}$} & \multicolumn{4}{|c}{ Módulo da Variação Máxima de Tensão (\%) } \\
\cline { 2 - 6 } carga & $\begin{array}{c}\text { 80\% da } \\
\text { carga }\end{array}$ & $\begin{array}{c}\text { 60\% da } \\
\text { carga }\end{array}$ & $\begin{array}{c}40 \% \text { da } \\
\text { carga }\end{array}$ & $\begin{array}{c}\text { 20\% da } \\
\text { carga }\end{array}$ \\
\hline+8 & 3,63 & 0,69 & 3,12 & 5,60 & 7,98 \\
\hline+7 & 4,85 & 1,47 & 2,14 & 4,38 & 6,74 \\
\hline+6 & 6,03 & 2,66 & 1,20 & 3,34 & 5,55 \\
\hline+5 & 7,18 & 3,81 & 0,86 & 2,42 & 4,40 \\
\hline+4 & 8,29 & 4,92 & 1,98 & 1,53 & 3,45 \\
\hline+3 & 9,37 & 6,00 & 3,06 & 0,68 & 2,58 \\
\hline+2 & 10,41 & 7,04 & 4,12 & 1,51 & 1,74 \\
\hline+1 & 11,43 & 8,06 & 5,14 & 2,54 & 0,94 \\
\hline 0 & 12,42 & 9,05 & 6,13 & 3,54 & 1,20 \\
\hline-1 & 13,38 & 10,01 & 7,09 & 4,51 & 2,18 \\
\hline-2 & 14,32 & 10,94 & 8,02 & 5,45 & 3,13 \\
\hline-3 & 15,23 & 11,84 & 8,93 & 6,36 & 4,05 \\
\hline-4 & 16,12 & 12,73 & 9,81 & 7,25 & 4,94 \\
\hline-5 & 16,99 & 13,58 & 10,67 & 8,11 & 5,81 \\
\hline-6 & 17,83 & 14,42 & 11,50 & 8,94 & 6,65 \\
\hline-7 & 18,65 & 15,23 & 12,31 & 9,75 & 7,46 \\
\hline-8 & 19,46 & 16,02 & 13,10 & 10,54 & 8,26 \\
\hline
\end{tabular}

\section{Considerações finais}

Os resultados obtidos permitiram uma maior compreensão do problema estudado nesta pesquisa. Foi observado que o quanto maior-a demanda do sistema ou a injeção de potência pela GD, maior será a variação de tensão causada pela desconexão dos geradores. Nos cenários em que o gerador opera em CFP, a injeção de potência reativa reduziu a quantidade de posições de tap obtidas pelo método. Quando a GD opera em CFP, a variação de tensão não é influenciada significativamente pela posição do tap dos reguladores de tensão, porém quando os geradores operam em CT, esta relação existe e pode influenciar os resultados obtidos pelo método. A maior participação de injeção de potência ativa pelos geradores operando em CFP diminuiu a quantidade de posições de tap obtidas pelo método, porém, quando os geradores operam em CT foram obtidas mais posições de tap que não provocam violações de tensão após a desconexão da GD. 